Florida International University

FIU Digital Commons

FIU Electronic Theses and Dissertations

University Graduate School

3-18-2019

\title{
Heart Disease and Its Risk Factors Among Slum-Dwelling Women in Mysore, India
}

Karl Krupp

Florida International University, kkrup002@fiu.edu

Follow this and additional works at: https://digitalcommons.fiu.edu/etd

Part of the International Public Health Commons

\section{Recommended Citation}

Krupp, Karl, "Heart Disease and Its Risk Factors Among Slum-Dwelling Women in Mysore, India" (2019). FIU Electronic Theses and Dissertations. 3958.

https://digitalcommons.fiu.edu/etd/3958

This work is brought to you for free and open access by the University Graduate School at FIU Digital Commons. It has been accepted for inclusion in FIU Electronic Theses and Dissertations by an authorized administrator of FIU Digital Commons. For more information, please contact dcc@fiu.edu. 


\section{FLORIDA INTERNATIONAL UNIVERSITY}

Miami, Florida

\section{HEART DISEASE AND ITS RISK FACTORS AMONG SLUM-DWELLING WOMEN IN MYSORE, INDIA}

A dissertation submitted in partial fulfillment of

the requirements for the degree of

DOCTOR OF PHILOSPHY

in

PUBLIC HEALTH

by

Karl Francis Krupp 
To: Dean Tomás R. Guilarte

Robert Stempel College of Public Health and Social Work

This dissertation, written by Karl Francis Krupp, and entitled Heart Disease and its Risk Factors Among Slum-Dwelling Women in Mysore, India, having been approved in respect to style and intellectual content, is referred to you for judgement.

We have read this dissertation and recommend that it be approved.

H. Virginia McCoy

Dionne Stephens

Gladys E. Ibanéz

Elena Bastida, Major Professor

Date of Defense: March 18, 2019

The dissertation of Karl Krupp is approved.

Dean Tomás R. Guilarte

Robert Stempel College of Public

Health and Social Work

Andrés G. Gil

Vice President for Research and

Economic Development Dean of the University Graduate School

Florida International University, 2019 
(C) Copyright 2019 by Karl Francis Krupp

All rights reserved. 


\section{DEDICATION}

This dissertation is dedicated to the ones who have been my greatest encouragement and support: my wife Purnima Madhivanan who brought me into Public Health and my daughter Paavlena Madhivanan who tolerated so many conversations about global health over the years. 


\section{ACKNOWLEDGMENTS}

I would like to express my deep appreciation to the Department of Health Promotion and Disease Prevention and its faculty, who have brought me to this far point. In particular, I want to thank those patient individuals who served on my committee: my Major Professor Dr. Elena Bastida who I am certain at times was unsure about whether I would graduate at all, and Drs. McCoy, Stephens, and Ibañez for their help, encouragement, and mentoring along the way. I am thankful for Dr. William Darrow's teaching on bioethics; it was an inspiration as I struggled with the ethical difficulties of conducting cross-cultural research in India. Finally, a big thanks to Dr. Rashida Biggs who was patient and supportive as I first tried my hand at teaching public health.

I also want to express my appreciation to those mentors and colleagues who, in spite of being outside of the university, still unselfishly provided support and assistance. In particular I want to thank Dr. Arun Srinivas, Head of Department and Chief Cardiologist for Apollo Hospital in Mysore, India, contributed at every stage of the research and negotiated free healthcare services for study participants. Dr. Khurram Nasir, Yale New Haven Hospital who was instrumental in shaping the research design and giving much helpful advice on the pathophysiologic and diagnostic aspects of heart disease. Finally, I want to thank Mrs. Poornima Jayakrishna, the entire staff at Public Health Research Institute of India, and the courageous women who volunteered for the study; without who it would have been impossible to complete this study.

There are too many other people who assisted along the way, to name them all. Several though, need to be mentioned. My wife, Purnima Madhivanan, has always been an inspiration to me for her drive and commitment to providing healthcare for the world's women and children. It was her good works that first attracted me to public health. I also wish to recognize the influence of Bradley Angel, one of the seminal leaders in the U.S. environmental health movement. He made me believe that it is possible to change the risk trajectories and health outcomes of people 
living in even the most difficult circumstances. I came to public health late in life, so I will close with a quotation dedicated to all those individuals who choose to be endless bloomers:

"The most beautiful thing is that despite the shallow life we sometimes succumb to - the soul has no timeline and it knows what it wants and will yearn within until it seeks the journey"

— Malebo Sephodi 


\author{
ABSTRACT OF THE DISSERTATION \\ HEART DISEASE AND ITS RISK FACTORS AMONG SLUM- \\ DWELLING WOMEN IN MYSORE, INDIA \\ by \\ Karl Francis Krupp \\ Florida International University, 2019 \\ Miami, Florida \\ Professor Elena Bastida, Major Professor
}

Background: Cardiovascular diseases (CVDs) are the largest cause of premature mortality globally. Annually, about 18 million people die from all CVDs, and about 7.6 million, from coronary heart disease (CHD) [2, 3]. About three quarters of CHD-related mortality occurs in low- and-middle income countries (LMIC) with India having the greatest number of deaths worldwide. Risk for CHD in India is thought to be highest among residents of Indian slums since studies have found a high prevalence of CHD risk factors like hypertension and tobacco use among slum dwellers but no studies to date have assessed the prevalence of CHD in this population.

Methods: A cross-sectional survey was carried out between October 2017 and May 2018 among a nonprobability sample of 607 slum-dwelling women, 40 to 64 years of age, residing in governmentdesignated slums in Mysore, India. The study measured knowledge about cardiovascular risk factors, and collected data on socio-demographics, tobacco use, alcohol consumption, diet, physical activity, sleep, quality of life, and personal and family history of diagnosed cardiometabolic Results: Cardiovascular disease risk factor knowledge was low in this population. A prevalence of CHD of $6.4 \%$ was found among participants. Nulliparous women were at heightened risk for CHD compared to parous women with up to five live births. In this sample of slum dwelling women, snoring was associated with obesity, and cardio-metabolic disorders. Conclusion: There is a need for interventions focused on lowering CHD in this population 


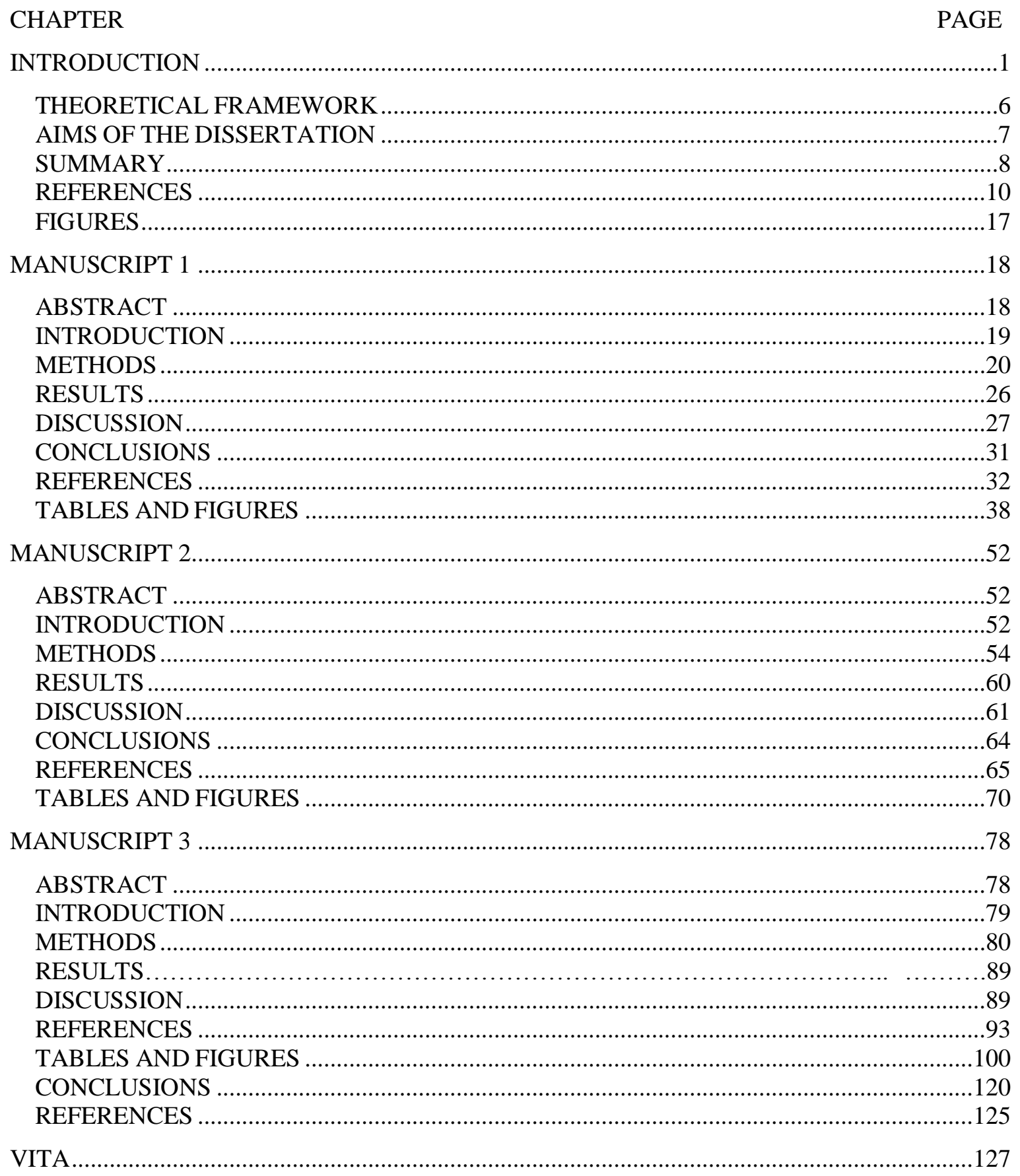




\section{TABLES AND FIGURES}

TABLE/FIGURE

PAGE

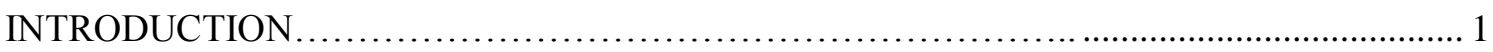

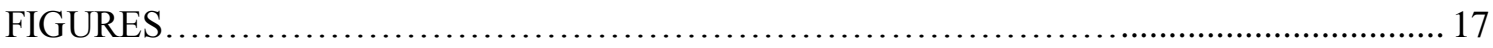

Figure 1. The Precaution Adoption Process Model (79)............................................ 17

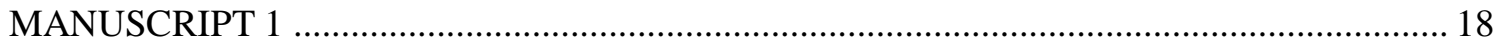

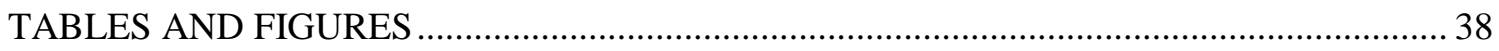

Table 1. Description of the sample of slum dwelling women in Mysore, India $(n=607) \quad \ldots . .38$

Table 2. Responses to the heart disease risk factor knowledge measure among a sample of slum

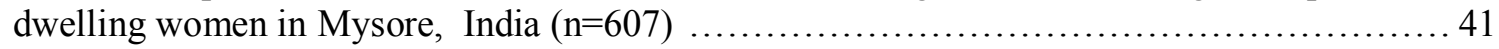

Table 3. Heart disease risk factor knowledge by social economic among a sample of slum dwelling women in Mysore, India $(n=607)$

Table 4a. Logistic regression analysis of the association of demographic characteristics with knowledge about heart health among slum swelling women in Mysore, India .46

Table $4 \mathrm{~b}$. Logistic regression analysis of the association of demographic characteristics with knowledge about heart health among slum dwelling women in Mysore, India....

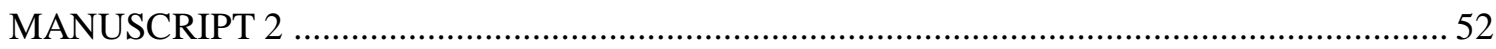

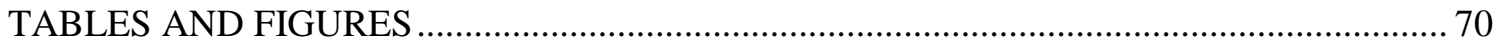

Table 1. Description of sample of slum dwelling women in Mysore, India $(n=607) \quad \ldots \ldots \ldots \ldots . . . . . . .70$

Table 2. Sociodemographic characteristics and chd among slum dwelling women in Mysore,

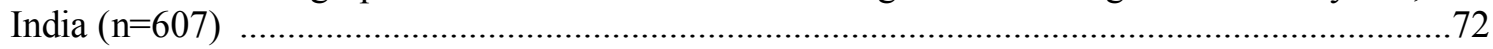

Table 3. Logistic regression and odds of chd urban slum dwelling women in Mysore, India $(\mathrm{n}=607)$

Table 4. Unadjusted and adjusted association for chd by parity among slum dwelling women in

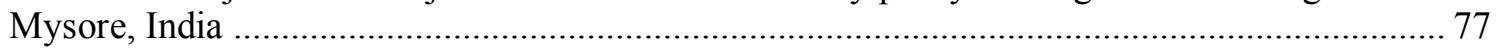

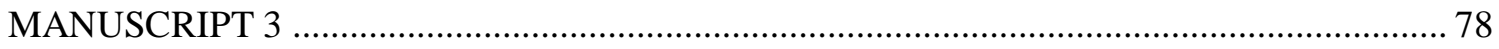

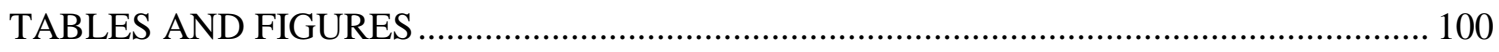

Table 1. Description of study sample of slum dwelling women in Mysore, India $(n=607) \quad \ldots . .100$

Table 2. Factors associated with body mass index among slum dwelling women in Mysore, India

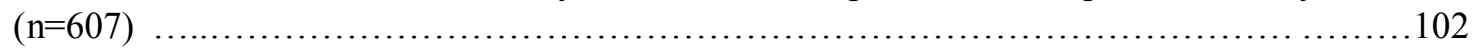

Table 3. Factors associated with snoring among slum dwelling women in Mysore, India $(\mathrm{n}=607)$

Table 4. Odds of being overweight versus underweight/normal weight among slum dwelling women in Mysore, India ( $\mathrm{n}=607)$

Table 5. Odds of being obese i versus underweight/normal weight among slum dwelling women in Mysore, India $(\mathrm{n}=607)$ 
Table 6. Odds of being obese ii versus underweight/normal weight among slum dwelling women in Mysore, India $(\mathrm{n}=607)$ 


\section{ABBREVIATIONS AND ACRONYMS}

\begin{tabular}{|c|c|}
\hline AAM & Age-Adjusted Mortality \\
\hline ARRBH & Adoption of Risk Reducing Behaviors Instrument \\
\hline ANOVA & Analysis of Variance \\
\hline AOR & Adjusted Odds Ratio \\
\hline BMI & Body Mass Index \\
\hline CARRS & Centre for cArdiometabolic Risk Reduction in South Asia \\
\hline CHD & Coronary Heart Disease \\
\hline $\mathrm{CI}$ & Confidence Interval \\
\hline CVD & Cardiovascular Diseases \\
\hline eAG & Estimated Average Glucose \\
\hline ECG & Electrocardiogram \\
\hline EDTA & Ethylenediamine tetraacetic acid \\
\hline ESS & Epworth Sleepiness Scale \\
\hline $\mathrm{HbA1c}$ & Hemoglobin A1c \\
\hline HCL & Hypercholesterolemia \\
\hline HDFQ & Heart Disease Risk Factor Knowledge \\
\hline HDL-C & High-Density Lipoprotein-associated Cholesterol \\
\hline HS & Habitual Snoring \\
\hline IRB & Institutional Review Board \\
\hline INR & Indian Rupees \\
\hline LDL-C & Low-Density Lipoprotein-associated Cholesterol \\
\hline LMIC & Low- and Middle-Income Countries \\
\hline NHLBI & National Heart Lung Blood Institute \\
\hline
\end{tabular}




$\begin{array}{ll}\text { OBC } & \text { Other Backward Caste } \\ \text { OR } & \text { Odds Ratio } \\ \text { PAPM } & \text { Precaution Adoption Process Model } \\ \text { PT } & \text { Pretesting } \\ \text { SC/ST } & \text { Schedule Caste/Schedule Tribe } \\ \text { SDB } & \text { Sleep-Disordered Breathing } \\ \text { SES } & \text { Socioeconomic Status } \\ \text { SHHS } & \text { Sleep Heart Health Study } \\ \text { TC } & \text { Total Cholesterol } \\ \text { TG } & \text { Total Triglycerides } \\ \text { USD } & \text { United States Dollar }\end{array}$




\section{INTRODUCTION}

Cardiovascular diseases (CVD) are the largest cause of premature mortality worldwide [1]. About 18 million people die annually from all CVD and approximately 7.6 million from coronary heart disease (CHD) [2,3]. Three quarters of CHD mortality occurs in low-and-middle income countries (LMIC) with the largest number, about 2.2 million annual deaths, occurring in India [4-6]. During 2010-2013, about 23\% of the country's total mortality, and 32\% of all adult deaths, were due to CHD [6].

While age-adjusted CHD rates have fallen in developed countries by more than $60 \%$ since their peak in 1960s, rates have continued to rise in LMIC [7]. It is estimated that CHD and stroke-related deaths could triple over the next two decades in many developing countries [8].

The reasons are multifactorial. They include increasing urbanization, changes in the nature of work, and rising prosperity, all of which have contributed to increasing levels of cardiovascular risk [9]. In addition, evidence suggests that an epidemiological transition in LMICs is both increasing life expectancy and shifting the causes of premature mortality from communicable, maternal, and neonatal conditions towards CVD and other non-communicable diseases [10]. This has been accompanied by changes in the social patterning of chronic disease with the primary burden shifting from populations with high socioeconomic status (SES) to individuals with lower SES, increasing morbidity and mortality in some of the world's most vulnerable populations [11].

India is a striking example of the dramatic changes in the prevalence and distribution of CVD and its risk factors. Between 1990 and 2016, CVD death rates in India have risen from 155.7 to 209.1 per 100,000 people. In contrast, in the U.S., heart disease related mortality has 
dropped from 300 deaths per 100,000 in 1990, to 176 per 100,000 in 2016 [14]. In the 80s and 90s there was a positive gradient for CVD risk factors, with the main burden falling on the upper and middle classes [15-17]. Recent studies however, have shown a convergence of risk factor prevalence between upper and lower-income groups [18].

In western countries, $23 \%$ of heart disease deaths occur before age 70 , while in India, $52 \%$ of CVD-related deaths occurs before the same age [19]. This alarming rise in both CVD risk factors and cardiovascular deaths in Indian population has led to recent calls for research in India to increase "understanding of the complex dynamics of cardiovascular disease risk factors and their interactions" [20]

\section{Slum Health}

The United Nations estimated that in 2014, about a third of all of the world's urban residents, roughly 880 million people, lived in slums [21]. That number is expected to grow to two billion by 2030 [22]. The impact on public health is concerning since slum dwellers have generally poorer health outcomes, higher morbidity, mortality, and health risks compared to other urban populations [23]. Research also suggests that slum dwelling populations also have higher rates of modifiable risk factors for CVD including smoking, hypertension, dyslipidemia, diabetes, obesity, poor dietary habits and a lack of physical activity [24, 25].

To date, surprisingly little is known about the health of slum dwellers compared to other urban populations [26]. One challenge is that the definition of what constitutes a slum differs by region, country and even city, making comparisons challenging [27]. The United Nations has an operational definition: It defines a slum household as "a group of individuals living under the same roof in an urban area who lack one or more of the following:1) Durable housing of a permanent nature that protects against extreme climate conditions; 2) Sufficient living space which means not more than three people sharing the same room; 3) Easy access to safe water in sufficient amounts at an affordable price; 4) Access to adequate sanitation in the form of a private 
or public toilet shared by a reasonable number of people; and 5) Security of tenure that prevents forced evictions." [28]. Currently the world's largest slums are located in South Africa, Kenya, India, Mexico, and Pakistan [29]. In India, it is estimated that approximately 104 million, or about $9 \%$ of the population live in slums [30].

The Registrar General of India has adopted the following definition of 'slum' for purposes of the Census of India and government development programs: Slum areas shall include: “All specified areas in a town or city notified as 'Slum' by State or Local Government under any Act including a 'Slum Act'; and a compact area of at least 300 populations or about 60-70 households of poorly built congested tenements, in unhygienic environment usually with inadequate infrastructure and lacking in proper sanitary and drinking water facilities" [31]. The purposes of state and local designation of an area as a 'slum' are several and include improvement, clearance, and redevelopment, provision of low-income housing; improvement of basic amenities, including drinking water, street lights, roads, drains, community bathrooms, storm water drains and provision of basic services including water supply, sanitation and education, health and social security [32]. In Mysore where this research was carried out, there were 43 communities officially designated as notified slums by the Karnataka Slum Development Board [33].

\section{Prevalence of CVD Risk Factors Among Indian Slum-Dwellers}

While there is little information that disaggregates health data from Indian slum-dwellers and other urban populations, the few studies that are available suggest that Indian slum-dwellers may be at heightened risk for CVD. Studies from different areas of India assessing the prevalence of high blood pressure among slum dwellers found that about one-in-four had hypertension $[34,35]$. Rooban et al in a study comparing tobacco use by male slum-dwellers compared to urban male non-slum dwellers found that $30.1 \%$ used cigarettes or beedis and $35.2 \%$ smokeless tobacco products compared to $26.4 \%$ and $26.9 \%$ respectively of their non- 
slum peers [36]. Gupta and colleagues reported in a multi-site study that about $48 \%$ of slumdwelling men and $11.9 \%$ of women reporting tobacco use [37]. Other studies have also found a high rate of obesity and sedentariness among slum-dwelling populations. A population-based study in urban slums in Patna, Bihar for instance, found that $32 \%$ of residents were obese, and $34 \%$ were sedentary [38]. Similarly, a study of slum-dwellers in north India found that when obesity was assessed by percentage of body fat, $10.6 \%$ of male and $40.2 \%$ of female slumdwellers were obese [39]. Researchers have also found a high prevalence of diabetes in different slums dwellings populations ranging from $10.3 \%$ to $18.8 \%[39,40]$.

\section{Coronary Heart Disease in Indian Slums}

A review of the literature located only one study of the prevalence of CHD in Indian slum-dwellers. Waingankar et al carried out a cross-sectional study of CHD in an urban slum community in Mumbai, India [41]. CHD was diagnosed using a Rose Angina Questionnaire and/or documentary evidence of myocardial infarction. The study found a prevalence of CHD to be 1.58 among participants aged 25 to 64 years. Prevalence was higher among males (2.08) than females (1.05), with the highest rates (9.91) among participants aged 55 to 64 years.

\section{Knowledge of CVD Risk Factors Among Indian Slum Dwellers}

Studies suggest that knowledge about cardiovascular disease risk factors is low in most populations in India $[42,43]$. Saeed et al found that only about $41 \%$ of patients attending a tertiary care hospital in New Delhi, India, had good knowledge about CVD risk factors [42]. A study of risk factor knowledge among Indian women found that CVD knowledge was also poor with a minority of participants identifying family history (24\%), tobacco (48\%), alcohol (47\%), high serum glucose (44\%), and high blood lipids (42\%) as risk factors for CVD [43]. A population-based study in Coimbatore found that while many participants identified smoking, 
obesity and high blood pressure as risk factors, few knew that age (10\%), and a family history or heart disease (32\%) increased risk for CVD [44]. There was only one study of knowledge of CVD risk factors among slum dwellers. A study of CHD patients from a slum in Mumbai found that $20.7 \%$ of patients had no knowledge that hypertension was a risk factor for cardiovascular disease, $18.5 \%$ were also unaware that smoking, and $43.5 \%$ that alcohol, were risk factors for heart disease [41].

\section{Factors Driving CVD Risk in Middle Aged and Older Indian Women}

Globally, heart disease is the leading source of mortality for women, representing $33.2 \%$ of total female deaths in 2008 substantially ahead of the two next largest causes, infectious and parasitic diseases (13.9\%), and cancer $(13.0 \%)$ [45,46]. Three large population-based studies suggest that age-standardized CVD mortality rates of 225-299 per 100,000 for women is relatively high compared to the age-standardized global rate of 235 per 100,000 population for both men and women [14]. Factors that studies suggest may add differential risk for cardiovascular disease in women compared to men include lower knowledge about cardiovascular risk factors compared to men [47], reproductive factors including pregnancy complicated with conditions including Gestational Diabetes, Preeclampsia, Preterm Labor, older women [48]. In addition, certain CVD risk factors such as obesity are more common in women and contribute disproportionately more to women's CVD risk, compared to men's $[49,50]$.

As one of the major independent risk factors for cardiovascular disease in middle-aged adults [51, 52], obesity has recently become a major focus of intervention addressing upstream risk factors for cardiovascular disease [53-55]. Recent research suggests that snoring, a manifestation of sleep disordered breathing, may be associated with overweight and obesity [5659]. The relationship appears to be bi-directional [60]. On the one hand, obesity and neck circumference have been shown to increase risk for snoring [61]: disordered breathing increases 
negative intraluminal pressure encouraging constriction of the airway and vibration of pharyngeal soft tissues $[62,63]$. Other research however, suggests that snoring may also be linked to weight gain by contributing to metabolic load [64-66]. It appears to increase risk factors for obesity including sleep fragmentation [67, 68], impaired circulatory function [69], hypertension [70], metabolic syndrome [71], diabetes [72], and impaired glucose control [73]. There are currently few studies that have examined sleep quality, duration, or sleep-related disorders like snoring among slum dwellers [73]. Furthermore, evidence for interactions between snoring and other parameters of sleep such as duration have been mixed, so there is a need for further research to understand the pathways and mechanisms that potentially connect snoring to heightened CVD risk [74-76]. This is the first study to our knowledge to explore the prevalence of snoring in slum-dwellers; its relationship to obesity; and any interactions between snoring and other sleep parameters that may increase risk for both obesity and CVD.

\section{Current Study}

The Mera Dil Study used a cross-sectional survey design to assess risk and burden of Coronary Heart Disease among a sample of slum-dwelling women, 40 - 64 years of age, living in Mysore, India. The purpose of the study was to evaluate knowledge and beliefs about heart disease and its risk factors; assess modifiable risk factors for CHD; and measure prevalent CHD defined as physician diagnosed disease, prescribed medication for treatment of CHD, positive responses to items in the Rose Angina Questionnaire [77], or resting electrocardiogram (ECG) abnormalities suggestive of asymptomatic CHD [78].

\section{THEORETICAL FRAMEWORK}

The Precaution Adoption Process Model (PAPM), developed by Weinstein and Sandman, was used as a theoretical framework in the Mera Dil study to help understand the relationship between knowledge and readiness to adopt heart healthy behaviors [79]. PAPM 
posits that adoption/maintenance of health behaviors is associated with a series of stages [53]. According to the theory, people may be: (1) unaware of an issue; (2) aware of an issue but not personally engaged by it; (3) engaged and deciding what to do next; (4) planning to act, but not yet acting; 5) deciding not to act; (6) taking-action; and (7) maintaining the results of an action. Each stage has specific patterns of beliefs, behaviors, and experience. PAPM suggests that specific factors are associated with advancement across the continuum, and others are necessary for stage transitions. In this study, PAPM stage will be identified with seven stage descriptions adapted from a study by Patricia Weinstein [54]: 1) I don't think I'm at greater risk of getting heart disease than any other person; 2) I know I am at risk for heart disease but I haven't thought much about it; 3) I am thinking about changing my behaviors to decrease my chances for getting heart disease, but I haven't made up my mind it's something I want to do; 4) I have thought about changing some of my behaviors to decrease my chances for getting heart disease but I have decided against it; 5) I have decided to change some of my behaviors to decrease my chances for getting heart disease, but I have not started doing them yet; 6) I have recently changed some of my behaviors within the last month to decrease my chances for getting heart disease; and 7) I have made changes in my behavior to decrease my chances for getting heart disease for at least 6 months. The questionnaire seeks to identify: 1) knowledge and beliefs about CHD risk factors and personal risk; 2) thought patterns associated with intentions to maintain health behaviors or adopt new ones; 3) weight loss and attempted weight loss; 4) smoking cessation and attempted smoking cessation; 5) discontinuation or lowered alcohol use; 6) health-seeking and lifestyle changes to lower serum cholesterol, blood pressure, and serum glucose; and 7) adoption or nonadoption of healthier and physical activity behaviors.

\section{AIMS OF THE DISSERTATION}

The overarching objective of this dissertation was to determine the burden of CHD and its risk factors in a population of slum-dwelling women in Mysore, India by examining the 
following specific aims:

Aim 1: Describe the level of cardiovascular risk factor knowledge among slumdwelling women in Mysore, India;

Research Question 1: Is CVD risk factor knowledge associated with heart healthy behavior change in a sample of slum-dwelling women in Mysore, India?

Hypothesis 1: The level of CVD risk factor knowledge will be correlated with reported changes in behavior intended to lower cardiovascular risk.

Aim 2: Assess whether the lifetime number of live births for a woman is associated with

later-life risk for CHD.

Research Question 2: Is parity associated with later-life risk for CHD among slumdwelling women in Mysore, India?

Hypothesis 2: High parity will be significantly associated with increasing risk for CHD among slum-dwelling women in Mysore, India.

Aim 3: Determine whether snoring is associated with increased risk for Obesity among women.

Research Question 3: Is snoring a risk factor for obesity in slum-dwelling Indian women?

Hypothesis 3: Snoring will be significantly associated with obesity in slum-dwelling women in Mysore, India

\section{SUMMARY}

The purpose of the study was to evaluate knowledge and beliefs about heart disease and its causes; assess modifiable risk factors for CHD; and measure prevalent CHD in a sample of 
slum-dwelling women living in Mysore, India. The remainder of this dissertation is divided into four additional chapters. The next three will summarize the data, analysis, and conclusions for each of the study aims and hypotheses. Chapter 2 will examine cardiovascular risk factor knowledge and behaviors among slum-dwelling women in Mysore, India.

\section{REFERENCES}

1. Roth GA, Huffman MD, Moran AE, Feigin V, Mensah GA, Naghavi M, et al. Global and regional patterns in cardiovascular mortality from 1990 to 2013. Circulation, 2015. 132(17): p. 1667-78.

2. World Health Organization, Cardiovascular Disease. Found at: https://www.who.int/cardiovascular_diseases/en/Accessed on December 12, 2018.

3. Institute of Medicine,Epidemiology of Cardiovascular Disease, in Promoting Cardiovascular Health in the Developing World: A Critical Challenge to Achieve Global Health, V Fuster, Kelly BB. Editor. 2010, The National Academies Press: Washington, DC.

4. World Bank, Death rate, crude (per 1,000 people). Found at: https://data.worldbank.org/indicator/SP.DYN.CDRT.IN Accessed on January 3, 2019.

5. World Population Review, India Population 2018. Found at: http://worldpopulationreview.com/countries/india-population/Accessed on January 3, 2018.

6. Gupta R, Mohan I, Narula J. Trends in Coronary Heart Disease Epidemiology in India. Ann Glob Health, 2016. 82(2): p. 307-15.

7. Jones DS, Greene JA. The decline and rise of coronary heart disease: understanding public health catastrophism. Am J Public Health, 2013. 103(7): p. 1207-18.

8. American Heart Association, Statistical Fact Sheet-Populations; International Cardiovascular Disease Statistics. Found at: http://www.sld.cu/galerias/pdf/servicios/hta/international_cardiovascular_disease_statisti cs.pdf Accessed on December 12, 2018. 
9. Gersh BJ, Sliwa K, Mayosi BM, Yusuf S. Novel therapeutic concepts: the epidemic of cardiovascular disease in the developing world: global implications. Eur Heart J, 2010. 31(6): p. 642-8.

10. Mendoza W, Miranda JJ. Global Shifts in Cardiovascular Disease, the Epidemiologic Transition, and Other Contributing Factors: Toward a New Practice of Global Health Cardiology. Cardiol Clin, 2017. 35(1): p. 1-12.

11. Gaziano TA, Bitton A, Anand S, Abrahams-Gessel S, Murphy A. Growing epidemic of coronary heart disease in low- and middle-income countries. Curr Probl Cardiol, 2010. 35(2): p. 72-115.

12. Stringhini S, Bovet P. Commentary: The social transition of cardiovascular disease in low- and middle-income countries: wait and see is not an option. Int J Epidemiol, 2013. 42(5): p. 1429-31.

13. Phillips JE, Klein WM. Socioeconomic Status and Coronary Heart Disease Risk: The Role of Social Cognitive Factors. Soc Personal Psychol Compass, 2010. 4(9): p. 704727.

14. Prabhakaran D, Singh K, Roth GA, Banerjee A, Pagidipati NJ, Huffman MD. Cardiovascular Diseases in India Compared with the United States. J Am Coll Cardiol, 2018. 72(1): p. 79-95.

15. Agarwal AK, Yunus M, Khan A, Ahmad J. A clinical-epidemiological study of hypertension in rural population of Jawan Block, Distt, Aligarh (UP) India. $J R$ Soc Health, 1994. 114(1): p. 17-9.

16. Rao PS, Inbaraj SG, Subramaniam VR. Blood pressure measures among women in south India. J Epidemiol Community Health, 1984. 38(1): p. 49-53.

17. Corsi DJ, Subramanian SV. Association between socioeconomic status and selfreported diabetes in India: a cross-sectional multilevel analysis. BMJ Open, 2012. 2(4).

18. Deepa M, Anjana RM, Manjula D, Narayan KM, Mohan V. Convergence of prevalence rates of diabetes and cardiometabolic risk factors in middle and low income groups in urban India: 10-year follow-up of the Chennai Urban Population Study. $J$ Diabetes Sci Technol, 2011. 5(4): p. 918-27.

19. Prabhakaran D, Jeemon P, Roy A. Cardiovascular Diseases in India: Current Epidemiology and Future Directions. Circulation, 2016. 133(16): p. 1605-20.

20. American College of Cardiology, Review Addresses the Burden of CVD in India. Found at: $\quad$ https://www.acc.org/latest-in-cardiology/articles/2018/06/25/12/14/reviewaddresses- the-burden-of-cvd-in-india Accessed on January 3, 2018, 2018. 
21. United Nations, Goal 11: Make cities and human settlements inclusive, safe, resilient and sustainable. Found at: https://unstats.un.org/sdgs/report/2017/goal-11/Accessed on January 3, 2018.

22. United Nations, Urban slum dwellers could double to 2 billion by 2030, UN agency says. Found at: https://news.un.org/en/story/2003/10/81152-urban-slum-dwellers-coulddouble-2-billion-2030-un-agency-says Accessed on January 3, 2018.

23. Riley LW, Ko AI, Unger A, Reis MG. Slum health: diseases of neglected populations. BMC Int Health Hum Rights, 2007. 7: p. 2.

24. Vickar J, Dietary Pattern and Metabolic Syndrome Among Urban Slum Women, Accra, Ghana. Found at: https://lib.ugent.be/fulltxt/RUG01/002/275/167/RUG01002275167_2016_0001_AC.pdf Accessed on January 3, 2018, 2016.

25. Dhar, L. Preventing coronary heart disease risk of slum dwelling residents in India. J Family Med Prim Care, 2014. 3(1): p. 58-62.

26. Snyder RE, Rajan JV, Costa F, Lima H, Calcagno JI, Couto RD, et al. Differences in the Prevalence of Non-Communicable Disease between Slum Dwellers and the General Population in a Large Urban Area in Brazil. Trop Med Infect Dis, 2017. 2(3).

27. Nolan LB. Slum Definitions in Urban India: Implications for the Measurement of Health Inequalities. Popul Dev Rev, 2015. 41(1): p. 59-84.

28. UN-HABITAT, Slums: Some Definitions. Found at: http://mirror.unhabitat.org/documents/media_centre/sowcr2006/SOWCR 5.pdf Accessed on January 3, 2018.

29. Habitat for Humanity Great Britain, The World's Largest Slums: Dharavi, Kibera, Khayelitsha \& Neza. Found at: https://www.habitatforhumanity.org.uk/blog/2017/12/theworlds-largest-slums-dharavi- kibera-khayelitsha-neza/ Accessed on January 3, 2018.

30. World Population Review, Found at:

http://worldpopulationreview.com/world- cities/mumbai-population/ Accessed on November 11, 2018, 2018.

31. Yojana RA., Slum Free City Plan of Action - Tiruppur Corporation. Found at: http://mohua.gov.in/upload/uploadfiles/files/36TNSCB-Tiruppur-sfcp-min.pdf Accessed on January 3, 2018.

32. Karnataka Slum Development Board, Objectives. Found at: http://ksdb.kar.nic.in/objectives.asp Accessed on January 3, 2018. 
33. Karnataka Slum Development Board, Notified Slums in Mysore City as of 1 February 2016. Found at: https://www.karnataka.gov.in/ksdb/Pages/Slum-Statistics.aspx Accessed on January 3, 2018.

34. Chaturvedi S, Pant M, Neelam, Yadav G. Hypertension in Delhi: prevalence, awareness, treatment and control. Trop Doct, 2007. 37(3): p. 142-5.

35. Lavanya KM, Thomas V, Rao N, Rani UKM. Cardiovascular Risk Factors Among Adults - A Cross Sectional Study In Urban Slums of Hyderabad, Andhra Pradesh, India. Int J Med Health Sci, 2014. 3(4): p. 272-77.

36. Rooban T, Joshua E, Rao UK, Ranganathan K. Prevalence and correlates of tobacco use among urban adult men in India: a comparison of slum dwellers vs non-slum dwellers. Indian J Dent Res, 2012. 23(1): p. 31-8.

37. Gupta V, Yadav K, Anand K. Patterns of tobacco use across rural, urban, and urban-slum populations in a north Indian community. Indian J Community Med, 2010. 35(2): p. 24551.

38. Singh R, Mukherjee M, Kumar R, Ranabir P. Study of Risk factors of Coronary Heart Disease in Urban Slums of Patna. Nepal J Epidemiology, 2012. 2(3): 205-12. Misra A, Pandey RM, Devi JR, Sharma R, Vikram NK, Khanna N. High prevalence of diabetes, obesity and dyslipidaemia in urban slum population in northern India. Int J Obes Relat Metab Disord, 2001. 25(11): p. 1722-9.

39. Singh AK, Mani K, Krishnan A, Aggarwal P, Gupta SK. Prevalence, Awareness, Treatment and Control of Diabetes Among Elderly Persons in an Urban Slum of Delhi. Indian J Community Med, 2012. 37(4): p. 236-239.

40. Waingankar PJ, Pandit DD. A cross sectional study of coronary heart disease in an urban slum population of Mumbai. Int J Medical Clin Res, 2012. 3(5): p. 180-189.

41. Saeed O, Gupta V, Dhawan N, Streja L, Shin JS, Ku M, et al. Knowledge of modifiable risk factors of Coronary Atherosclerotic Heart Disease (CASHD) among a sample in India. BMC Int Health Hum Rights, 2009. 9: p. 2.

42. Meena J, Verma A, Banerjee B, Ingle GK. Cardiovascular disease determinants: Burden and knowledge among women in a rural community of Delhi. Intl Journal of Medical Science and Public Helath 2015. 4(2): p. 298-303.

43. George C, Andhuvan G. A population - based study on Awareness of Cardiovascular Disease Risk Factors. Indian Pharmacy Practice, Apr-Jun, 2014. 7(2): p. 23-25.

44. NCD Alliiance, Non-Communicable Diseases: A Priority for women's Health and Development. Found at: https://www.who.int/pmnch/topics/maternal/2011_women_ncd_report.pdf.pdf Accessed on January 3, 2018, 2010. 
45. McGill HC, Jr., McMahan CA, Gidding SS. Preventing heart disease in the 21st century: implications of the Pathobiological Determinants of Atherosclerosis in Youth (PDAY) study. Circulation, 2008. 117(9): p. 1216-27.

46. Chow C, Patel AA. Women's cardiovascular health in India. Heart, 2012. 98(6): p. 456-9.

47. Shen L, Wu J, Xu G, Song L, Yang S, Yuan J, et al. Parity and Risk of Coronary Heart Disease in Middle-aged and Older Chinese Women. Sci Rep, 2015. 5: p. 16834.

48. Cirillo PM, Cohn BA. Pregnancy complications and cardiovascular disease death: 50year follow-up of the Child Health and Development Studies pregnancy cohort. Circulation, 2015. 132(13): p. 1234-42.

49. Moller-Leimkuhler, A.M., Gender differences in cardiovascular disease and comorbid depression. Dialogues Clin Neurosci, 2007. 9(1): p. 71-83.

50. Pradeepa R, Anjana RM, Joshi SR, Bhansali A, Deepa M, Joshi PP, Dhandania VK, Madhu SV, Rao PV, Geetha L, Subashini R, Unnikrishnan R, Shukla DK, Kaur T, Mohan V, Das AK, Icmr-Indiab Collaborative Study Group. Prevalence of generalized $\&$ abdominal obesity in urban \& rural India--the ICMR-INDIAB Study (Phase-I) [ICMR- NDIAB-3]. Indian J Med Res, 2015. 142(2): p. 139-50.

51. Zhou B, Wu Y, Yang J, Li Y, Zhang H, Zhao L. Overweight is an independent risk factor for cardiovascular disease in Chinese populations. Obes Rev, 2002. 3(3): p. 14756.

52. Mayor S. Obesity in middle age is an independent risk factor for cardiovascular disease. BMJ, 2006. 332(7533): p. 71.

53. Fliotsos M, Zhao D, Rao VN, Ndumele CE, Guallar E, Burke GL, Vaidya D, Delaney JCA, Michos ED. Body Mass Index From Early-, Mid-, and Older- Adulthood and Risk of Heart Failure and Atherosclerotic Cardiovascular Disease: MESA. J Am Heart Assoc, 2018. 7(22): p. e009599.

54. Karunathilake SP, Ganegoda GU. Secondary Prevention of Cardiovascular Diseases and Application of Technology for Early Diagnosis. Biomed Res Int, 2018. 2018: p. 5767864.

55. Agha M, Agha RA, Sandall J. Interventions to reduce and prevent obesity in preconceptual and pregnant women: a systematic review and meta-analysis. PLoS One, 2014. 9(5): p. e95132.

56. Leinum CJ, Dopp JM, Morgan BJ. Sleep-disordered breathing and obesity: pathophysiology, complications, and treatment. Nutr Clin Pract, 2009. 24(6): p. 67587. 
57. Cho N, Joo S, Kim J, Abbott R, Kim J, Kimm K, Shin C. Relation of habitual snoring with components of metabolic syndrome in Korean adults. Diabetes Res Clin Pract, 2006. 71(3): p. 256-63.

58. Yanjie Xia Y, Ying Li Y, Guo M, Zhou L, Huanhuan Liu H, Wu Y, Zhao L. Association Between Habitual Snoring and Metabolic Syndrome in Chinese Population: A CrossSectional Study. Circulation, 2018. 136(A14634).

59. Sun L, Pan A, Yu Z, Li H, Shi A, Yu D, Zhang G, Zong G, Liu Y, Lin X. Snoring, inflammatory markers, adipokines and metabolic syndrome in apparently healthy Chinese. PLoS One, 2011. 6(11): p. e27515.

60. Xiao Q, Gu F, Caporaso N, Matthews CE. Relationship between sleep characteristics and measures of body size and composition in a nationally-representative sample. $B M C$ Obes, 2016. 3: p. 48.

61. Knuiman M, James A, Divitini M, Bartholomew H. Longitudinal study of risk factors for habitual snoring in a general adult population: the Busselton Health Study. Chest, 2006. 130(6): p. 1779-83.

62. Zancanella E, Haddad FM, Oliveira LA, Nakasato A, Duarte BB, Soares CF, Cahali MB, Eckeli A, Caramelli B, Drager L, Ramos BD, Nobrega M, Fagondes SC, Andrada NC. Associacao Brasileira de Otorrinolaringologia e Cirurgia, Cervico-Facial, Academia Brasileira de Neurologia, Sociedade Brasileira de Cardiologia, Sociedade Brasileira de Pediatria, Sociedade Brasileira de Pneumologia de Tisiologia. Obstructive sleep apnea and primary snoring: treatment. Braz J Otorhinolaryngol, 2014. 80(1 Suppl 1): p. S17-28.

63. Sogebi OA, Oyewole EA, Olusoga-Peters OO. Sleep disordered breathing (SDB) experiences associated with snoring in adult Nigerians. Afr Health Sci, 2011. 11(3): p. $309-14$.

64. Wells J. The Metabolic Ghetto: An Evolutionary Perspective on Nutrition, Power Relations and Chronic Disease (p. 375). 2016, Cambridge UK: Cambridge University Press.

65. Marchesini G, Pontiroli A, Salvioli G, Novi RF, Vitacolonna E, Taboga C, Ciccarone AM, Grossi E, Quovadis Study Group. Snoring, hypertension and Type 2 diabetes in obesity. Protection by physical activity. J Endocrinol Invest, 2004. 27(2): p. 150-7.

66. Oates CS. Psychological and Metabolic Correlates of Obesity in African-Americans and Caucasians. Found at: https://apps.dtic.mil/dtic/tr/fulltext/u2/1014221.pdf Accessed on January 3, 2018, 2006.

67. O'Brien LM, Mervis CB, Holbrook CR, Bruner JL, Klaus CJ, Rutherford J, Raffield TJ, Gozal D, Neurobehavioral implications of habitual snoring in children. Pediatrics, 2004. 114(1): p. 44-9. 
68. Beccuti G, Pannain S. Sleep and obesity. Curr Opin Clin Nutr Metab Care, 2011. 14(4): p. 402-12.

69. Lugaresi E, Cirignotta F, Coccagna G, Pian C. Some epidemiological data on snoring and cardiocirculatory disturbances. Sleep, 1980. 3(3-4): p. 221-4.

70. Al-Delaimy WK, Manson JE, Willett WC, Stampfer MJ, Hu FB. Snoring as a risk factor for type II diabetes mellitus: a prospective study. Am J Epidemiol, 2002. 155(5): p. 387-93.

71. Joo S, Lee S, Choi HA, Kim J, Kim E, Kimm K, Kim J, Shin C. Habitual snoring is associated with elevated hemoglobin A1c levels in non- obese middle-aged adults. $J$ Sleep Res, 2006. 15(4): p. 437-44.

72. Pradeepa R, Anjana RM, Joshi SR, Bhansali A, Deepa M, Joshi PP, et al. Prevalence of generalized \& abdominal obesity in urban \& rural India--the ICMR-INDIAB Study (Phase-I) [ICMR- NDIAB-3]. Indian J Med Res, 2015. 142(2): p. 139-50.

73. Zhang X, Giovannucci EL, Wu K, Gao X, Hu F, Ogino S, Schernhammer ES, Fuchs CS, Redline S, Willett WC, Ma J. Associations of self-reported sleep duration and snoring with colorectal cancer risk in men and women. Sleep, 2013. 36(5): p. 681-688.

74. Song Q, Hu W, Zhou W, Liu A, Wang X, Wu S. Long Sleep Duration Is an Independent Risk Factor for Incident Atrial Fibrillation in a Chinese Population: A Prospective Cohort Study. Scientific Reports, 2017. 7(3679).

75. Endeshaw Y, Rice TB, Schwartz AV, Stone KL, Manini TM, Satterfield S, Cummings S, Harris T, Pahor M. ABC Health Study, Snoring, daytime sleepiness, and incident cardiovascular disease in the health, aging, and body composition study. Sleep, 2013. 36(11): p. 1737-45.

76. Rose GA. The diagnosis of Ischaemic heart pain and intermittent claudication in field surveys. Bull World Health Organ, 1962. 27: p. 645-58.

77. Chou R, Arora B, Dana T, Fu R, Walker M, Humphrey L. Screening Asymptomatic Adults for Coronary Heart Disease with Resting or Exercise Electrocardiography: Systematic Review to Update the 2004 U.S. Preventive Services Task Force Recommendation. 2011: Rockville (MD).

79. Weinstein ND, Sandman PM. A model of the precaution adoption process: evidence from home radon testing. Health Psychol, 1992. 11(3): p. 170-80. 


\section{FIGURES}

Figure 1. The Precaution Adoption Process Model (79).

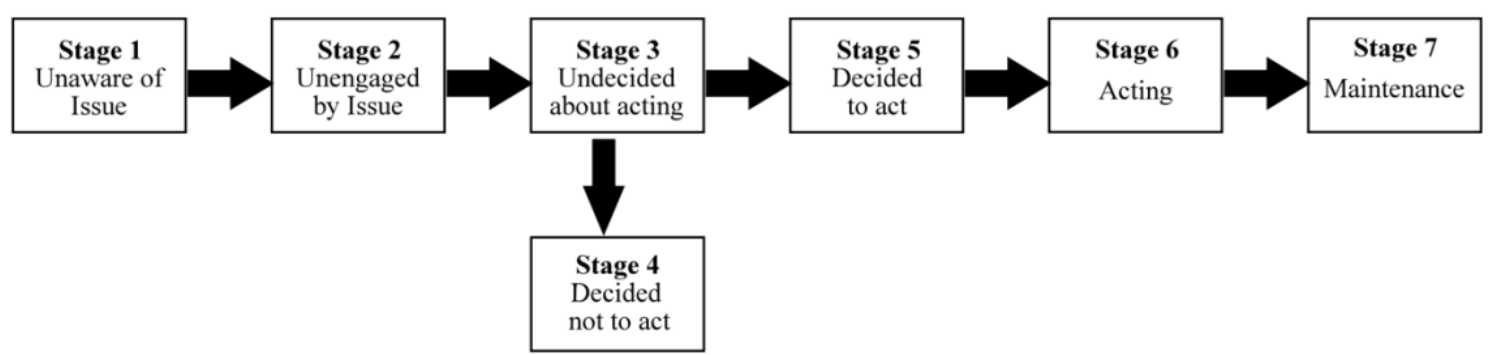




\title{
MANUSCRIPT 1
}

\section{CARDIOVASCULAR RISK FACTOR KNOWLEDGE AND BEHAVIORS AMONG SLUM- DWELLING WOMEN IN MYSORE, INDIA}

\begin{abstract}
Background: Three quarters of cardiovascular disease (CVD) deaths occur in low- and middleincome countries killing more than twice as many people as HIV, malaria, and tuberculosis combined. The World Health Organization estimates that as much as $80 \%$ of premature CVD deaths are preventable through behavioral changes related to seven modifiable risk factors (blood pressure, cholesterol, serum glucose, physical activity, diet, weight, and smoking). This study is one of the first to assess knowledge about modifiable CVD risk factors among slumdwelling Indian women.
\end{abstract}

Methods: The study used a cross-sectional design to collect data from a nonprobability sample of 607 urban slum-dwelling women, 40 - 64 years of age, living in Mysore city, India, between October 2017 and May 2018. Participants underwent an interviewer administered questionnaire measuring demographics, CVD risk factor knowledge, and chronic disease medical history. Participants underwent a biomedical examination that included testing for anemia, hypertension, blood glucose, lipids, and a resting electrocardiogram.

Results: Heart disease risk factor knowledge was extremely low in this population. CVD knowledge was significantly associated with age, education, monthly household income, marital status and caste.

Conclusions: Previous research among slum dwellers in India report a high prevalence of modifiable CVD risk factors compared to more affluent urban peers. Our results suggest that interventions aimed at educating slum-dwellers about CVD risk factors may be an important first step in controlling the burden of heart disease in this vulnerable population. 


\section{INTRODUCTION}

Worldwide, about 17.9 million people die each year from cardiovascular disease (CVD); this represents roughly a third (31\%) of all mortality [1]. Three-quarters of these deaths occur in low- and middle-income countries (LMIC) where CVD kills more than twice as many people as HIV, malaria, and tuberculosis combined [2,3]. In high-income countries, age-adjusted CVD mortality has fallen more than $60 \%$ following its peak in the 1960s [4,5]. In contrast, LMIC continue to experience both increasing CVD incidence and age-adjusted mortality [6]. The social patterning of CVD also appears different with developing countries generally having a lower median age at first heart attack and CVD-related death [7]. The reasons are multifactorial, but include low population knowledge about CVD risk factors, a lack of preventative interventions, and poor access to affordable medical care [8]. As a consequence, individuals living in LMIC are one and a half times more likely to die prematurely from conditions like CVD compared to their peers in high-income nations [9].

The World Health Organization (WHO) estimates that $80 \%$ of premature heart disease is preventable [10]. Population-based studies suggest that lifestyle changes and management of seven modifiable cardiovascular risk factors (blood pressure, cholesterol, serum glucose, physical activity, diet, weight, and smoking) reduce CVD risk by as much as two-thirds [1113]. In high-income countries, prevention efforts have focused on improving CVD risk factor knowledge since this knowledge has been shown to be a prerequisite to the lifestyle changes required for reducing CVD morbidity and mortality [14,15]. In LMIC, studies suggest generally low knowledge about CVD risk factors, particularly in populations at the highest risk for heart disease [16-18].

India leads the globe in annual CVD deaths [19]. In 2016, CVD was responsible for almost a third (28.1\%) of the country's mortality and $14.1 \%$ of total disability-adjusted life years 
[20]. Little is known about levels of CVD risk factor knowledge among urban Indian adults [21- 28]. The majority of existing studies were carried out in tertiary care hospitals [21, 25-29], or rural settings $[22,24,29]$, and these found relatively low knowledge about underlying risks for heart disease. The only study examining urban adults was carried out in Bangalore among a young ( $82 \%$ were under age 50) and well-educated (64\% of participants had completed secondary school or higher education) sample [23]. This study is one of the first to examine CVD risk factor knowledge among urban slum-dwelling women in India.

\section{METHODS}

Overview

This was a cross-sectional study used to collect data from a nonprobability sample of urban slum-dwelling women, 40 - 64 years of age, living in Mysore city, India, between October 2017 and May 2018. Along with CVD risk factor knowledge, data were collected on biological and reported measures of anemia, blood pressure, lipids, serum glucose, physical activity, diet, weight, smoking, anthropometry, medical and family history of chronic disease, diet, sleep, and reproductive history.

\section{Study Sites and Population}

The study was carried out in six urban slums in Mysore, India, (Kesere, Kudaremala, Ekalavya Nagara, Amrutha badavane, and Ganeshnagar) randomly selected from a sampling frame of 63 communities officially designated as slums in the city by the Karnataka Slum Development Board [30]. According to the 2011 census, Mysore had a population of 920,550, of

which 459,508 were females. Approximately one in five residents lived below the poverty line, and about 39,029 residents lived in slums (as defined by the Karnataka Slum Act). Approximately $73.6 \%$ were Hindus, $21.9 \%$ Muslims, $2.8 \%$ Christians, and the remainder 
belonged to other religions. The city has a literacy rate of $87.7 \%$, and Kannada is the most widely spoken regional language. The study population included women who had consented to participate in the study, were aged 40-64 years, and had lived for at least the prior six months in selected slums.

\section{Theoretical Framework}

The Precaution Adoption Process Model (PAPM), developed by Weinstein and Sandman, was used as a theoretical framework in the Mera Dil study to help understand the relationship between knowledge and readiness to adopt heart healthy behaviors [31]. PAPM posits that adoption and maintenance of health behaviors is associated with a series of stages [32].

According to the theory, people may be: (1) unaware of an issue; (2) aware of an issue but not personally engaged by it; (3) engaged and deciding what to do next; (4) planning to act, but not yet acting; (5) deciding not to act; (6) taking-action; and (7) maintaining the results of an action. Each stage has specific patterns of beliefs, behaviors, and experience. PAPM suggests that specific factors are associated with advancement across the continuum, and others are necessary for stage transitions. In this study, PAPM stage will be identified with seven stage descriptions adapted from a study by Patricia Weinstein which assessed awareness of cardiovascular risk in women with Systemic Lupus Erythematosus [34]: 1) I don't think I'm at greater risk of getting heart disease than any other person; 2) I know I am at risk for heart disease but I haven't thought much about it; 3) I am thinking about changing my behaviors to decrease my chances for getting heart disease, but I haven't made up my mind it's something I want to do; 4) I have thought about changing some of my behaviors to decrease my chances for getting heart disease but I have decided against it; 5) I have decided to change some of my behaviors to decrease my chances fgetting heart disease, but I have not started doing them yet; 6) I have recently changed some of my behaviors within the last month to decrease my chances for getting heart disease; 
and 7) I have made changes in my behavior to decrease my chances for getting heart disease for at least six months. The questionnaire seeks to identify: 1) knowledge and beliefs about CHD risk factors and personal risk; 2) thought patterns associated with intentions to maintain health behaviors or adopt new ones; 3) weight loss and attempted weight loss; 4) smoking cessation and attempted smoking cessation; 5) discontinuation or lowered alcohol use; 6) health-seeking and lifestyle changes to lower serum cholesterol, blood pressure, and serum glucose; and 7) adoption or non-adoption of healthier and physical activity behaviors. PAPM was operationalized using the Adoption of Risk Reducing Behaviors Instrument (ARRBI) adapted from a measure developed and validated by Weinstein et al (34).

\section{Study Recruitment}

Study staff visited selected slums one day prior to study recruitment and distributed study brochures in Kannada which described the study purpose and activities. Potential participants interested in participating were told to come to a specified meeting point having fasted from 8.00 PM the previous evening. They were asked to bring any of their medical reports or medications that concerned diabetes, heart disease, or stroke, as well as reports that detailed physical examinations and blood tests, particularly those that had measures of anemia, high blood pressure, cholesterol, or serum glucose. On recruitment day, participants were transported by van to a medical clinic, where all study activities were carried out. Prior to the beginning of data collection, participants underwent a group informed consent process that consisted of study staff explaining the study purpose, reading the informed consent document out loud verbatim, describing all study procedures, and answering any questions. Participants who wished to enroll in the study were taken to private space and study staff met with them on a one-on-one basis to read the consent document out loud a second time and clarify any doubts. If potential participants decided to participate, they were required to give written informed consent prior to data collection. A brief anonymous survey was also conducted among potential participants who 
declined to enroll to determine if there were any systematic biases in participant recruitment. Participants received a stipend of INR 200 (USD 3.33), an amount traditional for studies of this type, to compensate them for their time and transportation expenses. A protocol for the study was approved by Institutional Review Boards at Florida International University in Miami, US, and the Public Health Research Institute of India in Mysore, India.

\section{Translation and Cross-cultural Adaptation of Instruments}

Kannada language versions of study measures were translated and tested prior to data collection with the goal of producing culturally relevant instruments that were conceptually equivalent to English versions. This was accomplished in a four-step process: 1) Forward translation from English to Kannada, the local regional language; 2) Expert panel backtranslation from Kannada to English; 3) Pre-testing (PT) and cognitive interviewing among a sample of study participants to establish equivalency; and 4) development of a final version based on input from Pre-testing and cognitive interviewing [35]. Detailed information on the methods used for translation and cross-cultural adaptation can be found elsewhere [36]. Study instruments included:

1. Study Questionnaire: A standardized interviewer-administered questionnaire was adapted from the CARRS (Centre for cArdiometabolic Risk Reduction in South-Asia) Surveillance Study [37]. It included questions on demographics, socio-economic status, current employment, and residence. Data on tobacco and alcohol consumption, dietary habits, physical activity, sleep, and quality of life were also collected along with personal and family history of diagnosed cardiometabolic disorders and their risk factors; diabetes; heart disease, stroke, chronic obstructive pulmonary disease, angina, peripheral vascular disease, kidney disease, and respiratory disease. Sleep duration and quality were measured with scales adapted from the National Heart Lung Blood Institute (NHLBI) Sleep Habits Questionnaire, which covered sleep characteristics, patterns, and snoring [38]. Daytime sleepiness was measured using an adapted Epworth 
Sleepiness Scale (ESS) [39]. Medical history and medication adherence were collected in five disease-specific sections on Hypertension, Diabetes, Hyperlipidemia, Heart Disease, Stroke, and Chronic Kidney Disease. Adherence was quantified with the question: "How regular are you in taking your physician-prescribed medicines for [the condition]?’. There were five possible responses: 1 . Taking regularly; 2 . Forget to take occasionally; 3 . Take medications only when I feel [the condition] is high; 4. Discontinued for more than a month at a time; and 5. Never taken any medications.

2. Heart Disease Risk Factor Knowledge: A 17-item instrument measuring participant knowledge of heart disease risk factors was adapted from Wagner et al's Heart Disease Fact Questionnaire (HDFQ) (40). HDFQ measures 10 cardiovascular risk domains: family history of heart disease, age, sex, smoking, physical activity, glycemic control, lipids, blood pressure, weight, and whether a person would know if heart disease was present [40]. Seventeen items were included in the HDFQ after extensive pretesting, cognitive interviewing and adaptation for cultural relevance, understandability, and ease of administration and scoring. Response options on the HDFQ were 'yes', ‘no', and 'I don’t know'.

3. Adoption of Risk Reducing Behaviors Instrument (ARRBI): The AARBI, a measure operationalizing the PAPM theoretical framework was adapted from a measure developed and validated by Weinstein et al (34). Participants were asked to "Select one answer that best describes your feelings about your behavior and changes of getting heart disease”. Responses could be classified intoone of the seven PAPM stages: 1. Unaware of the Issue, 2. Unengaged by the Issue, 3. Undecided about Acting, 4. Decided not to Act, 5. Decided to Act, 6. Acting, 7. Maintenance.

\section{Study Variables}

CVD Risk Factor Knowledge was measured using the HDFQ. 'Don't Know' responses were scored as incorrect answers. Heart disease risk factor knowledge was classified as poor 
( $<50 \%$ correct answers), moderate (50-69\% correct answers) or good knowledge ( $\geq 70 \%$ correct answers) [16].

Readiness to adopt heart healthy behaviors were assessed from participant responses that could be categorized into: Unaware of the Issue, Unengaged by the Issue, Undecided about Acting, Decided not to Act, Decided to Act, Acting, and Maintenance A Participant response was classified as reporting durable behavior change if they selected the response option: "I have changed my behavior to reduce my risk for heart disease and have maintained that change for six or more months."

\section{Statistical Analysis}

Data were presented as frequencies and percentage of total for categorical variables, and as mean and standard deviation (SD) or median values for continuous variables. Multinomial logistic regression models were used to identify significant factors of CV knowledge. Factors that were conservatively associated with CV knowledge ( $p<0.200$ for appropriate tests) were selected a priori as covariates in model 1 . Factors that were conservatively associated with both $\mathrm{CV}$ knowledge and readiness to adopt heart healthy behaviors were selected a priori as covariates in model 2. Variables were excluded from the models if there was little variation in response (if $\geq 90 \%$ of the sample fell into a single response category) or if variables were highly correlated. Correlation and multicollinearity were assessed using Pearson's correlation coefficients I and variance inflation factors (VIFs), respectively. A P-value of 0.05 was considered statistically significant. Standard errors were adjusted for clustering by slum (6 clusters). A P-value of 0.05 was considered statistically significant. Statistical analysis was performed in SPSS 22 (SPSS Statistics, IBM Corp. Armonk, NY, USA) and STATA version 12 (Statacorp, College Station, Texas, US). 


\section{RESULTS}

\section{Sample Characteristics}

Participants averaged 50 years of age, and a large majority reported their religion as Hindu (84.2\%) (Table 1). Nearly two out of three participants had no formal schooling (62.8\%) and six in ten were employed (61.4\%). Half were married (51.4\%), slightly less than half $(47.1 \%)$ belonged to a scheduled caste or tribe, and a majority (53.0\%) lived in a household with a monthly household income ranging from 3,000 to 10,000 Indian Rupees (1 USD=66.78 INR) [41]. About four in ten participants were obese based on Revised Consensus Body Mass Indices for Asian Indians (38.7\%) [42].

\section{CVD Risk Factor Knowledge among Slum-dwelling Indian Women}

Responses to the CVD risk factor knowledge measures are included in Table 2. In general, knowledge about CVD risk factors was extremely poor in this population. Score on the HDFQ ranged from 0.0 to 94.1 with a mean score of 49.7 (standard deviation: \pm 29.9 ). Nearly half of the participants were categorized as having poor knowledge about CVD risk factors (47.3\%), while only one-third had good knowledge (33.9\%). Among participants, the most frequently recognized CVD risk factors were lack of physical activity (66.9\%), smoking (66.7\%), being overweight (64.1\%), and having high cholesterol (61.6\%). Only 46\%, 45\%, $43.5 \%$, and $27.3 \%$ of women respectively knew that age, having hypertension, having family history of heart disease, or having diabetes increased risk for CVD. While a majority of women (60.6\%) said that quitting cigarettes would reduce their risk for heart disease, only $43.2 \%$ believed that managing their serum glucose levels would alter their CVD risk.

CVD risk factor knowledge was significantly associated with age, education, monthly household income, marital status and caste (Table 3). Lower age was significantly associated with a greater CVD knowledge. The average age $( \pm$ SD) of women with low knowledge was 51.4 years $( \pm 7.3)$; moderate knowledge, 48.5 years $( \pm 7.3)$; and good knowledge 49 years $( \pm 7.1)$. 
Greater educational achievement was also associated with higher CVD knowledge scores: $71 \%$ of the respondents in the poor CVD knowledge category had no schooling, compared to $55.3 \%$ in both the moderate or good knowledge category. Similarly, only $3.8 \%$ of women in the poor knowledge category reported having a secondary school education or higher, while $10.5 \%$ and $12.1 \%$ of the participants with moderate and good knowledge respectively, had completed high school or a higher level of education. The mean number of "don't know" responses for each item on the risk factor assessment was significantly lower among women with secondary education vs. no schooling (4.7 vs. $8.3, \mathrm{p}<0.001)$; and significantly lower among women with high school education vs. no schooling (5.7 vs. 8.3, p<0.001). CVD knowledge was low across all income categories with the lowermost knowledge scores found among people with lower incomes; $54.3 \%$ among the $<3000$ INR group ( $<\$ 42$ USD); $42.7 \%$ in the $3000-10000(\$ 42-\$ 139)$ INR group; and $51.3 \%$ of participants with family incomes $>10,000$ INR (>\$139) had poor knowledge about CVD risk factor knowledge [43]. Having marital status as being single (71.4\%) was associated with poor risk factor knowledge as was being a member of a general caste as compared to scheduled castes or tribes (SC/ST) or Other Backward Castes; 50.3\% of SC/ST, $40.6 \%$ of Other Backward Castes, and $52.9 \%$ of General Caste women, had poor CVD risk factor knowledge scores. CVD risk factor knowledge was not associated with hypertension, diabetes, hyperlipidemia, or CVD medication adherence (data not shown).

\section{PAPM and CVD Risk Behavior}

Of the 607 women completing the ARRBI, 60\% (n=364) reported that they had not been thinking about changing their behavior to reduce their risk for heart disease and did not intend to do so in the next 6 months; $7.6 \%(n=46)$ reported they were not changing their behavior to reduce risk for heart disease but intended to do so in the next six months; $3.8 \%(n=23)$ reported having decided what behavior (weight loss, quitting smoking, etc.) they needed to change; $4.4 \%$ $(n=27)$ reported having changed behavior within the last six months; and 24.2\% ( $n=147)$ 
reported having changed behavior for six or more months. Among participants who reported not having thought about changing their CVD risk behavior; $55.2 \%$ had poor, $17.6 \%$ moderate, and $27.2 \%$ good knowledge about CVD risk factors, respectively.

Among participants who reported an intention to change their behavior in the next six months, $28.3 \%$ had poor, $30.4 \%$ moderate, and $41.3 \%$ good CVD risk factor knowledge; those that had made behavior changes but not yet maintained that change for more than six months, $40.7 \%$, $18.4 \%$, and $40.7 \%$ had poor, moderate, and good knowledge respectively; and among those who had maintained CVD risk factors for more than six months, $37.4 \%, 18.4 \%$ and $44.5 \%$ had poor, moderate, and good knowledge, respectively. There was a significant association between CVD risk factor knowledge and risk behavior $(\mathrm{p}<0.001)$.

\section{Factors Associated with CVD Knowledge}

The results of the logistic regression models are presented in Tables 4a and 4b. Age, education, religion, and CVD risk behavior are significant factors of poor (compared to good) CVD knowledge. For every one-year increase in age, the odds of poor (compared to good) CVD knowledge significantly increases by $5 \%(\mathrm{p}=0.001)$. As compared to no schooling, the odds of having poor (compared to good) CVD knowledge is $48 \%$ and $75 \%$ lower among participants with a high school diploma and those educated beyond high school, respectively ( $\mathrm{p}=0.007$ and $\mathrm{p}<0.001$, respectively). Women belonging to Muslim religion and those that reported they had not been thinking about changing their behavior to reduce their risk for CVD have over two times the odds of poor (compared to good) CVD knowledge as women belonging to Hindu religion and those who said they had changed their behavior and maintained it for more than six months, respectively ( $\mathrm{p}=0.029$ and $\mathrm{p}<0.001$, respectively). The only significant factor of moderate (compared to good) CVD knowledge is caste. The odds of moderate (compared to good) CVD knowledge is 53\% lower among women who are members of a scheduled caste or tribe compared to those who are members of a general caste $(\mathrm{p}=0.033)$. 


\section{DISCUSSION}

This research was part of a larger study assessing the burden of coronary heart disease in slum-dwelling women in Mysore, India. Considering that more than 104 million people live in Indian urban slums, surprisingly little is known about the prevalence and correlates of CHD in this population $[44,45]$. As Riley et al had observed, we know almost nothing about the "magnitude, distribution, and risk factors for these illnesses before they manifest as stroke, myocardial infarction, kidney failure, suicide, multidrug-resistant TB, heart valve disease, and AIDS" [45]. To our knowledge, this is one of the first studies to assess knowledge levels about modifiable CVD risk factors among India's slum-dwelling population. This study correlated knowledge levels with health-related behavior change assessed using a PAPM model.

In this study, we found that slum-dwelling women had low knowledge about modifiable CVD risk factors; a finding consistent with studies of other slum-dwellers in other parts of the world $[16,46]$. About half $(47 \%)$ of the participants answered less than $50 \%$ of questions correctly, and only a third had knowledge scores above $70 \%$, which we defined as 'good knowledge'. Only four of seven traditional CVD risk factors; physical activity, smoking, overweight, and high cholesterol were recognized by greater than half of participants. On the other hand, only $46 \%, 43.5 \%$, and $27.3 \%$ of women respectively knew about some of the most important risk factors including hypertension, family history of heart disease, or diabetes increased risk for CVD. Consistent with studies in other disadvantaged populations, we found that CVD risk factor knowledge was significantly associated with age, education, monthly household income, marital status [47-50]. The lowest knowledge levels were found among older single women with no education and monthly household incomes of less than 3000 INR (approximately \$42 USD). Furthermore, women with no schooling had more 'Don't know' responses as compared to women with secondary education or more. Interestingly, women in lower castes had more knowledge about CVD risk factors than those in general or higher castes. 
We hypothesize that this increased knowledge is due to greater healthcare access provided by the Government of India's National Urban Health Mission, which provides low- and no-cost medical treatment to the lowest income families in India's urban slums [51].

In this study, we found that knowledge of CVD risk factors was significantly associated with reported change and maintenance of health behavior. While this finding is consistent with other studies reporting that adequate knowledge about health risk is an important prerequisite for making appropriate health decisions $[52,53]$, the present study design was inadequate for assessing whether knowledge alone was sufficient to facilitate change or maintenance of health behavior. A large body of theory suggests that health behaviors are complicated and multifactorial, and behavior change is dependent on a large number of internal factors including attitudes, beliefs, motivation, self-efficacy, social norms, and sociocultural contexts [49, 54]. There is a clear and significant association between low health knowledge, adverse health outcomes, and poor use of health-care services [55]. Studies also suggest that higher levels of health knowledge influences attitudes toward behavior change [56], improves self-regulation skills and abilities, and enhances social facilitation [57]. The finding that $60 \%$ of participants in this study reported they were not thinking about changing their heart health behavior and a majority (55.2\%) of those had poor knowledge about heart disease risk factors, points to a serious public health need for health information interventions in this population.

This study has several limitations. Our sample of 607 slum-dwelling women was relatively small and limited to a nonprobability sample of women who agreed to participate, limiting the generalizability of the findings to a wider population. The participants self-reported smoking; alcohol use; diet; and sleep duration and quality; and the accuracy of this data is likely limited by social desirability and recall biases. Despite these limitations, the study also had many strengths including being one of the first studies to examine knowledge about CVD risk factors in an Indian slum population; which included detailed biological measurements along with anthropometrics, biological measurements of hypertension, serum cholesterol, serum glucose, 
and electrocardiography. In addition, the study was informed by a theoretical framework, Precaution Adoption Process Model that has been widely used to study lifestyle change and chronic disease [31].

\section{CONCLUSIONS}

Previous studies among slum-dwellers in India report a high prevalence of modifiable CVD risk factors compared to their more affluent urban peers [58-60]. Our results suggest that that interventions aimed at educating slum-dwellers about CVD risk factors may be an important first step to controlling the burden of cardiovascular disease among some of India's most vulnerable populations.

\section{REFERENCES}

1. World Health Organization. Cardiovascular Disease. Found at: https://www.who.int/cardiovascular_diseases/en/Accessed on December 12, 2018.

2. Global Burden of Disease and Risk Factors. Disease Control Priorities Project. Eds. Lopez AD, Mathers CD, Ezzati M, Jamison DT, Murray CJL. Vol. ISBN-10: 0-82136262-3ISBN-13: 978-0-8213-6262-4. 2006, Washington DC: The International Bank for Reconstruction and Development / The World Bank; New York: Oxford University Press.

3. World Health Organization, Cardiovascular Diseases. Found at: http://www.who.int/cardiovascular_diseases/world-heart-day/en/Accessed on October 10, 2018, 2018.

4. Organization for Economic Cooperation and Development, Policy Brief: Cardivascular Disease and Diabetes. Found at: https://www.oecd.org/health/healthsystems/Cardiovascular-Disease-and-Diabetes-Policy-Brief.pdf Accessed on December 17, 2018, 2015.

5. Centers for Disease Control and Prevention. Achievements in Public Health, 19001999: Decline in Deaths from Heart Disease and Stroke -- United States, 1900-1999. Found at: https://www.cdc.gov/mmwr/preview/mmwrhtml/mm4830a1.htm Accessed on December 17, 2018. 
6. Gaziano TA, Gaziano TA, Bitton A, Anand S, Abrahams-Gessel S, Murphy A. Growing epidemic of coronary heart disease in low- and middle-income countries. Curr Probl Cardiol. 2010 Feb;35(2):72-115. doi: 10.1016/j.cpcardiol.2009.10.002. Review.

7. Institute of Medicine (US) Committee on Preventing the Global Epidemic of Cardiovascular Disease: Meeting the Challenges in Developing Countries; Fuster V, Kelly BB, editors. Promoting Cardiovascular Health in the Developing World: A Critical Challenge to Achieve Global Health. Washington (DC): National Academies Press (US); 2010.

8. Schwalm JD, McKee M, Huffman MD, Yusuf S. Resource Effective Strategies to Prevent and Treat Cardiovascular Disease. Circulation. 2016 Feb 23;133(8):742-55.

9. Allen L, Cobiac L, Townsend N. Quantifying the Global Distribution of Premature Mortality from Non-communicable Diseases. J Public Health (Oxf). 2017 Dec 1;39(4):698-703.

10. World Health Organization. Overview - Preventing Chronic Diseases: a Vital Investment. Found at: http://www.who.int/chp/chronic_disease_report/part1/en/index11.html Accessed on October 10, 2018, 2018.

11. Peng Y, Wang Z. Association of Life's Simple 7 and Presence of Cardiovascular Disease in General Australians. Open Heart, 2017. 4(2): p. e000622.

12. Xanthakis V, Enserro DM, Murabito JM, Polak JF, Wollert KC, Januzzi JL, Wang $\mathrm{TJ}$, et al. Ideal cardiovascular health: associations with biomarkers and subclinical disease and impact on incidence of cardiovascular disease in the Framingham Offspring Study. Circulation. 2014 Nov 4;130(19):1676-83.

13. Folsom AR, Shah AM, Lutsey PL, Roetker NS, Alonso A, Avery CL, Miedema MD, et al. American Heart Association's Life's Simple 7: Avoiding Heart Failure and Preserving Cardiac Structure and Function. Am J Med. 2015 Sep;128(9):970-6.e2.

14. DiClemente CC, Prochaska JO, Fairhurst SK, Velicer WF, Velasquez MM, Rossi JS. The Process of Smoking Cessation: An Analysis of Precontemplation, Contemplation, and Preparation Stages of Change. J Consult Clin Psychol. 1991 Apr;59(2):295-304.

15. Prochaska JO, DiClemente CC. Stages of Change in The Modification of Problem Behaviors. Prog Behav Modif, 1992. 28: p. 183-218.

16. Boateng D, Wekesah F, Browne JL, Agyemang C, Agyei-Baffour P, Aikins AD, Smit HA, et al. Knowledge and Awareness of and Perception Towards Cardiovascular Disease Risk in Sub-Saharan Africa: A Systematic Review. PLoS One. 2017 Dec 12;12(12):e0189264.

17. Surka S, Steyn K, Everett-Murphy K, Gaziano TA, Levitt N. Knowledge and Perceptions of Risk For Cardiovascular Disease: Findings Of A Qualitative 
Investigation From A Low-Income Peri-Urban Community In The Western Cape, South Africa. Afr J Prim Health Care Fam Med. 2015 Oct 22;7(1):891.

18. George GM, Sharma KK, Ramakrishnan S, Gupta SK. A Study of Cardiovascular Risk Factors and Its Knowledge Among School Children of Delhi. Indian Heart J. 2014 May-Jun;66(3):263-71.

19. World Health Organization, World Data Table. Found at: https://www.google.com/url?sa=t\&rct=j\&q=\&esrc=s\&source=web\&cd=1\&ved=2ah UKEwiqs8KyoHeAhWSrFkKHU6nBFsQFjAAegQICRAC\&url=http\%3A\%2F\%2F www.who.int $\% 2 \mathrm{Fcardiovascular}$ diseases $\% 2 \mathrm{Fen} \% 2 \mathrm{Fcvd}$ atlas 29 world data table .pdf\&usg=AOvVaw19GzjFGVjpIlcgc9h00KLK Accessed on Oct 10, 2018, 2002.

20. India State-Level Disease Burden Initiative CVD Collaborators. The Changing Patterns of Cardiovascular Diseases and Their Risk Factors in The States of India: The Global Burden of Disease Study 1990-2016. Lancet Glob Health, 2018. S2214109X(18)30407-8.

21. Saeed O, Gupta V, Dhawan N, Streja L, Shin JS, Ku M, Bhoi S, Verma S. Knowledge of Modifiable Risk Factors of Coronary Atherosclerotic Heart Disease (CASHD) among A Sample in India. BMC Int Health Hum Rights. 2009 Feb 4;9:2.

22. Zaman MJ, Patel A, Jan S, Hillis GS, Raju PK, Neal B, Chow CK. Socio-Economic Distribution of Cardiovascular Risk Factors and Knowledge in Rural India. Int J Epidemiol. 2012 Oct;41(5):1302-14.

23. Duber HC, McNellan CR, Wollum A, Phillips B, Allen K, Brown JC, Bryant M, Guptam RB, Li Y, Majumdar P, Roth GA, Thomson B, Wilson S, Woldeab A, Zhou M, Ng M. Public Knowledge of Cardiovascular Disease and Response to Acute Cardiac Events in Three Cities in China and India. Heart. 2018 Jan;104(1):67-72.

24. Meena J, Verma A, Banerjee B, Ingle GK. Cardiovascular Disease Determinants: Burden and Knowledge among Women in a Rural Community of Delhi. Intl J Med Sc Public Health 2015; 4(2): 298-303.

25. Gandhi A, Ayyappan P, Sahana C, Poovizhi S, Sivasakthi K. Knowledge of Modifiable Risk Factors of Heart Disease Among Patients with Cardiovascular Risk. Asian J Pharmaceutical Clin Research, 2017; 10(1): 99-102.

26. Patnaik L, Pattanaik S, Sahu T, Panda BK. Awareness of symptoms and risk factors of Myocardial Infarction among adults seeking health care from a rural hospital of India. J Cardiovasc Disease Res. 2016;7(2):83-5.

27. George C, G Andhuvan. A Population Based Study on Awareness of Cardiovascular Disease Risk Factors. Indian J Pharmacy Practice, Apr-Jun, 2014; 7(2): 23-25.

28. Sharma K, Gulati M. Coronary Artery Disease in Women: A 2013 Update. Glob Heart, 2013. 8(2): 105-12. 
29. Kumar R, Kumar HS. A Comparative Study on Awareness of Cardiovascular Risk Determinants Among Rural and Urban Women Population of Davangere District, Karnataka, India. Int J Comm Med Public Health, 2015. 4(2): 3336-3339.

30. Karnataka Slum Development Board, Slum Details at a Glance. Found at: https://www.karnataka.gov.in/ksdb/Pages/Slum-Statistics.aspx Accessed on Nov 13, $2018,2018$.

31. Weinstein ND, PM Sandman. A Model of The Precaution Adoption Process: Evidence from Home Radon Testing. Health Psychol, 1992. 11(3): 170-80.

32. Weinstein ND, Sandman PM, Blalock SJ. The Precaution Adoption Process Model. Found at: https://www.psandman.com/articles/PAPM.pdf Accessed on January 3, 2018.

33. Wenstein P. Awareness of Increased Risk For Heart Disease And Cardiovascular Risk Factors In Women With Systemic Lupus Erythematosus. Found at: https://stars.library.ucf.edu/cgi/viewcontent.cgi?referer=https://www.google.com/\&ht tpsredir=1\&article $=5020 \&$ context=etd Accessed on January 3, 2018, 2009.

34. Weinstein PK, Amirkhosravi A, Angelopoulos TJ, Bushy A, Covelli MM, Dennis KE. Reducing cardiovascular risk in women with lupus: perception of risk and predictors of risk-reducing behaviors. J Cardiovasc Nurs, 2014. 29(2): p. 130-9.

35. WHO, Process of translation and adaptation of instruments. Found at http://www.who.int/substance_abuse/research_tools/translation/en/Accessed on April 16, 2017, 2017

36. Beaton DE, Bombardier C, Guillemin F, Ferraz MB. Guidelines for the process of cross-cultural adaptation of self-report measures. Spine (Phila Pa 1976). 2000 Dec 15;25(24):3186-91. Review.

37. EMORY Rollins School of Public Health Global Diabetes Research Center, CARRS Cohort Study. Found at: http://diabetes.emory.edu/research/CARRS-Cohort.html Accessed on January 3, 2018.

38. National Heart Lung and Blood Institute, Sleep Heart Health Study (SHHS). Found at: https://biolincc.nhlbi.nih.gov/studies/shhs/ Accessed on January 3, 2018.

39. Johns MW. A new method for measuring daytime sleepiness: the Epworth sleepiness scale. Sleep, 1991. 14(6): 540-5.

40. Wagner J, Lacey K, Chyun D, Abbott G. Development of a questionnaire to measure heart disease risk knowledge in people with diabetes: the Heart Disease Fact Questionnaire. Patient Educ Couns, 2005. 58(1): 82-7.

41. Pound Sterling Live, Historical Rates for the USD/INR currency conversion on 01 May 2018 (01/05/2018). Found at: https://www.poundsterlinglive.com/best- 
exchange-rates/us-dollar-to-indian-rupee-exchange-rate-on-2018-05-01 Accessed on December 18, 2018, 2018.

42. Aziz N, SD Kallur, PK Nirmalan. Implications of the Revised Consensus Body Mass Indices for Asian Indians on Clinical Obstetric Practice. J Clin Diagn Res, 2014. 8(5): OC01-3.

43. XE, XE Currency Converter: INR to USD. Found at: https://www.xe.com/currencyconverter/convert/?Amount=1\&From=INR \&To=USD Accessed on November 11, 2018, 2018.

44. World Population Review, Found at: http://worldpopulationreview.com/worldcities/mumbai-population/Accessed on November 11, 2018, 2018.

45. Riley LW, Ko AI, Unger A, Reis MG. Slum health: diseases of neglected populations. BMC International Health and Human Rights. 2007. 7(2)

46. Aminde LN, Takah N, Ngwasiri C, Noubiap JJ, Tindong M, Dzudie A, Veerman JL. Population Awareness of Cardiovascular Disease and Its Risk Factors in Buea, Cameroon. BMC Public Health, 2017. 17(1): 545.

47. Wong BM, Garcia Y, Barr A, Glazier RH, Abramson BL. Cardiovascular Risk Factor Awareness in A Disadvantaged Inner-city Population--Implications For Preventive Strategies. Can J Cardiol, 2008. 24(9): 677-82.

48. Tsuji M, Arima H, Ohkubo T, Nakamura K, Takezaki T, Sakata K, Okuda N, Nishi N, Kadota A, Okamura T, Ueshima H, Okayama A, Miura K. Socioeconomic Status and Knowledge of Cardiovascular Risk Factors: NIPPON DATA2010. J Epidemiol, 2018. 28 Suppl 3: p. S46-S52.

49. Davis SK, Winkleby MA, Farquhar JW. Increasing Disparity in Knowledge of Cardiovascular Disease Risk Factors and Risk-reduction Strategies by Socioeconomic Status: Implications for Policymakers. Am J Prev Med, 1995. 11(5): 318-23.

50. Potvin L, Richard L, Edwards AC, Knowledge of Cardiovascular Disease Risk Factors Among the Canadian Population: Relationships with Indicators of Socioeconomic Status. CMAJ, 2000. 162(9 Suppl): S5-11.

51. Rao KD, Peters DH. Urban Health in India: Many Challenges, Few Solutions. Lancet Glob Health, 2015. 3(12): p. e729-30.

52. Homko CJ, Santamore WP, Zamora L, Shirk G, Gaughan J, Cross R, Kashem A, Petersen S, Bove AA. Cardiovascular Disease Knowledge and Risk Perception Among Underserved Individuals at Increased Risk of Cardiovascular Disease. $J$ Cardiovasc Nurs, 2008. 23(4): p. 332-7. 
53. Boo S, Oh H, Froelicher ES, Suh CH. Knowledge and Perception of Cardiovascular Disease Risk Among Patients with Rheumatoid Arthritis. PLoS One, 2017. 12(4): e0176291.

54. Kwasnicka D, Dombrowski SU, White M, Sniehotta F. Theoretical Explanations for Maintenance of Behaviour Change: A Systematic Review of Behaviour Theories. Health Psychol Rev, 2016. 10(3): p. 277-96.

55. Berkman ND, Sheridan SL, Donahue KE, Halpern DJ, Crotty K. Low Health Literacy and Health Outcomes: An Updated Systematic Review. Ann Intern Med, 2011. 155(2): 97-107.

56. Fabrigar LR, Petty RE, Smith SM, Crites SL Jr. Understanding Knowledge Effects on Attitude-behavior Consistency: The Role of Relevance, Complexity, And Amount of Knowledge. J Pers Soc Psychol, 2006. 90(4): p. 556-77.

57. Ryan P. Integrated Theory of Health Behavior Change: Background and Intervention Development. Clin Nurse Spec, 2009. 23(3): 161-70; quiz 171-2.

58. Chaturvedi S, Pant M, Neelam, Yadav G. Hypertension in Delhi: Prevalence, Awareness, Treatment and Control. Trop Doct, 2007. 37(3): 142-5.

59. Gupta V, Yadav K, Anand K. Patterns of Tobacco Use Across Rural, Urban, And Urban-Slum Populations in A North Indian Community. Indian J Community Med, 2010. 35(2): 245-51.

60. Parikh S, Choksi J, Bala DV. The Study of Epidemiological and Determinants of Hypertension in Urban Health Training Centre (UHTC). Gujrat Med J., 2011. 66: 22- 7. 


\section{TABLES AND FIGURES}

Table 1. Description of sample of slum dwelling women in Mysore, India (N=607)

$\begin{array}{lcc} & \mathbf{N} & \% \\ \begin{array}{l}\text { Age (in years) } \\ \text { Mean (SD) }\end{array} & & \\ \text { Median (Q1, Q3) } & 50.035 & (7.318) \\ & 50 & (44,55)\end{array}$

Education

No schooling

$381 \quad 62.8$

Primary school

$61 \quad 10.0$

High school

117

19.3

Secondary and above

48

7.9

Religion

Hindu

510

84.2

Muslim

76

12.5

Christian

20

3.3

Caste

$\mathrm{SC} / \mathrm{ST}$

286

47.1

Other backward caste

217

35.7

General caste

104

17.1

Marital Status 


$\begin{array}{lcc}\text { Single } & 7 & 1.2 \\ \text { Married } & 312 & 51.4 \\ \text { Other } & 288 & 47.4\end{array}$

Work Status

Employed $\quad 373 \quad 61.4$

$\begin{array}{lll}\text { Housewife } & 234 & 38.6\end{array}$

Monthly Household Income (INR)

$\begin{array}{lcc}<3000 & 129 & 21.3 \\ 3000-10,000 & 321 & 53.0 \\ >10,000 & 156 & 25.7\end{array}$

\section{BMI}

$\begin{array}{lll}\text { Underweight/normal } & 270 & 45.8\end{array}$

$\begin{array}{lll}\text { Overweight } & 91 & 15.4\end{array}$

$\begin{array}{lll}\text { Obese I } & 171 & 29.0\end{array}$

$\begin{array}{lll}\text { Obese II } & 57 & 9.7\end{array}$

Abbreviations: $\mathrm{SD}=$ standard deviation; $\mathrm{Q} 1=$ first quartile; $\mathrm{Q} 3=$ third quartile; $\mathrm{SC} / \mathrm{ST}=$ scheduled caste/scheduled tribe; INR= Indian Rupees; $\mathrm{BMI}=$ body mass index

Education: Defined as: No Schooling, Primary School (1-7 years), High School (8-12 years), and Secondary School or above (12+ years)

Marital Status: "Other" includes separated, divorced, and widow/widower. 
BMI: Underweight $<18.5 \mathrm{~kg} / \mathrm{m}^{2}$; Normal weight 18.5-22.9 kg/m²; Overweight= 23-24.9 kg/m²; Obese I= 25-29.9 kg/m²; Obese II $\geq 30 \mathrm{~kg} /$ 
Table 2. Responses to the Heart disease risk factor knowledge measures among a sample of slum dwelling women in Mysore, India ( $\mathrm{N}=607)$

\begin{tabular}{|c|c|c|c|c|}
\hline Item & Question & Correct & $\mathrm{n}$ & $(\%)$ \\
\hline 1 & A person always knows when they have heart disease & FALSE & 376 & $(61.9)$ \\
\hline 2 & $\begin{array}{l}\text { If you have a family history of heart disease, you are at } \\
\text { risk for developing heart disease. }\end{array}$ & TRUE & 166 & $(27.3)$ \\
\hline 3 & $\begin{array}{l}\text { The older a person is, the greater their risk of having } \\
\text { heart disease. }\end{array}$ & TRUE & 279 & $(46.0)$ \\
\hline 4 & Smoking is a risk factor for heart disease & TRUE & 405 & $(66.7)$ \\
\hline 5 & $\begin{array}{l}\text { A person who stops smoking will lower their risk of } \\
\text { developing heart disease }\end{array}$ & TRUE & 368 & $(60.6)$ \\
\hline 6 & $\begin{array}{l}\text { High blood pressure is a risk factor for developing } \\
\text { heart disease }\end{array}$ & TRUE & 273 & $(45.0)$ \\
\hline 7 & $\begin{array}{l}\text { Keeping blood pressure under control will reduce a } \\
\text { person's risk for developing heart diseases. }\end{array}$ & TRUE & 267 & $(44.0)$ \\
\hline 8 & $\begin{array}{l}\text { High cholesterol is a risk factor for developing heart } \\
\text { disease. }\end{array}$ & TRUE & 374 & $(61.6)$ \\
\hline 9 & $\begin{array}{l}\text { Eating fatty foods does not affect blood cholesterol } \\
\text { levels }\end{array}$ & FALSE & 21 & $(3.5)$ \\
\hline 10 & $\begin{array}{l}\text { Being overweight increases a person's risk for heart } \\
\text { disease. }\end{array}$ & TRUE & 389 & $(64.1)$ \\
\hline 11 & $\begin{array}{l}\text { Regular physical activity will lower a person's chance } \\
\text { of getting heart disease }\end{array}$ & TRUE & 406 & $(66.9)$ \\
\hline 12 & Diabetes is a risk factor for developing heart disease & TRUE & 264 & $(43.5)$ \\
\hline 13 & High blood sugar makes the heart work harder & TRUE & 234 & $(38.6)$ \\
\hline 14 & $\begin{array}{l}\text { A person who has diabetes can reduce their risk of } \\
\text { developing heart disease if they keep their blood sugar } \\
\text { levels under control }\end{array}$ & TRUE & 262 & $(43.2)$ \\
\hline 15 & $\begin{array}{l}\text { Abdominal obesity (fat belly) is a risk factor for } \\
\text { developing heart diseases }\end{array}$ & TRUE & 329 & $(54.2)$ \\
\hline
\end{tabular}


16 Stress may cause an increase in blood sugar, blood pressure, and cholesterol levels

TRUE

17 Slow deep breaths, counting to 10 before speaking, going for a walk, are examples of stress stoppers
TRUE

283

(46.6) 
Table 3. Heart disease risk factor knowledge by social economic status among a sample of slum dwelling women in Mysore, India $(\mathrm{N}=607)$

\begin{tabular}{|c|c|c|c|c|c|c|c|c|}
\hline & \multirow{3}{*}{ SES Factor } & \multicolumn{6}{|c|}{ Heart Disease Risk Factor Knowledge* } & \multirow{3}{*}{ P-value } \\
\hline & & \multicolumn{2}{|r|}{ Poor } & \multicolumn{2}{|c|}{ Moderate } & \multicolumn{2}{|r|}{ Good } & \\
\hline & & $\mathrm{n}$ & (Column \%) & $\mathrm{n}$ & (Column \%) & $\mathrm{n}$ & (Column \%) & \\
\hline \multirow{2}{*}{$\begin{array}{l}\text { Age (in } \\
\text { years) }\end{array}$} & Mean (SD) & 51.4 & (7.3) & 48.5 & (7.3) & 49.0 & (7.1) & \multirow[t]{2}{*}{$<0.001$} \\
\hline & Median (min, max) & 50.0 & $(40.0,64.0)$ & 48.0 & $(40.0,64.0)$ & 47.0 & $(40.0,64.0)$ & \\
\hline \multirow{4}{*}{$\begin{array}{l}\text { Educational } \\
\text { Status }\end{array}$} & Secondary or above & 11 & $(3.8 \%)$ & 12 & $(10.5 \%)$ & 25 & $(12.1 \%)$ & \multirow[t]{4}{*}{0.001} \\
\hline & High school & 43 & $(15.0 \%)$ & 28 & $(24.6 \%)$ & 46 & $(22.3 \%)$ & \\
\hline & Primary school & 29 & $(10.1 \%)$ & 11 & $(9.7 \%)$ & 21 & $(10.2 \%)$ & \\
\hline & No schooling & 204 & $(71.1 \%)$ & 63 & $(55.3 \%)$ & 114 & $(55.3 \%)$ & \\
\hline \multirow{3}{*}{$\begin{array}{l}\text { Monthly } \\
\text { Household } \\
\text { Income } \\
\text { (INR) }\end{array}$} & $<3,000$ & 70 & $(24.4 \%)$ & 16 & $(14.0 \%)$ & 43 & $(21.0 \%)$ & \multirow[t]{3}{*}{0.037} \\
\hline & $3,000-10,000$ & 137 & $(47.7 \%)$ & 74 & $(64.9 \%)$ & 110 & $(53.7 \%)$ & \\
\hline & $>10,000$ & 80 & $(27.9 \%)$ & 24 & $(21.1 \%)$ & 52 & $(25.4 \%)$ & \\
\hline Employmen & Employed & 168 & $(58.5 \%)$ & 74 & $(64.9 \%)$ & 131 & $(63.6 \%)$ & 0.367 \\
\hline
\end{tabular}




\begin{tabular}{|c|c|c|c|c|c|c|c|c|}
\hline t Status & Housewife & 119 & $(41.5 \%)$ & 40 & $(35.1 \%)$ & 75 & $(36.4 \%)$ & \\
\hline \multirow{3}{*}{$\begin{array}{l}\text { Marital } \\
\text { Status }\end{array}$} & Single & 5 & $(1.7 \%)$ & 0 & $(0.0 \%)$ & 2 & $(1.0 \%)$ & 0.021 \\
\hline & Married & 134 & $(46.7 \%)$ & 73 & $(64.0 \%)$ & 105 & $(51.0 \%)$ & \\
\hline & Other & 148 & $(51.6 \%)$ & 41 & $(36.0 \%)$ & 99 & $(48.1 \%)$ & \\
\hline \multirow{4}{*}{ Religion } & Hindu & 244 & $(85.3 \%)$ & 91 & $(79.8 \%)$ & 175 & $(85.0 \%)$ & 0.582 \\
\hline & Muslim & 35 & $(12.2 \%)$ & 18 & $(15.8 \%)$ & 23 & $(11.2 \%)$ & \\
\hline & Sikh & 0 & $(0.0 \%)$ & 0 & $(0.0 \%)$ & 0 & $(0.0 \%)$ & \\
\hline & Christian & 7 & $(2.5 \%)$ & 5 & $(4.4 \%)$ & 8 & $(3.9 \%)$ & \\
\hline \multirow{3}{*}{ Caste } & $\mathrm{SC} / \mathrm{ST}$ & 144 & $(50.2 \%)$ & 39 & $(34.2 \%)$ & 103 & $(50.0 \%)$ & 0.008 \\
\hline & Other backward caste & 88 & $(30.7 \%)$ & 54 & $(47.4 \%)$ & 75 & $(36.4 \%)$ & \\
\hline & General caste & 55 & $(19.2 \%)$ & 21 & $(18.4 \%)$ & 28 & $(13.6 \%)$ & \\
\hline
\end{tabular}

Notes: Heart disease risk factor knowledge is defined as poor ( $<50 \%$ correct answers), moderate (50-69\% correct answers) or good knowledge ( $\geq 70 \%$ correct answers). 
Education: Defined as: No Schooling, Primary School (1-7 years), High School (8-12 years), and Secondary School or above (12+ years)

Marital Status: "Other" includes separated, divorced, and widow/widower. 
Table 4a. Logistic regression analysis of the association of demographic characteristics with knowledge about heart health among slum dwelling women in Mysore, India.

\begin{tabular}{|c|c|c|c|c|c|c|c|c|}
\hline \multirow{2}{*}{$\begin{array}{l}\text { Knowledge } \\
\text { Poor } \\
\text { (vs. Good) }\end{array}$} & \multirow{3}{*}{$\begin{array}{l}\text { Factor } \\
\text { Age (in years) }\end{array}$} & \multicolumn{3}{|c|}{ Unadjusted Model } & \multirow[b]{2}{*}{ P-value } & \multicolumn{2}{|c|}{ Adjusted Model } & \multirow[b]{2}{*}{ P-value } \\
\hline & & \multirow{2}{*}{$\begin{array}{r}\text { OR } \\
1.05\end{array}$} & \multicolumn{2}{|c|}{$(95 \% \mathrm{CI})$} & & \multirow{2}{*}{$\begin{array}{l}\text { AOR } \\
1.04\end{array}$} & $(95 \% \mathrm{CI})$ & \\
\hline & & & $(1.02$ & 1.07) & 0.001 & & $(1.01,1.07)$ & 0.006 \\
\hline & \multicolumn{8}{|l|}{ Educational Status } \\
\hline & Secondary or above & 0.25 & $(0.12$ & 0.52) & $<0.001$ & 0.31 & $(0.14, \quad 0.68)$ & 0.004 \\
\hline & High school & 0.52 & $(\mathbf{0 . 3 3}$ & 0.84) & 0.007 & 0.50 & $(0.30, \quad 0.85)$ & 0.010 \\
\hline & Primary school & 0.77 & $(0.42$ & $1.42)$ & 0.402 & 0.83 & $(0.43, \quad 1.62)$ & 0.589 \\
\hline & No schooling & Ref. & Ref. & & & Ref. & Ref. & \\
\hline & \multicolumn{8}{|l|}{ Monthly H. Income (INR) } \\
\hline & $<3,000$ & 1.06 & $(0.63$ & $1.77)$ & 0.830 & 0.72 & $(0.40,1.27)$ & 0.256 \\
\hline & $3,000-10,000$ & 0.81 & $(0.53$ & $1.24)$ & 0.335 & 0.70 & $(0.43,1.11)$ & 0.130 \\
\hline & $>10,000$ & Ref. & Ref. & & & Ref. & Ref. & \\
\hline & \multicolumn{8}{|l|}{ Employment Status } \\
\hline & Employed & 0.81 & $(0.56$ & $1.17)$ & 0.257 & 0.88 & $(0.58,1.32)$ & 0.528 \\
\hline & Housewife & Ref. & Ref. & & & Ref. & Ref. & \\
\hline
\end{tabular}


Religion

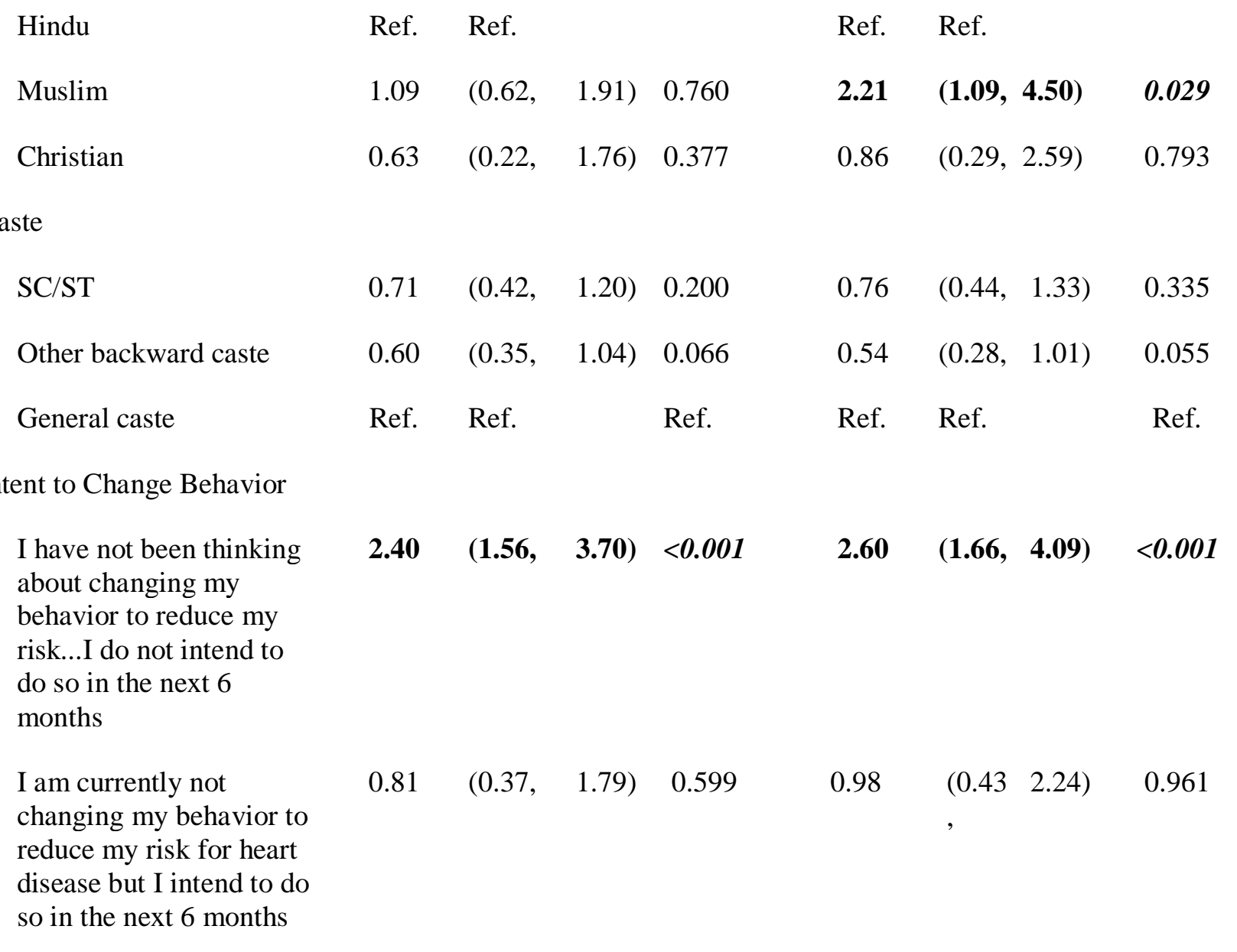


I have decided what behavior (weight loss, quitting smoking, etc.) I need to change to reduce my risk for heart disease

I have changed my behavior to reduce my risk for heart disease but it is less than 6 months since I started

I have changed my behavior to reduce my risk for heart disease and I have maintained that change for 6 or more months
$0.69 \quad(0.25,1.87) \quad 0.466$

0.68

$(0.24 \quad 1.95)$

0.475
1.18
$(0.48, \quad 2.94)$
0.719
1.18
$(0.45,3.10)$
0.733

Ref. Ref

Ref

Ref. 
Table 4b. Logistic regression analysis of the association of demographic characteristics with knowledge about heart health among slum dwelling women in Mysore, India.

\begin{tabular}{|c|c|c|c|c|c|c|c|}
\hline \multirow{2}{*}{ Knowledge } & \multirow{2}{*}{ Factors } & \multicolumn{3}{|c|}{ Unadjusted Model } & \multicolumn{3}{|c|}{ Adjusted, Full Model } \\
\hline & & OR & $(95 \% \mathrm{CI})$ & P-value & AOR & $(95 \% \mathrm{CI})$ & P-value \\
\hline \multirow{2}{*}{\multicolumn{8}{|c|}{$\begin{array}{l}\text { Moderate } \\
\text { (vs. Good) }\end{array}$}} \\
\hline & & & & & & & \\
\hline & Age (in years) & 0.99 & $(0.96,1.02)$ & 0.506 & 1.00 & $(0.96,1.03)$ & 0.834 \\
\hline \multicolumn{8}{|c|}{ Educational Status } \\
\hline & Secondary or above & 0.87 & $(0.41,1.85)$ & 0.714 & 0.75 & $(0.34,1.68)$ & 0.487 \\
\hline & High school & 1.10 & $(0.63,1.93)$ & 0.736 & 0.95 & $(0.52,1.74)$ & 0.870 \\
\hline & Primary school & 0.95 & $(0.43,2.09)$ & 0.895 & 1.01 & $(0.43,2.36)$ & 0.981 \\
\hline & No schooling & Ref. & Ref. & & Ref. & Ref. & \\
\hline \multicolumn{8}{|c|}{ Monthly Income (INR) } \\
\hline & $<3,000$ & 0.81 & $(0.38,1.71)$ & 0.574 & 0.78 & $(0.36,1.73)$ & 0.544 \\
\hline & $3,000-10,000$ & 1.46 & $(0.83,2.57)$ & 0.192 & 1.48 & $(0.82,2.67)$ & 0.194 \\
\hline & $>10,000$ & Ref. & Ref. & & Ref. & Ref. & \\
\hline \multicolumn{8}{|c|}{ Employment Status } \\
\hline & Employed & 1.06 & $(0.66,1.71)$ & 0.814 & 0.96 & $(0.57,1.60)$ & 0.868 \\
\hline
\end{tabular}


Housewife

Religion

Hindu

Muslim

Christian

Caste

\section{SC/ST}

Other backward caste

General caste

Intent to Change

Behavior

I have not been thinking

about changing my

behavior to reduce my

risk...I do not intend to

do so in the next 6

months

I am currently not

changing my behavior to

reduce my risk for heart

disease, but I intend to do

so in the next 6 months
Ref. Ref.

Ref. Ref

Ref. Ref.

$1.51 \quad(0.77,2.93) \quad 0.229$

$\begin{array}{lll}1.20 & (0.54,2.63) & 0.657\end{array}$

1.20

$(0.38, \quad 3.78)$

0.753

1.05

$(0.31,3.53) \quad 0.940$

$0.51 \quad(0.26,0.99)$

0.047

0.47

$(0.24,0.94)$

0.033

$0.96 \quad(0.49, \quad 1.87) \quad 0.904$

0.86

$(0.42,1.79) \quad 0.688$

Ref. Ref.

Ref.

Ref.

1.56

$(0.90,2.69)$

0.114

1.53

$(0.87,2.69)$

0.139

1.77

$(0.78,4.04)$

0.172

1.72

$(0.73,4.02)$ 
I have changed my

behavior to reduce my

risk for heart disease, but

it is less than 6 months

since I started

I have changed my behavior

]to reduce my risk for heart]

disease and I have maintained

that change for 6 or more months

$\mathrm{OR}=$ odds ratio; $\mathrm{CI}=$ confidence interval; $\mathrm{AOR}=$ adjusted odds ratio; $\mathrm{SC} / \mathrm{ST}=$ scheduled caste/scheduled tribe; $\mathrm{INR}=$ Indian Rupees

Heart disease risk factor knowledge is defined as poor ( $<50 \%$ correct answers), moderate (50-69\% correct answers) or good knowledge $(\geq 70 \%$ correct answers).

Education: Defined as: No Schooling, Primary School (1-7 years), High School (8-12 years), and Secondary School or above (12+ years)

Marital Status: "Other" includes separated, divorced, and widow/widower 


\title{
MANUSCRIPT 2
}

\section{PARITY AND LATER LIFE RISK FOR CORONARY HEART DISEASE AMONG SLUM- DWELLING WOMEN IN MYSORE, INDIA}

\begin{abstract}
Background: The World Health Organization estimates that $80 \%$ of premature heart disease deaths are preventable through assessment and management of cardiovascular risk factors. Recent research suggests that current CVD risk algorithms underestimate risk among women because they over-emphasize traditional risk factors and fail to account for health hazards that are unique to women. Methods: A cross-sectional survey was carried out between October 2017 and May 2018 among a nonprobability sample of slum-dwelling women, 40 to 64 years of age, in government-designated slums in Mysore, India. In addition to socio-demographics, data were collected on tobacco and alcohol consumption, diet, physical activity, sleep, quality of life, and personal and family history of diagnosed cardiometabolic disorders. Body mass Index (BMI) was calculated using anthropometry. Serum was tested for HbA1c and lipids.

Electrocardiography was carried out by a trained medical technician. Results: This study found a $6.4 \%$ prevalence of coronary heart disease among middle-aged slum-dwelling Indian women. Nulliparous women were at heightened risk for CHD compared to parous women with up to five live births. In the fully adjusted model, women who had 1-2 and 3-5 live births had 0.15 lower odds (95\%CI: 0.04-0.53) and .17 lower odds (95\%CI: 0.05-0.56) of CHD respectively, as compared to nulliparous women. Conclusion: Further studies are needed to evaluate the relationship between pregnancy-related variables like parity, and CHD.
\end{abstract}

\section{INTRODUCTION}

Cardiovascular disease (CVD) is the number one killer of people worldwide [1]. CVD- 
related mortality has increased by $41 \%$ from 12.3 million deaths to 17.3 million deaths, between 1990 and 2013 [2]. About eight in every ten of these deaths occurs in low- and middle-income countries, with mortality being almost equally split between men and women [3, 4]. In developed countries, CVD age-adjusted mortality (AAM) rates are diverging by gender with male CVDrelated AAM declining significantly faster than for women [5]. In the U.S., for instance, overall rates for coronary heart disease among women aged 35-54 have actually been increasing [6]. Accurate rates and trends unfortunately, are unavailable for most LMIC. The 2001 Global Burden of Disease Study for instance, reported no data on causes of death by age and sex for $24.3 \%$ of the global population [7]. Data were unavailable for only $0.3 \%$ of the population in high-income countries but $89.8 \%$ of the population in sub-Saharan Africa, $48.1 \%$ in the Middle East and North Africa, 24.2\% in South Asia, and 21.1\% in East Asia and the Pacific with the paucity of data most pronounced for disadvantaged areas such as rural areas or urban or semiurban slums.

The World Health Organization estimates that $80 \%$ of premature heart disease is preventable through assessment and management of total cardiovascular risk [8,9]. While both women and men share many risk factors for CVD, the significance and relative weighting for risk factors are different [10]. Recent research also suggests that current CVD risk algorithms tend to underestimate actual cardiovascular risk among reproductive- age women because they overemphasize traditional CVD risk factors and fail to account for both behavioral and biological risks that are unique to women [11]. There is research for instance, that suggests that parity may pose risk for CVD among middle-age women [12-14]. At present, the evidence is conflicting. Some studies show that parity increases risk [13,15-18], while others showed no association between number of offspring and heart disease [19-23], and still others described an inverse association [24], a J-shaped relation [25], or a nonlinear association [26].

Cardiovascular disease is now the leading cause of death among Indian women [27]. According to the Global Burden of Diseases Study, total CVD deaths among females rose from 
673,000 in 1990 to more than $1,146,000$ by 2015 [28]. Given the alarming increase in CVD among women, surprisingly little is known about the risk profile for this group representing $48 \%$ of India's population [29]. Some research suggests that Indian women may have a higher prevalence of certain risk factors such as hypertension, diabetes, and obesity compared to men, but to date, no studies we are aware of have examined whether pregnancy-related factors such as high parity increase risk for CHD in this population [29, 30]. The purpose of this study was to examine whether parity is associated with CHD in middle-aged slum-dwelling Indian women.

\section{METHODS}

Overview

The study used a cross-sectional design to examine cardiovascular risk factors among a sample of 607 slum dwelling women, 40 - 64 years of age, living in Mysore City, India. The study measured demographics, health and obstetric history, knowledge and beliefs about CHD and CHD risk factors; modifiable risk factors (smoking, use of alcohol, weight, physical activity, healthy diet, blood pressure, serum cholesterol, and blood glucose), and prevalence and correlates of CHD (defined as previously diagnosed disease, symptoms on the Rose Angina questionnaire, or ischemic changes on electrocardiography).

\section{Study Sites}

The study was carried out in six urban slums (Kesere, Kudaremala, Ekalavya Nagara, Amrutha badavane, and Ganeshnagar) randomly selected from a sampling frame of 63 communities officially designated as slums by the Karnataka Slum Development Board in Mysore, India [31]. According to the 2011 Census, Mysore has a population of 920,550, of which 459,508 are females [32]. Approximately $19 \%$ of the population live below the poverty line, and 49,352 residents live in slums (as defined by the Karnataka Slum Act) [31]. According to the Census, $73.6 \%$ of the population are Hindus, $21.9 \%$ are Muslims, $2.8 \%$ are Christians, and the remaining, 
other religions. Mysore has an $87.7 \%$ literacy rate, and Kannada is the most widely spoken regional language [32].

\section{Community Preparedness}

Community preparedness activities were carried out prior to recruitment. Key stakeholders including residents, civic and religious leaders, and staff from nonprofits doing similar work, were consulted prior to data collection. A study protocol was presented in community meetings and stakeholder input was used to refine study methods prior to the beginning of data collection.

\section{Study Recruitment}

Study staff visited selected slums one day prior to recruitment and distributed brochures describing eligibility criteria and study activities. To be included in the study, participants had to be female; aged 40-64 years; residents of urban Mysore (defined as living in Mysore for a period of six months or more); and be willing and able to undergo informed consent and all study procedures including a physical examination, collection of biological samples, a resting electrocardiogram (ECG), and an interviewer-administered survey. Exclusion criteria included having a known history of hemophilia, hospitalization within the past three months, and any other condition that might pose a risk for participants undergoing study procedures. Women were told to arrive at a specific meeting point the following morning having fasted from $8.00 \mathrm{PM}$ the previous evening. They were asked to bring any medical reports or allopathic medications they were currently taking. The next morning potential participants were transported by minivan to a clinic in central Mysore. On arrival, they underwent an informed consent process. Study staff explained the study purpose, read the informed consent document verbatim, described all study procedures, and answered any study questions potential participants might have. A brief anonymous survey was also conducted among those women who declined to enroll in order to determine if there were any systematic biases in participant recruitment. Participants received a stipend of INR 200 (USD 3.33), 
an amount traditional for studies of this type, to compensate them for their time and transportation expenses. A protocol for the study was approved by Institutional Review Boards at Florida International University and Public Health Research Institute of India.

\section{Data Collection and Measures}

Data were collected between October 2017 and May 2018 using an interviewer administered standardized questionnaire adapted from the CARRS Cohort, a collaboration between the US Centers for Disease Control and Prevention, the Indian Council of Medical Research, nine Indian collaborators, and nine other international partners [33]. It included questions on demographics, socio-economic status, current employment, and residence. Data on tobacco and alcohol consumption, dietary habits, physical activity, sleep, and quality of life were also collected along with personal and family history of diagnosed cardio-metabolic disorders and their risk factors including diabetes, heart disease, stroke, chronic obstructive pulmonary disease, angina, peripheral vascular disease, kidney disease, and respiratory disease. The study questionnaire was translated into the local language of Kannada and validated using the American Academy of Orthopedic Surgeons guidelines for the Cross-Cultural Adaptation of Health Status Measures [34]. In brief, translation and adaptation included five steps: Translation, Synthesis, Back Translation, Expert Committee Review, and Pretesting. An English version of the CARRS instrument was forward translated by two independent bilingual translators who resolved discrepancies through consensus. A third bilingual translator mediated any differences not resolved

during this process. Finally, another bilingual translator blinded to the original survey, back-translated the instrument into English to ensure equivalence. An expert committee comprised of a health worker, a physician, and a community outreach staff person reviewed and consolidated different survey versions with the goal of ensuring equivalence between the source and a final pilot version. The 
consolidated instrument was pretested in a sample of 28 women recruited from selected Mysore slums and their input informed a final version.

\section{Medical Procedures}

Anthropometry and Blood Pressure Measurement were recorded by trained research team members. Anthropometric measures were taken three times and the mean was recorded: height (centimeters $[\mathrm{cm}]$ ), weight (kilogram[kg]) and waist circumference $(\mathrm{cm})$. Height was measured using a Stadiometer Height-Rod without shoes. Weight was measured on a calibrated digital scale to the nearest 100 grams. Waist circumference was measured using a woven measuring tape at the midpoint between the lower border of the rib cage and upper border of the iliac crest. Blood pressure (BP) was measured three times using an electronic manometer and cuff, and the systolic and diastolic blood pressure recorded were an average of those readings as recommended by the American Heart Association [35].

\section{Biochemistry and Electrocardiography}

Blood was drawn from the participants by a trained phlebotomist in a $3 \mathrm{ml}$ tube with EDTA for $\mathrm{HbA1c}$ testing, and in a $5 \mathrm{ml}$ tube for a serum lipid profile. Samples were stored in a refrigerator and processed the same day. Serum was tested for glycated hemoglobin (HbA1c), triglycerides (TG), total cholesterol (TC), low-density lipoproteins (LDL), high-density lipoproteins (HDL). Electrocardiography (ECG) was carried by a trained medical technician and ECGs were read by a cardiologist at the Cardiology Department at Apollo Hospital, Mysore.

Biochemistry tests were carried out at Public Health Research Institute diagnostic laboratory in Mysore City. 


\section{Test Results}

Participants were told a date and place they could pick up their test results. Medical referrals were written for any patients that testing revealed might have a potentially serious medical condition. Results and written medical referrals to the Department of Cardiology at Apollo Hospital in Mysore were delivered to participants at the specified time and location. Each participant was also given a brochure outlining how they could reduce their existing CHD risk through behavior change including smoking cessation, lowered alcohol use, medication, diet and exercise.

\section{Primary Outcome}

Coronary Heart Disease (CHD) was defined as previously diagnosed CHD (verified by medical records where available), symptoms detected by the Rose Angina questionnaire, or electrocardiographic (ECG) changes suggestive of ischemia [36, 37]. The 12-lead electrocardiograph machine (Contec 1200G) was used to test for routine ECG parameters for HR, P-R interval, P Duration, QRS Duration, T Duration, Q-T interval, Q-Tc, P Axis, QRS Axis, T Axis, R(V5), S(V1), R(V5)+S(V1). Electrocardiograms were read by a cardiologist unaware of the patient's clinical history based using criteria from the AHA/ACCF/HRS Recommendations for the Standardization and Interpretation of the Electrocardiogram criteria for abnormalities in ST Segment, T, U Waves, and QT Interval [38]. Participants with ECG abnormalities were also examined by a trained cardiologist to confirm a diagnosis of CHD.

\section{Explanatory Variables}

The main independent variable was parity or number of biologically live births reported by a participant. This information was obtained by personal interview at the time of the study survey. Questions were open-ended, e.g., "how many live births have you had?" and "how many times 
have you been pregnant, including pregnancies that ended up in miscarriages or still births?" For data analysis of the present study, parity was categorized into four groups $(0,1,2,3$ and $\geq 4)$.

Other study covariates were based on a review of the literature and included: demographic characteristics including age, socioeconomic status, education level, and marital status; traditional cardiovascular risk factors including systolic and diastolic blood pressure; waist circumference; triglycerides; total, HDL, and LDL cholesterol levels; and HbA1c; and other health-related factors including tobacco use, alcohol use; menopause or hysterectomy status; reported physical activity; and dietary factors that have been associated with CHD and/or total parity including intake of salt, sugar, fruits, nuts, and fiber

\section{Statistical Analysis}

Data were entered in an Access database (Microsoft Corporation, Redmond, WA). The primary outcome was CHD, analyzed as a binary outcome variable. Univariate associations of baseline characteristics with CHD were made using Pearson chi-squared test or Fisher exact method.

Continuous variables were compared between groups using Student t-test or the Mann-Whitney test for nonparametric data. Variables with P-values less than 0.1 were considered for inclusion in a logistic regression model. A series of regression models were performed to calculate the adjusted odds ratio (OR) and 95\% Confidence Intervals (CI) for the risk of CHD by parity.

Women with no live births (nulliparous) were used as the reference group.

The first adjusted model (Model 1) included age; the second (Model 2) included age, sociodemographic and lifestyle factors (education, marital status, occupation, income, tobacco use, history of hypertension, diabetes or CHD); the third model (Model 3) included all variables in Model 2 along with reproductive factors (menarche, abortions, infant deaths, menopause), and final model (Model 4) included Model 3 factors along with reported family history of hypertension, diabetes, or CHD. Individuals with missing data were excluded only from the affected analysis. A P-value of 0.05 was considered statistically significant. Standard errors were adjusted for clustering 
by slum (6 clusters). Statistical analysis was performed in SPSS 22 (SPSS Statistics, IBM Corp. Armonk, NY, USA) and STATA version 12 (Statacorp, College Station, Texas, US).

\section{RESULTS}

The vast majority of women (94\%) from select slums who were eligible, agreed to participate in the study. A total of eight women who visited the study clinic declined either to provide a blood sample or to undergo some other study procedure. Of the remaining 607 completing all procedures (98.7\%), 39 was diagnosed as positive for $\mathrm{CHD}$, for a prevalence of 6.4\% (95\%CI: 4.6-8.7). (Figure 1) Characteristics of the study population are shown in Table 1. The median age of study participants was 50 years, (Range: 44 to 55 years). About $62.8 \%$ of women reported having no formal education, $10 \%$ had completed primary school or less (1-7 years), and $27 \%$ had completed middle school or higher (>8 years). A large majority ( $84 \%)$ reported their religion as Hindu. More than half (51.4\%) were married, $47.5 \%$ were separated or widowed, and $1 \%$ said they had never married. About a third of participants reported being housewives (38.6\%) and the remainder reported working fulltime. About $74 \%$ of the women had a monthly household income of less than 10,000 INR (1 USD =66.78 INR) [39], 19.6\% reported incomes ranging from 10,001 to 20,000 INR, and 6.1\% had an income greater than 20,000 INR.

About $11 \%$ reported ever consuming alcohol, $14 \%$ ever using tobacco, and $78.8 \%$

currently reported smokeless tobacco use. Based on ethnic-specific guidelines for Asians in the American Diabetes Association's Standards for Medical Care, about $43.6 \%$ had a normal body mass index (BMI), $40.6 \%$ were overweight or obese, and $15.8 \%$ were underweight [40]. In response to questions about their health history, $23.9 \%$ of participants said they had been diagnosed by a physician as having hypertension, $17.6 \%$, diabetes, and $2.3 \%$, heart disease.

About $21.4 \%$ of women reported a family history of hypertension, and $23.9 \%$ and $13.0 \%$ a family history of diabetes or heart disease respectively. The average age of menarche was 13.2 
years (SD \pm 1.55$)$ with $9.6 \%$ attaining early, and $39 \%$ late menarche, respectively. Women had a median of three pregnancies and three live births [Range 2-4] in their lifetime. Six percent reported having still births and $20.9 \%$ had at least one abortion/miscarriage. Finally, almost $70 \%$ of the study participants reported being menopausal.

Table 2 describes CHD risk factors associated with Parity. Sociodemographic factors such as age, education, marital status, being a fulltime housewife, and household income were significantly associated with parity. The prevalence of CHD was lowest among women who had 12 live births and highest among those who were nulliparous. Having ever used tobacco and having a diagnosis of hypertension or diabetes were significantly associated with parity. Reproductive factors such as menopause and history of miscarriage were also significantly associated with parity. Factors associated with CHD are described in Table 3. The odds of having CHD increased with increasing monthly household income; a diagnosis of diabetes and heart disease; and a family history of diabetes, heart disease or hypertension. On the other hand, the odds of CHD were significantly lower with every unit increase in age at menarche.

The unadjusted and adjusted logistic regression models examining the association of parity and CHD are presented in Table 4. Both the unadjusted and adjusted multivariable models showed that women who had 1-2, and 3-5 live births had significantly lower odds of having CHD as compared to nulliparous women. In the fully adjusted model (Model 4), after adjusting for age, socioeconomic, lifestyle, reproductive factors, and family history of hypertension, diabetes and CHD, women who had 1-2 live births had 0.15 lower odds (95\%CI: 0.04-0.53) of CHD as compared to nulliparous women. Similarly, women with 3-5 live births had 0.17 lower odds (95\%CI: 0.05-0.56) of CHD as compared to nulliparous women. This relation was not seen among women with greater than five live births. 


\section{DISCUSSION}

This study of middle-aged slum-dwelling Indian women found 6.4\% prevalence of CHD. Nulliparous women were at heightened risk for CHD compared to parous women with up to five live births. In the full model, after adjusting for demographic factors including age, education, marital status, occupation, and income; behavioral and health factors including tobacco use, hypertension, diabetes mellitus, CHD; a family history of hypertension, diabetes and CHD; and reproductive factors including menarche, abortions, infant deaths, menopause, the relationship between parity and CHD strengthened further.

The prevalence of $6.4 \%$ in this population was within the range of $2.5 \%$ to $13.4 \%$ reported in other population studies for females living in other urban areas of India [41-46]. Thisis the first study to our knowledge to measure the prevalence of CHD among slum-dwelling women. Previous studies examining the relationship between parity and cardiovascular outcomes have had conflicting findings [17, 19-22, 26, 47, 48]. Jacobson et al found no association between parity and CHD mortality among 19,688 non-alcohol drinking, nonsmoking, California Seventh-day Adventist women [20]. Other studies by Gallagher et al, and Cooper and colleagues, had similar findings among Chinese textile workers and college educated U.S. women respectively [21, 22]. Conversely, Jaffee et al found a nonlinear relationship between parity and cardiovascular death with having no children or having more than eight children associated with excess mortality [26]. Steenland et al found rate ratios for women with no live births or 1,2, 3, 4, 5, and $\geq 6$ livebirths of $1.00,0.95,0.89,0.82,0.94,0.98,0.94$, respectively [19]. They also observed an increased risk for the highest parity category (rate ratio: $1.18 ; 95 \%$ confidence interval: $1.04-1.34$ ) among the 585,445 women in the American Cancer Society Cancer Prevention Survey II. Colditz et al studied 118,963 nurses for six years and found that when compared with parous women, nulliparous women had a slightly higher risk for incident CHD and that there was no trend of increasing risk by parity among parous women [49]. Parikh and colleagues found that parity was associated with incident maternal CVD in a J-shaped fashion with adjusted models showing that compared to 
women with 2 childbirths, women with 1 and $\geq 5$ births were at modestly increased risk for any cardiovascular event [50]. In this study, we did not find an increased risk for CHD among multiparous women; on the contrary, as compared to nulliparous women, women with 1-5 live births had lower odds for CHD.

Current evidence suggests that multiparity is a risk factor for CHD outcomes, but our study does not provide support for that conclusion. Our study findings are similar to those from Steenland et al and Colditz and colleagues who found no increased cardiovascular risk among parous vs. nulliparous women $[19,49]$. It is possible as Steenland has suggested, that other studies showing a positive association may have had uncontrolled confounding or residual confounding by imperfectly controlled variables. As compared to general population studies that showed increasing CHD risk by parity, samples in our, Steenland, and Colditz and colleagues' studies, were relatively homogenous for socioeconomic characteristics—and this may have posed less potential risk of uncontrolled and residual confounding. In addition, there is recent evidence that breastfeeding may modify the relationship of CHD and multiparity. A study of more than 520,000 women in 10 countries found that while parity increased risk of CHD in later life, multiparous women who breastfed had a significantly lower CHD risk compared to nulliparous women [51]. In that study, women breastfeeding was associated with an adjusted HR for CHD of 0.71 (95\%CI: 0.52-0.98) compared to not breastfeeding. Another study of 139,681 postmenopausal parous women found that among women with an average of 7.9 years study participation, those who breastfed for 7-12 months were significantly less likely to develop cardiovascular disease compared to women who never breastfed [52]. Other studies have shown similar effects of breastfeeding on cardiovascular risk in later life $[51,53]$. In our population which was low- income slum-dwelling women, 99\% (602/607) of parous women reported breastfeeding all offspring so it was impossible to test this hypothesis. It seems possible, however, based on recent evidence, that this may have contributed to reduced odds of CHD among parous women in this study. 
This study had several limitations. Since it was cross-sectional, it is not possible to establish temporality or causality in observed relationships. Women reproduce in their 20's or 30's and most cardiovascular disease is reported at a later age, so we can assume parity almost always preceded CVD events with the exception of congenital heart defects, viral infections of the heart, and heart diseases acquired in childhood due to illnesses or genetic syndromes [54]. This study was not population-based, so findings have limited generalizability. In addition, the research used a non-probability sample and this may have resulted in selection bias. Demographics, diet, alcohol, and tobacco use were self-reported so there is also a possibility of recall and social acceptability bias. Although our findings were robust after adjusting for several major confounders, it is possible the observed associations may have been subject to unmeasured or residual confounding, particularly to confounding related to physiological, cultural, or socioeconomic factors that occurred early in life. Finally, no data were collected on several pregnancy-related factors that have been shown to be associated with the risk of CVD in later life, including gestational diabetes, gestational obesity, preeclampsia and polycystic ovary syndrome. Despite these limitations, the study had several strengths. Biological and anthropometric data were collected in a clinic setting by trained medical personnel in a standardized manner. Questionnaires were administered by highly trained interviewers that had extensive experience working in these slum communities. All instruments had been previously validated in similar Indian populations. Electrocardiograms were read by a cardiologist at a Mysore tertiary care specialty hospital, and CHD outcome were also adjudicated by trained cardiologists. Finally, the study sample was highly homogenous for sociodemographic factors, education, and income and this may have posed less potential risk of uncontrolled and residual confounding of the relationship between parity and CHD in later life. 


\section{CONCLUSIONS}

We were unable to establish that parity was a risk factor for CHD in this population.

Further studies are needed to evaluate whether additional pregnancy-related variables including breastfeeding mediate the relationship between parity and CVD.

\section{REFERENCES}

1. Sharma K, Gulati M. Coronary artery disease in women: a 2013 update. Glob Heart. 2013 Jun;8(2):105-12.

2. Roth GA, Forouzanfar MH, Moran AE, Barber R, Nguyen G, Feigin VL, Naghavi M, Mensah GA, Murray CJ. Demographic and epidemiologic drivers of global cardiovascular mortality. N Engl J Med, 2015. 372(14): p. 1333-41.

3. Bowry AD, Lewey J, Dugani SB, Choudhry NK. The Burden of Cardiovascular Disease in Low- and Middle-Income Countries: Epidemiology and Management. Can J Cardiol, 2015. 31(9): p. 1151-9.

4. World Health Organization, About cardiovascular diseases. Found at: https://www.who.int/cardiovascular_diseases/about_cvd/en/Accessed on January 3, 2018.

5. Tunstall-Pedoe H, Kuulasmaa K, Mähönen M, Tolonen H, Ruokokoski E, Amouyel P. Contribution of trends in survival and coronary-event rates to changes in coronary heart disease mortality: 10-year results from 37 WHO MONICA project populations.

Monitoring trends and determinants in cardiovascular disease. Lancet, 1999. 353(9164): p. $1547-57$.

6. Ford ES. Trends in predicted 10-year risk of coronary heart disease and cardiovascular disease among U.S. adults from 1999 to 2010. J Am Coll Cardiol, 2013. 61(22): p. 224952.

7. Lopez AD, Mathers CD, Ezzati M, et al., editors. Global Burden of Disease and Risk Factors. Washington (DC): The International Bank for Reconstruction and Development / The World Bank; 2006. Available: https://www.ncbi.nlm.nih.gov/books/NBK11812/Copublished by Oxford University Press, New York.

8. World Health Organization, Preventing chronic diseases: a vital investment. Found at: https://www.who.int/chp/chronic_disease_report/en/_Accessed on January 3, 2018.

9. World Health Organization, Prevention of cardiovascular disease: guidelines for assessment and management of total cardiovascular risk. Found at:

http://apps.who.int/iris/handle/10665/43685 Accessed on January 3, 2018. 
10. Maas AH, Appelman YE. Gender differences in coronary heart disease. Neth Heart J, 2010. 18(12): p. 598-602.

11. Harvey RE, Coffman KE, Miller VM. Women-specific factors to consider in risk, diagnosis and treatment of cardiovascular disease. Womens Health (Lond), 2015. 11(2): p. 239-257.

12. Lawlor DA, Emberson JR, Ebrahim S, Whincup PH, Wannamethee SG, Walker M, Smith GD; British Women's Heart and Health Study; British Regional Heart Study. Is the association between parity and coronary heart disease due to biological effects of pregnancy or adverse lifestyle risk factors associated with child-rearing? Findings from the British Women's Heart and Health Study and the British Regional Heart Study. Circulation, 2003. 107(9): p. 1260-4.

13. Catov JM, Newman AB, Sutton-Tyrrell K, Harris TB, Tylavsky F, Visser M, Ayonayon HN, Ness RB. Parity and cardiovascular disease risk among older women: how do pregnancy complications mediate the association? Ann Epidemiol, 2008. 18(12): p. 873-9.

14. Oliver-Williams CT, Heydon EE, Smith GC, Wood AM. Miscarriage and future maternal cardiovascular disease: a systematic review and meta-analysis. Heart, 2013. 99(22): p. 1636-44.

15. Humphries KH, Westendorp IC, Bots ML, Spinelli JJ, Carere RG, Hofman A, Witteman JC. Parity and carotid artery atherosclerosis in elderly women: The Rotterdam Study. Stroke, 2001. 32(10): p. 2259-64.

16. Palmer JR, Rosenberg L, Shapiro S. Reproductive factors and risk of myocardial infarction. Am J Epidemiol, 1992. 136(4): p. 408-16.

17. Ness RB, Harris T, Cobb J, Flegal KM, Kelsey JL, Balanger A, Stunkard AJ, D'Agostino RB. Number of pregnancies and the subsequent risk of cardiovascular disease. N Engl J Med, 1993. 328(21): p. 1528-33.

18. Atsma F, Bartelink ML, Grobbee DE, Rutten A, Bots ML, Prokop M, van der Schouw YT. Reproductive factors, metabolic factors, and coronary artery calcification in older women. Menopause, 2008. 15(5): p. 899-904.

19. Steenland K, Lally C, Thun M. Parity and coronary heart disease among women in the American Cancer Society CPS II population. Epidemiology, 1996. 7(6): p. 641-3.

20. Jacobsen BK, Knutsen SF, Oda K, Fraser GE. Parity and total, ischemic heart disease and stroke mortality. The Adventist Health Study, 1976-1988. Eur J Epidemiol, 2011. 26(9): p. 711-8.

21. Gallagher LG, Davis LB, Ray RM, Psaty BM, Gao DL, Checkoway H, Thomas DB. Reproductive history and mortality from cardiovascular disease among women textile workers in Shanghai, China. Int J Epidemiol, 2011. 40(6): p. 1510-8. 
22. Cooper GS, Ephross SA, Weinberg CR, Baird DD, Whelan EA, Sandler DP. Menstrual and reproductive risk factors for ischemic heart disease. Epidemiology, 1999. 10(3): p. 255-9.

23. Koski-Rahikkala H, Pouta A, Pietiläinen K, Hartikainen AL. Does parity affect mortality among parous women? J Epidemiol Community Health, 2006. 60(11): p. 968-73.

24. Jacobs MB, Kritz-Silverstein D, Wingard DL, Barrett-Connor E. The association of reproductive history with all-cause and cardiovascular mortality in older women: the Rancho Bernardo Study. Fertil Steril, 2012. 97(1): p. 118-24.

25. Parikh NI, Cnattingius S, Dickman PW, Mittleman MA, Ludvigsson JF, Ingelsson E. Parity and risk of later-life maternal cardiovascular disease. Am Heart J, 2010. 159(2): p. 215-221 e6.

26. Jaffe DH, Eisenbach Z, Manor O. The effect of parity on cause-specific mortality among married men and women. Matern Child Health J, 2011. 15(3): p. 376-85.

27. Office of Registrar General India, Report on Causes of Death: 2001-2003 in India. 2009, Found at: http://censusindia.gov.in/Vital_Statistics/Summary_Report_Death_01_03.pdf. Accessed on January 6, 2018: New Delhi.

28. India State-Level Disease Burden Initiative CVD Collaborators. The changing patterns of cardiovascular diseases and their risk factors in the states of India: the Global Burden of Disease Study 1990-2016. Lancet Glob Health, 2018. 6(12 e1339-e1351): p. 10.1016/S2214-109X(18)30407-8.

29. Bhatt P, Parikh P, Patel A, Parikh R, Patel A, Mehta JL, Parikh K. Unique Aspects of Coronary Artery Disease in Indian Women. Cardiovasc Drugs Ther, 2015. 29(4): p. 36976.

30. Pathak LA, Shirodkar S, Ruparelia R, Rajebahadur J. Coronary artery disease in women. Indian Heart J, 2017. 69(4): p. 532-538.

31. Karnataka Slum Development Board, Notified Slums in Mysore City as of 1 February 2016. Found at: https://www.karnataka.gov.in/ksdb/Pages/Slum-Statistics.aspx Accessed on January 3, 2018.

32. Government of India, Mysore City Census 2011 data. Found at:

http://www.census2011.co.in/census/city/452-mysore.html Accessed on January 6, 2018, 2011.

33. EMORY Rollins School of Public Health Global Diabetes Research Center, CARRS Cohort Study. Found at: http://diabetes.emory.edu/research/CARRS-Cohort.html Accessed on January 3, 2018. 
34. Beaton DE, Bombardier C, Guillemin F, Ferraz MB. Guidelines for the process of crosscultural adaptation of self-report measures. Spine (Phila Pa 1976), 2000. 25(24): p. 318691.

35. Smith R, Quinn D, St.Pierre S, Sinha P. Blood Pressure Averaging Methodology: Decreasing the Rate of Misdiagnosing Hypertension. Found at: https://www.welchallyn.com/content/dam/welchallyn/documents/upload-docs/ProductLiterature/Training-Docs/BPAveragingFinalPaper04252014.pdf Accessed on January 3, 2018.

36. Nikus K, Birnbaum Y, Eskola M, Sclarovsky S, Zhong-Qun Z, Pahlm O. Updated electrocardiographic classification of acute coronary syndromes. Curr Cardiol Rev, 2014. 10(3): p. 229-36.

37. Rose GA. The diagnosis of ischaemic heart pain and intermittent claudication in field surveys. Bull World Health Organ, 1962. 27: p. 645-58.

38. Rautaharju PM, Surawicz B, Gettes LS, Bailey JJ, Childers R, Deal BJ, Gorgels A, Hancock EW, Josephson M, Kligfield P, Kors JA, Macfarlane P, Mason JW, Mirvis DM, Okin P, Pahlm O, van Herpen G, Wagner GS, Wellens H; American Heart Association Electrocardiography and Arrhythmias Committee, Council on Clinical Cardiology; American College of Cardiology Foundation; Heart Rhythm Society. AHA/ACCF/HRS recommendations for the standardization and interpretation of the electrocardiogram: part IV: the ST segment, T and U waves, and the QT interval: a scientific statement from the American Heart Association Electrocardiography and Arrhythmias Committee, Council on Clinical Cardiology; the American College of Cardiology Foundation; and the Heart Rhythm Society. Endorsed by the International Society for Computerized Electrocardiology. J Am Coll Cardiol. 2009 Mar 17;53(11):982-91.

39. PoundSterling Live, Historical Rates for the USD/INR currency conversion on 01 May 2018 (01/05/2018). Found at: https://www.poundsterlinglive.com/best-exchangerates/us-dollar-to-indian-rupee-exchange-rate-on-2018-05-01 Accessed on December 18, $2018,2018$.

40. American Diabetes Association, Standards for medical care in diabetes-2015. Diabetes Care, 2015. 38 (Suppl 1): p. S1-S94.

41. Oommen AM, Abraham VJ, George K, Jose VJ. Prevalence of coronary heart disease in rural and urban Vellore: A repeat cross-sectional survey. Indian Heart J. 2016 JulAug;68(4):473-9.

42. Gupta R, Gupta VP, Sarna M, Bhatnagar S, Thanvi J, Sharma V, Singh AK, Gupta $\mathrm{JB}$, Kaul V. Prevalence of coronary heart disease and risk factors in an urban Indian population: Jaipur Heart Watch-2. Indian Heart J. 2002 Jan-Feb;54(1):59-66.

43. Gupta R, Prakash H, Majumdar S, Sharma S, Gupta VP. Prevalence of coronary heart disease and coronary risk factors in an urban population of Rajasthan. Indian Heart J, 1995. 47(4): p. 331-8. 
44. Kumar R, Singh MC, Singh MC, Ahlawat SK, Thakur JS, Srivastava A, Sharma MK, Malhotra P, Bali HK, Kumari S. Urbanization and coronary heart disease: a study of urban-rural differences in northern India. Indian Heart J, 2006. 58(2): p. 126-30.

45. Kamili M, Dar I, Ali G, Wazir H, Hussain S. Prevalence of coronary heart disease in Kashmiris. Indian Heart J, 2007. 59(1): p. 44-9.

46. Chadha SL, Radhakrishnan S, Ramachandran K, Kaul U, Gopinath N. Epidemiological study of coronary heart disease in urban population of Delhi. Indian J Med Res, 1990. 92: p. 424-30.

47. Green A, Beral V, Moser K. Mortality in women in relation to their childbearing history. BMJ, 1988. 297(1988): p. 391-395.

48. Dekker JM, Schouten EG. Number of pregnancies and risk of cardiovascular disease. $N$ Engl J Med, 1993. 329: p. 1893-1894.

49. Colditz GA, Willett WC, Stampfer MJ, Rosner B, Speizer FE, Hennekens CH. A prospective study of age at menarche, parity, age at first birth, and coronary heart disease in women. Am J Epidemiol, 1987. 126(5): p. 861-70.

50. S Parikh, J Choksi, DV Bala. The study of epidemiological and determinants of hypertension in urban health training centre (UHTC). Gujrat Med J, 2011. 66: p. 22-7.

51. Peters SA, van der Schouw YT, Wood AM, Sweeting MJ, Moons KG, Weiderpass E, Arriola L, Benetou V, Boeing H, Bonnet F, Butt ST, Clavel-Chapelon F, Drake I, Gavrila D, Key TJ, Klinaki E, Krogh V, Kühn T, Lassale C, Masala G, Matullo G, Merritt $\quad$ M, Molina-Portillo E, Moreno-Iribas C, Nøst TH, Olsen A, Onland-Moret NC, Overvad K, Panico S, Redondo ML, Tjønneland A, Trichopoulou A, Tumino R, Turzanski-Fortner R, Tzoulaki I, Wennberg P, Winkvist A, Thompson SG, Di Angelantonio E, Riboli E, Wareham NJ, Danesh J, Butterworth AS. Parity, breastfeeding and risk of coronary heart disease: A pan-European case-cohort study. Eur J Prev Cardiol, 2016. 23(16): p. 17551765 .

52. Schwarz EB, Ray RM, Stuebe AM, Allison MA, Ness RB, Freiberg MS, Cauley JA. Duration of lactation and risk factors for maternal cardiovascular disease. Obstet Gynecol, 2009. 113(5): p. 974-82.

53. Rajaei S, Rigdon J, Crowe S, Tremmel J, Tsai S, Assimes TL. Breastfeeding Duration and the Risk of Coronary Artery Disease. J Womens Health (Larchmt). 2019 Jan;28(1):30-36.

54. Jayaprasad N. Heart Failure in Children. Heart Views, 2016. 17(3): p. 92-99. Review 


\section{TABLES AND FIGURES}

Table 1. Description of sample of slum dwelling women in Mysore, India (N=607)

\begin{tabular}{|c|c|c|}
\hline & $\mathbf{N}$ & $\%$ \\
\hline \multicolumn{3}{|l|}{ Age (in years) } \\
\hline Mean (SD) & 50.035 & (7.318) \\
\hline Median (Q1, Q3) & 50 & $(44,55)$ \\
\hline \multicolumn{3}{|l|}{ Education } \\
\hline No schooling & 381 & 62.8 \\
\hline Primary school & 61 & 10.0 \\
\hline High school & 117 & 19.3 \\
\hline Secondary and above & 48 & 7.9 \\
\hline \multicolumn{3}{|l|}{ Religion } \\
\hline Hindu & 510 & 84.2 \\
\hline Muslim & 76 & 12.5 \\
\hline Christian & 20 & 3.3 \\
\hline \multicolumn{3}{|l|}{ Caste } \\
\hline $\mathrm{SC} / \mathrm{ST}$ & 286 & 47.1 \\
\hline Other backward caste & 217 & 35.7 \\
\hline General caste & 104 & 17.1 \\
\hline \multicolumn{3}{|l|}{ Marital Status } \\
\hline Single & 7 & 1.2 \\
\hline Married & 312 & 51.4 \\
\hline Other & 288 & 47.4 \\
\hline Work Status & & \\
\hline
\end{tabular}




\begin{tabular}{lcc}
\hline Employed & 373 & 61.4 \\
Housewife & 234 & 38.6 \\
Monthly Household Income (INR) & & \\
$<3000$ & 129 & 21.3 \\
$3000-10,000$ & 321 & 53.0 \\
$>10,000$ & 156 & 25.7 \\
BMI & & \\
Underweight/normal & 270 & 45.8 \\
Overweight & 91 & 15.4 \\
Obese I & 171 & 29.0 \\
Obese II & 57 & 9.7 \\
\hline
\end{tabular}

$\mathrm{SD}=$ standard deviation; $\mathrm{Q} 1=$ first quartile; $\mathrm{Q} 3=$ third quartile; $\mathrm{SC} / \mathrm{ST}=$ scheduled caste/scheduled tribe; INR= Indian Rupees; $\mathrm{BMI}=$ body mass index

Education: Defined as: No Schooling, Primary School (1-7 years), High School (8-12 years), and Secondary School or above (12+ years)

Marital Status: “Other” includes separated, divorced, and widow/widower.

BMI: Underweight $<18.5 \mathrm{~kg} / \mathrm{m} 2$; Normal weight $18.5-22.9 \mathrm{~kg} / \mathrm{m} 2$; Overweight $=23-24.9 \mathrm{~kg} / \mathrm{m} 2$; Obese I $=25-29.9 \mathrm{~kg} / \mathrm{m} 2$; Obese II $\geq 30 \mathrm{~kg} / \mathrm{m} 2$ 
Table 2. Sociodemographic characteristics and CHD among slum-dwelling women in Mysore, India. (N=607)

\begin{tabular}{|c|c|c|c|c|}
\hline \multirow[b]{2}{*}{ Characteristic } & \multirow[b]{2}{*}{$\mathbf{N}(\%)$} & \multicolumn{2}{|c|}{ CHD } & \multirow[b]{2}{*}{$\begin{array}{c}\text { p- } \\
\text { value }\end{array}$} \\
\hline & & $\mathbf{n}$ & $\%$ & \\
\hline Age Categories & & & & 0.634 \\
\hline $39-49$ & $292(48.1 \%)$ & 16 & 5.48 & \\
\hline $50-59$ & $213(35.1 \%)$ & 15 & 7.04 & \\
\hline$>59$ & $102(16.8 \%)$ & 8 & 7.84 & \\
\hline Highest level of education & & & & 0.676 \\
\hline No formal education & $381(62.8)$ & 22 & 5.77 & \\
\hline Primary school or less & $61(10.1)$ & 5 & 8.20 & \\
\hline Middle school or higher & $165(27.2)$ & 12 & 7.27 & \\
\hline Religion & & & & 0.425 \\
\hline Hindu & $510(84.0)$ & 31 & 6.08 & \\
\hline Other & $97(16.0)$ & 8 & 8.25 & \\
\hline Caste & & & & 0.882 \\
\hline Lower (SC/ST/other backward) & $406(79.6)$ & 25 & 6.16 & \\
\hline Other & $104(20.4)$ & 6 & 5.77 & \\
\hline Marital status & & & & 0.526 \\
\hline Married & $312(51.4)$ & 22 & 7.05 & \\
\hline Never married & $7(1.15)$ & 1 & 14.29 & \\
\hline Other (widowed, separated) & $288(47.5)$ & 16 & 5.56 & \\
\hline Monthly Household Income (INR) & & & & 0.023 \\
\hline$<10,000$ & $451(74.3)$ & 22 & 4.88 & \\
\hline $10,001-20,000$ & $119(19.6)$ & 12 & 10.08 & \\
\hline$>20,000$ & $37(6.10)$ & 5 & 13.51 & \\
\hline h/o Hypertension & & & & 0.297 \\
\hline Yes & $145(23.9)$ & 12 & 8.28 & \\
\hline No & $462(76.1)$ & 27 & 5.84 & \\
\hline h/o Diabetes & & & & 0.008 \\
\hline Yes & $107(17.6)$ & 13 & 12.15 & \\
\hline No & $500(82.37)$ & 26 & 5.20 & \\
\hline
\end{tabular}


h/o Heart Disease

0.000

Yes

No

$\begin{array}{ccc}14(2.31) & 7 & 50.00 \\ 593(97.7) & 32 & 5.40\end{array}$

Family h/o Hypertension

Yes

$130(21.4)$

17

.000

No

477 (78.6)

22

13.1

4.6

Family h/o Diabetes

Yes

145 (23.9)

16

No

$462(76.1)$

23

Family h/o Heart Disease

Yes

No

Gravida

0

1-2

3-5

$\geq 6$

Parity

0

1-2

3-5

$\geq 6$
79 (13.0)

$528(86.9)$

26 (4.28)

158 (26.03)

341 (56.18)

82 (13.51)

(1)

$44(7.25)$

252 (41.52)

283 (46.62)

28 (4.61)
11.0

4.9

0.009

0.000

18.9

4.6

0.003

19.23

5.06

4.69

12.2

0.018

3.97

6.71

10.71

$\mathrm{SD}=$ standard deviation; $\mathrm{Q} 1=$ first quartile; $\mathrm{Q} 3=$ third quartile; USD= United States dollar Religion: Other includes Muslim ( $\mathrm{n}=76)$ and Christian $(\mathrm{n}=20)$.

Caste: Lower includes scheduled tribe $(n=131)$, scheduled caste $(n=146)$ and other backward caste $(n=129)$. Other includes general castes $(n=104)$.

Marital status: Other includes widowed $(n=257)$ and separated $(n=31)$. 
Table 3. Logistic regression and odds of CHD in Urban Slum Dwelling Women in Mysore, India $(\mathrm{N}=607)$

\begin{tabular}{|c|c|c|c|}
\hline \multirow[b]{2}{*}{ Characteristic } & \multicolumn{3}{|c|}{ Unadjusted } \\
\hline & OR & $95 \% \mathrm{CI}$ & p-value \\
\hline Age in years & 1.02 & $0.97,1.06$ & 0.433 \\
\hline Education in years & 1.02 & $0.93,1.12$ & 0.635 \\
\hline \multicolumn{4}{|l|}{ Religion } \\
\hline Hindu & Ref & -- & \\
\hline Other & 1.39 & $0.62,3.12$ & 0.426 \\
\hline \multicolumn{4}{|l|}{ Caste } \\
\hline Lower (SC/ST/other backward) & Ref & -- & \\
\hline Other & 0.93 & $0.37,2.33$ & \\
\hline \multicolumn{4}{|l|}{ Marital status } \\
\hline Married & Ref & -- & \\
\hline Never married & 2.19 & $0.25,19.07$ & 0.475 \\
\hline Other (widowed, separated) & 0.78 & $0.39,1.51$ & 0.453 \\
\hline \multicolumn{4}{|l|}{ Annual household income (INR) } \\
\hline$<10,000$ & Ref & -- & \\
\hline $10,001-20,000$ & 2.19 & $1.04,4.55$ & 0.037 \\
\hline$>20,000$ & 3.05 & $1.08,8.58$ & 0.035 \\
\hline \multicolumn{4}{|l|}{ Ever used tobacco } \\
\hline Yes & Ref & -- & \\
\hline No & 1.11 & $0.42,2.93$ & 0.826 \\
\hline \multicolumn{4}{|l|}{ Currently using Tobacco } \\
\hline Yes & Ref & -- & \\
\hline No & 0.93 & $0.09,8.84$ & 0.947 \\
\hline \multicolumn{4}{|l|}{ Ever drank alcohol } \\
\hline Yes & Ref & -- & \\
\hline No & 0.58 & $0.24,1.36$ & 0.214 \\
\hline \multicolumn{4}{|l|}{ Body Mass Index (BMI) } \\
\hline Underweight $(<18.5)$ & Ref & -- & \\
\hline Normal ( $\geq 18.5-24.9)$ & 1.25 & $0.44,3.48$ & 0.673 \\
\hline
\end{tabular}


Overweight (25-29.9)

Obese (>30.0)

h/o Hypertension

Yes

No

h/o Diabetes

Yes

No

h/o Heart Disease

Yes

No

Family h/o Hypertension

Yes

No

Family h/o Diabetes

Yes

No

Family h/o Heart Disease

Yes

No

Gravida categories (gravida1)

0

1-2

3-5

$\geq 6$

Parity categories (parity1)

0

$1-2$

3-5

$\geq 6$

Age at menarche (in yrs)

Menopause

Yes
$1.75 \quad 0.61,4.97$
0.294
0.49
$0.09,2.64$
0.414

1.45

$0.72,2.95$

0.300

Ref

2.52

$1.25,5.08$

0.010

Ref

17.53

5.79, 53.01

0.000

Ref

--

$\begin{array}{ccc}3.11 & 1.59,6.05 & 0.001 \\ \operatorname{Ref} & -- & \end{array}$

2.37

$1.21,4.62$

0.011

Ref

4.92

2.45, 9.87

0.000

Ref

Ref

0.22

$0.07,0.75$

0.015

0.21

$0.06,0.62$

0.005

0.58

$0.18,1.89$

0.370

Ref

0.22

$0.08,0.61$

0.004

0.38

$0.15,0.97$

0.042

0.63

$0.15,2.69$

0.537

0.70

$0.55,0.91$

0.006

1.15

$0.56,2.37$

0.699 
No

Ref 
Table 4. Unadjusted and adjusted association for CHD by Parity among slum dwelling women in Mysore, India

\begin{tabular}{|c|c|c|c|c|}
\hline & \multicolumn{4}{|c|}{ Parity } \\
\hline & 0 & $1-2$ & $3-5$ & $\geq 6$ \\
\hline No. of Subjects & 44 & 252 & 283 & 28 \\
\hline No. of cases & 7 & 10 & 19 & 3 \\
\hline Unadjusted model & Ref & $0.22(0.08,0.61)$ & $0.38(0.15,0.97)$ & $\begin{array}{l}0.63(0.15, \\
2.69)\end{array}$ \\
\hline Model 1 & Ref & $0.22(0.08,0.63)$ & $0.38(0.15,0.97)$ & $\begin{array}{l}0.63(0.15, \\
2.68)\end{array}$ \\
\hline Model 2 & Ref & $0.20(0.06,0.67)$ & $0.24(0.08,0.75)$ & $\begin{array}{l}0.62(0.13, \\
3.04)\end{array}$ \\
\hline Model 3 & Ref & $0.20(0.06,0.69)$ & $0.23(0.07,0.73)$ & $\begin{array}{l}0.58(0.12, \\
2.93)\end{array}$ \\
\hline Model 4 & Ref & $0.15(0.04,0.53)$ & $0.17(0.05,0.56)$ & $\begin{array}{l}0.46(0.09, \\
2.46)\end{array}$ \\
\hline
\end{tabular}

Model 1: Age

Model 2: Model $1+$ education, marital status, occupation, income, tobacco use, h/o hypertension, h/o diabetes mellitus, h/o CHD

Model 3: Model 2 + menarche, abortions, infant deaths, menopause

Model 4: Model 3 + family h/o CHD, family h/o hypertension, family h/o diabetes mellitus 


\title{
MANUSCRIPT 3
}

\section{SNORING IS ASSOCIATED WITH OBESITY AMONG MIDDLE AGED SLUM-DWELLING WOMEN IN MYSORE, INDIA}

\begin{abstract}
Background: Globally, rates of obesity have trebled in the past four decades. India has more than 9.8 million men and 20 million women classified as obese. While poor diet and sedentary lifestyles are major causes, growing evidence suggests other factors like sleep-disorderedbreathing may also be contributors. Methods: A cross-sectional survey was carried out between October 2017 and May 2018 among a nonprobability sample of slum-dwelling women, 40 to 64 years of age, in government-designated slums in Mysore, India. In addition to sociodemographics, data were collected on tobacco and alcohol consumption, diet, physical activity, sleep, quality of life, and personal and family history of diagnosed cardiometabolic disorders. Body mass Index (BMI) was calculated using anthropometry. Serum was tested for HbA1c and lipids. Electrocardiography was carried out by a trained medical technician. Results: In this sample of slum dwelling women, snoring was associated with obesity. Habitual snorers had more than double the odds (Adjusted Odds Ratio [aOR] 2.05; 95\% Confidence Interval [CI]1.26-3.33; $\mathrm{p}<0.004$ ) of obesity I, and seven times the odds (aOR 7.71; CI: 3.58-16.62; $\mathrm{p}<0.001$ ) of having obesity II compared to non-snorers after adjustment for age, diabetes, hypertension, hypercholesterolemia, and daytime sleepiness. There was no difference in obesity status among participants reporting abnormal sleep duration, napping, daytime sleepiness, sleep apnea, insomnia, or use of sleep medication. Conclusion: The relationship of snoring and obesity has not been well explored. This study among slum-dwelling Indian women, found a significant relationship between snoring and obesity. Future research should explore the underlying mechanisms connecting snoring to BMI.
\end{abstract}




\section{INTRODUCTION}

Globally, rates of overweight and obesity have trebled in the past four decades. In 2016, almost two billion adults were classified as overweight, and 650 million, as obese [1]. Between 1975 and 2014, the share of adults that were overweight, or having a Body Mass Index (BMI) $\geq 25$, increased from $40.8 \%$ to $69.1 \%$ [2].

During the same period, age-standardized obesity (BMI $\geq 30 \mathrm{~kg} / \mathrm{m} 2)$ increased from $3.2 \%$ to $10.8 \%$ in men; and $6.4 \%$ to $14.9 \%$ in women [3]. The annual public health cost of obesity is estimated at 3.4 million premature deaths, and four percent of both potential years of life lost and disability-adjusted life years, worldwide [4].

Once considered mainly a problem in high-income nations, obesity is now a major public health issue in emerging economies where undernutrition was historically high [5]. In India during 1975 , for example, about 400,000 men and 800,000 women were obese; by 2014 , that had increased to 9.8 million and 20 million, respectively [3]. Across this country of more than a billion people, high rates of being overweight are more frequently associated with age, region, female gender, and being in an urban area as compared to rural populations [6-8]. Studies suggest that rates among south Indian women are particularly high; one study showed that women living in south Indian states were about $50 \%$ more likely to be overweight or obese compared to their peers in the northern India [7].

In addition to substantial evidence that an increasingly sedentary lifestyle and a nutritional transition to processed foods and high calorie diets are contributing to weight gain globally, a growing body of research also suggests that a number of behavioral factors may also be contributing to obesity $[9,10]$. Research suggests a strong link between sleep disorders for instance, and higher BMI $[11,12]$. Habitual snoring (HS), a sleep- related behavior, has also been associated with increasing BMI among pregnant women [13] and obesity [14]. This relationship appears to be bi-directional [15]. On the one hand, obesity and neck circumference have been shown to increase risk for snoring [16]: disordered breathing increases negative intraluminal 
pressure encouraging constriction of the airway and vibration of pharyngeal soft tissues $[17,18]$. Other research however, suggests that HS may also be linked to weight gain by contributing to metabolic load [19-21]. HS appears to increase risk factors for obesity including sleep fragmentation [22, 23], impaired circulatory function [24], hypertension [25], metabolic syndrome [26], diabetes [27], and impaired glucose control [28].

Currently there are few studies that have examined sleep quality, duration, or sleeprelated disorders like snoring among slum dwellers [29]. Furthermore, evidence for interactions between snoring and other parameters of sleep such as duration have been mixed, so there is a need for further research to understand the pathways and mechanisms that potentially connect snoring to heightened CVD risk [30-32]. This is the first study to our knowledge to explore the prevalence of snoring in slum-dwellers; its relationship to obesity; and any interactions between snoring and other sleep parameters that may increase risk for both obesity and CVD.

\section{METHODS}

\section{Overview}

This cross-sectional study was carried out between October 2017 and May 2018 among a nonprobability sample of slum-dwelling women, 40 to 64 years of age, living in government designated slums in urban Mysore, India. The research measured knowledge and beliefs about coronary heart disease (CHD), demographics, modifiable risk factors (smoking, use of alcohol, weight, physical activity, healthy diet, blood pressure, serum

cholesterol, and blood glucose), and correlates of CHD (defined as previously diagnosed CHD, symptoms on the Rose angina questionnaire, and/or ischemic changes on electrocardiography). 
Study Sites

The study was carried out in six urban slums (Kesere, Kudaremala, Ekalavya Nagara, Amrutha badavane, and Ganeshnagar) in Mysore City, India. The communities were randomly selected from a sampling frame of 63 Mysore communities designated as slums by the Karnataka Slum Development Board [33, 34]. According to the 2011 census Mysore City has a population of 920,550 of which 459,508 are females [35].

Approximately $19 \%$ of the population live below the poverty line, and about 39,029 residents reside in slums as defined by the Karnataka Slum Act [36]. As of 2011, 73.6\% of the population was Hindu, 21.9\% Muslim, 2.8\% Christian, and the remainder, other religions. Mysore also had an $87.7 \%$ literacy rate, and Kannada was the most widely spoken regional language.

\section{Community Preparedness}

Community preparedness activities were carried out prior to recruitment. Key stakeholders including residents, civic and religious leaders, and staff from nonprofits doing similar work, were consulted prior to data collection. A study protocol was presented to the Public Health Research Institute (PHRII) Community Advisory Board (CAB). Input from key stakeholders and the PHRII CAB informed revision and final design of the study protocol. Participants received a stipend of INR 200 (USD 3.33), an amount traditional for studies of this type, to compensate them for their time and transportation expenses A detailed protocol of the study was reviewed and approved by Institutional Review Boards at Florida International University in Miami, Florida, and Public Health Research Institute of India, Mysore, India.

\section{Study Recruitment}

Trained research staff visited study sites one day prior to recruitment and distributed brochures describing study. If residents expressed interest, staff members explained the purpose 
of the research, described study activities, and conducted a screening process using a standardized script. If potential participants declined to participate, they were asked a brief set of demographic questions to assess any potential systematic biases in participant recruitment. If potential participants met study eligibility criteria, they were told to gather at a central meeting point at a predetermined time on the following day having fasted from 8.00 PM on the prior evening.

Potential participants were also asked to bring any medical reports or medications for diabetes, high blood pressure, heart disease, or stroke. On recruitment day, participants were transported from the meeting point to the study clinic by van. Prior to data collection, potential participants underwent an informed consent process.

Study staff explained the study purpose, read the informed consent verbatim, described all study procedures, and solicited and answered any questions about the study. Women were asked if they understood what they were consenting to, and whether they had any further questions. After any doubts were clarified for potential participants, they gave written informed consent prior to data collection.

\section{Data Collection}

Data were collected from participants in Kannada, using an interviewer-administered standardized questionnaire adapted from the CARRS (Centre for cArdiometabolic Risk Reduction in South-Asia) surveillance Study [37]. Questions solicited information on demographics, socioeconomic status, employment, and residence. Data were also collected on knowledge about cardiovascular disease, willingness to adopt heart health behaviors, subjective judgement of general health, tobacco and alcohol consumption, dietary habits, physical activity, sleep, quality of life, and personal and family history of diagnosed cardio-metabolic disorders and their risk factors. This included diabetes; heart disease, stroke, chronic obstructive pulmonary disease, angina, peripheral vascular disease, kidney disease, and respiratory diseases. Sleep duration and quality were measured using scales adapted from the National Heart Lung Blood Institute (NHLBI) Sleep 
Habits Questionnaire; they included information about sleep patterns, snoring, and daytime sleepiness [38].

Anthropometry included height in centimeters $(\mathrm{cm})$, weight in kilograms $(\mathrm{kg})$, and waist circumference in centimeters $(\mathrm{cm})$. All measures were taken three times and the mean measurement recorded. Height was measured using a Stadiometer Height-Rod without shoes. Weight was measured on a calibrated digital scale to the nearest 100 grams. Waist circumference was measured using a woven measuring tape at the midpoint between the lower border of the rib cage and upper border of the iliac crest. Blood pressure (BP) was measured in sitting position with legs uncrossed using an electronic manometer and cuff, with an average systolic and diastolic blood pressure reading determined after three measurements.

Biochemical Measures and Electrocardiography: A trained phlebotomist collected blood in a $3 \mathrm{ml}$ tube with EDTA for $\mathrm{HbA1c}$ testing, and a $5 \mathrm{ml}$ tube for measurement of serum lipids. Samples were stored in a refrigerator and processed the same day. Serum was tested for glycated hemoglobin (HbA1c), triglycerides (TG), total cholesterol (TC), low-density lipoproteins (LDL), high-density lipoproteins (HDL).

Electrocardiography (ECG) was carried out by a trained medical technician and ECGs were read by a cardiologist at the Cardiology Department at Apollo Hospital, Mysore, according to a standardized protocol for resting Electrocardiography (ECG) [39]. All biological tests were carried out at Public Health Research Institute diagnostic laboratory in Mysore City.

Delivery of Test Results: Participants were provided with a date, time, and location where they could pick up their test results. Each participant was individually counselled on reducing risk for cardiometabolic diseases and given a brochure outlining how they could alter their existing CHD risk through behavior change including smoking cessation, lowered alcohol use, medication, diet, and exercise. Medical referrals were given for patients that had test results suggestive of potentially serious medical conditions. 


\section{Definition of Study Variables}

The primary outcome of this analysis was body mass index (BMI), calculated as weight in kilograms $(\mathrm{kg})$ divided by height in meters $(\mathrm{m})$ squared. BMI was categorized based on the recommended BMI cut-offs for South Asians: underweight $(<18.5 \mathrm{~kg} / \mathrm{m} 2)$, normal weight (18.5-22.9 kg/m2), overweight (23-24.9 kg/m2), obese I $(25-29.9 \mathrm{~kg} / \mathrm{m} 2)$, and obese II ( $\geq 30 \mathrm{~kg} / \mathrm{m} 2)$ [40]. Due to small cell sizes, underweight and normal categories were merged and used as the reference group for analysis of the relationship between BMI and snoring.

The main exposure variable for the study was 'frequency of snoring'. Categories were based on prior studies with participants defined as 'non-snorers' if they never snored or snored previously but no longer snored; as 'moderate snorers' if they currently snored 1-2 nights per week; and as 'habitual snorers' if they currently snored 3-7 nights per week [41].

The following potential confounders of the BMI-snoring relationship were included in the analysis: age; marital status; education; religion; caste; income; work status; tobacco use; alcohol use; caffeine consumption; physical activity. The prevalence of diabetes, hypertension, HTC, and anxiety/depression; sleep duration; daytime sleepiness; and frequency of napping, insomnia, and interrupted breathing while sleeping were also included in the analysis. Education was defined as no schooling, primary school (1-7 years), high school (8-12 years), and secondary school or above (12+ years). Marital status was defined as single, married, and other, with 'other' consisting of 'separated', 'divorced', and 'widow/widower'. Caffeine consumption was defined as 'any' consumption of coffee or tea. Physical activity was categorized into levels based on calculated metabolic equivalent (MET)-minutes (met-mins) [42]: inactive/low if <600 met-min; active if 6001200 met-min; and highly active if $>1200$ met-min [43]. A participant was categorized as diabetic if she had an estimated average glucose $(\mathrm{e} A \mathrm{G})>125 \mathrm{mg} / \mathrm{dL}$ or was taking medication for diabetes [44]. Hypertension was defined as having a systolic blood pressure $\geq 130 \mathrm{mmHg}$, diastolic blood 
pressure $\geq 80 \mathrm{mmHg}$, or use of medication for elevated blood pressure [45]. Hypercholesterolemia (HCL) was defined as low-density lipoprotein cholesterol (LDL-C) $\geq 190 \mathrm{mg} / \mathrm{dL}$ or use of cholesterol lowering medication, as defined in the ACC/AHA Updated Guideline on the Treatment of Blood Cholesterol to Reduce Atherosclerotic Cardiovascular Disease Risk [46, 47]. Anxiety and depression were measured by asking participants to select one of the following statements to best describe their health on the day the questionnaire was administered: "I am not anxious or depressed", "I am moderately anxious or depressed", or "I am extremely anxious or depressed".

Questions to assess sleep duration and quality were adapted from the US National Heart Lung and Blood Institute's Sleep Heart Health Study (SHHS) questionnaire [48]. Sleep duration was self-reported for workdays and non-workdays, and the weighted average was calculated as: $[($ number of hours of sleep on a workday* 6$)+($ number of hours of sleep on a non-workday) $] / 7$. Frequency of napping was defined as the number of times per week that the participant napped for five minutes or longer. 'Frequency of disrupted breathing while sleeping' was defined as rarely if experienced <1 night per week; sometimes if experienced 1-2 nights per week; frequently if experienced 3-5 nights per week; and always or almost always if experienced 6-7 nights per week. Insomnia was assessed using a 6-item scale that measured the frequency of the following sleep symptoms: (1) trouble falling asleep; (2) waking up during the night and having difficulty getting back to sleep; (3) waking up too early in the morning and being unable to get back to sleep; (4) feeling unrested during the day regardless of the number of hours of sleep; (5) not getting enough sleep; and (6) taking sleeping pills or other medication to get to sleep. Monthly frequency of insomnia symptoms was categorized into no (one or more symptoms less than twice per month); rarely (one or more symptoms 2-4 times per month); occasionally (one or more symptoms 5-15 times per month); and frequently (one or more symptoms 16-30 times per month [49]. Daytime sleepiness was measured using the Epworth Sleepiness Scale (ESS) [50] and categorized as 
normal sleepiness $(0 \leq \mathrm{ESS} \leq 6)$; average sleepiness $(7 \leq \mathrm{ESS} \leq 8)$; and abnormal sleepiness $(9 \leq$ $\mathrm{ESS} \leq 24)[51]$.

\section{Statistical Analysis}

Data were presented as frequencies and percentages for categorical variables, and as mean (standard deviation [SD]) and median (first quartile [Q1], third quartile [Q3]) for continuous variables. Differences in socio-demographics, health behaviors, health status, and sleep factors by BMI and by snoring status were assessed using chi-square $(\chi 2)$ tests and analysis of variance (ANOVA) for categorical and continuous variables, respectively. Multinomial logistic regression models, with underweight/normal weight used as the reference category for BMI, were used to assess the adjusted association between BMI and snoring. Factors that were conservatively associated with both BMI and snoring using $\chi^{2}$ test or ANOVA $(\mathrm{p}<0.20)$ were selected a priori as covariates to be included in the adjusted models. Variables were excluded from the model if there was little variation in response (i.e. if $\geq 90 \%$ of the sample fell into a single response category) or if variables were highly correlated. Correlation and multicollinearity were assessed using Pearson's correlation coefficients (r) and variance inflation factors (VIFs) respectively [52]. A P-value of 0.05 was considered statistically significant. Standard errors were adjusted for clustering by slum (6 clusters). Statistical analysis was performed in SPSS 22 (SPSS Statistics, IBM Corp. Armonk, NY, USA) and STATA version 12 (Statacorp, College Station, Texas, US).

\section{RESULTS}

\section{$\backslash$ Characteristics of the sample}

The participants in this study were, on average, 50 years of age and a majority reported their religion as Hindu $(84.2 \%)$ (Table 1). Nearly two out of three women had no formal schooling (62.8\%) and were employed (61.4\%). Half were married (51.4\%), belonged to a scheduled caste or tribe (47.1\%), and 53\% lived in a household with a monthly income of 3000-10,000 Indian rupees ( $1 \mathrm{USD}=66.78 \mathrm{INR}$ ) [53]. One out of three 
women were obese $(38.7 \%)$ and snored at the time of participation $(36.0 \%)$. The average BMI of the women in the study was $23.7 \mathrm{~kg} / \mathrm{m} 2(\mathrm{SD}=5.15$; median $=23.0$; interquartile range $=7.0$ ).

Association between BMI and snoring

The prevalence of snoring increased with higher BMI $(\mathrm{p}<0.001)$ (Table 2). Moderate and habitual snoring were 3 times more prevalent among women that were categorized as obese II than underweight/normal weight women.

\section{Factors associated with BMI}

Women who were overweight or obese were slightly younger $(\mathrm{p}=0.065)$ and generally more educated $(\mathrm{p}<0.001)$ than underweight/normal weight women (Table 2$)$. The proportion of obese women with secondary schooling or above was three times that of underweight/normal weight women. Current use of smokeless tobacco generally decreased with increasing BMI $(\mathrm{p}=0.001)$, while the prevalence of diabetes $(\mathrm{p}<0.001)$, hypertension $(\mathrm{p}<0.001)$, and abnormal daytime sleepiness $(\mathrm{p}=0.054)$ increased with increasing BMI.

Strikingly, the proportion of women classified as obese II with diabetes were nearly three times that of underweight/normal weight women. Abnormal daytime sleepiness among obese II women was four times that of underweight/normal weight women.

\section{Factors associated with snoring}

Women who snored were older than those that did not snore $(\mathrm{p}=0.001)$ (Table 3$)$. The prevalence of diabetes $(\mathrm{p}<0.001)$, hypertension $(\mathrm{p}<0.001)$, and abnormal daytime sleepiness $(\mathrm{p}<0.001)$ increased with increasing frequency of snoring. The prevalence of diabetes among 
habitual snorers was nearly double that of non-snorers. The prevalence of abnormal daytime sleepiness among both moderate and habitual snorers was at least triple that of non-snorers. Although the association was non-significant, the prevalence of anxiety/depression $(\mathrm{p}=0.053)$ was also higher among snorers compared to non-snorers.

Selection of covariates for the multinomial logistic regression models

Three factors were conservatively associated with both BMI and snoring $(\mathrm{p}<0.20)$ and met the criteria for inclusion in the regression models: age, diabetes, and hypertension.

\section{Odds of being overweight}

After adjusting for all covariates, the odds of being overweight (compared to underweight/normal weight) did not significantly differ between moderate snorers and nonsnorers $(\mathrm{p}=0.160)$, or between habitual snorers and non-snorers $(\mathrm{p}=0.241)($ Table 4$)$.

However, age and hypertension were significantly associated with BMI. The odds of being overweight decreased by $5.0 \%$ with every one-year increase in age $(\mathrm{p}=0.006)$. The odds of being overweight was nearly 4 times higher among women with hypertension compared to those without hypertension $(\mathrm{p}=0.002)$.

\section{Odds of being obese I}

After adjusting for all covariates, the odds of being obese I (compared to underweight/normal weight) was more than double among moderate and habitual snorers compared to non-snorers [p=0.046 (1.014-5.781) and $\mathrm{p}=0.002(1.310-3.384)$, respectively] (Table 5). Age, diabetes, and hypertension were also significantly associated with BMI. The odds of being obese I decreased by $5.9 \%$ with every one-year increase in age $(\mathrm{p}<0.001)$. The odds of being obese I was nearly double among diabetics compared to non-diabetics $(\mathrm{p}=0.010)$. The odds of being obese I was more than 4 times higher among women with hypertension compared to those without hypertension $(\mathrm{p}<0.001)$. 


\section{Odds of being obese II}

After adjusting for all covariates, the odds of being obese II (compared to underweight/normal weight) was nearly 9 times higher among moderate snorers and 7 times higher among habitual snorers compared to non- snorers $(\mathrm{p}<0.001$ and $\mathrm{p}<0.001$, respectively) (Table 6). Age and diabetes were also significantly associated with BMI. The odds of being obese II decreased by $8.8 \%$ with every one-year increase in age $(\mathrm{p}=0.001)$. The odds of being obese II was nearly 5 time higher among diabetics compared to nondiabetics $(\mathrm{p}<0.001)$. Although non- significant, the odds of being obese II was more than 6 times higher among women with hypertension compared to those without hypertension $(\mathrm{p}=0.058)$.

Finally, in adjusted models stratified by snoring, there were little association between sleep duration and BMI for those who did not report snoring (per sleep level: 0.35 $\mathrm{kg} / \mathrm{m} 2,95 \% \mathrm{CI}:-0.44,1.15 ; \mathrm{P}=0.39)$, but a significant and strong association for those who reported snoring (per sleep level: $3.66 \mathrm{~kg} / \mathrm{m} 2,95 \% \mathrm{CI}: 1.01,6.31 ; \mathrm{P}=0.01$ ).

\section{DISCUSSION}

In this sample of slum-dwelling women, snoring was associated with obesity and cardiometabolic disorders. In an adjusted model, habitual snorers had more than double the odds [OR 2.05 (1.26-3.33); $\mathrm{p}<0.004]$ of having obesity I and more than seven times the odds [OR 7.71 (3.5816.62); $\mathrm{p}<0.001]$ of having obesity II compared to people not reporting that they snored. Participants that reported moderate snoring which was significantly associated with obesity I, were at seven times increased odds for having obesity II. These relationships remained significant after

controlling for age, diabetes, hypertension, hypercholesterolemia, and daytime sleepiness. There was no difference in obesity status among participants reporting other sleep-related issues 
including short sleep duration, napping, daytime sleepiness, sleep apnea, insomnia, or use of sleep medication. Habitual snoring was less common among normal/underweight women, compared to women who were overweight or obese. These findings are consistent with previous studies showing that self-reported habitual snoring in women was strongly associated with age and BMI $[14,54,55]$. This study also identified a relationship between snoring and several cardio-metabolic disorders including hypertension and Diabetes Type 2. Moderate and habitual snoring were significantly associated with both current and previous diagnosis of hypertension and Diabetes Type $2(\mathrm{p}<0.001)$. Our results are consistent with evidence suggesting that snoring and obesity are closely linked [56].

Obesity-related fat deposits in the neck and tongue for instance, appear to reduce the size of the lumen, increase passive airway pressure, and enhance risk for snoring [57, 58]. Studies also suggest that snoring may increase risk for obesity. Lauderdale et al., for instance, demonstrated an interaction between short sleep duration, snoring, and obesity in 600 young adults [59]. Snoring appeared to moderate the relationship of short sleep duration, a factor associated with obesity in previous studies [60]. In this study, among women reporting snoring versus those who did not, there was a significantly stronger association between short sleep duration and obesity. In a longitudinal model, persons who reported snoring also gained more weight. Other studies show similar findings for sleep-disordered breathing (SDB) and childhood obesity [61-64]. While the mechanisms underlying these associations are still little understood, some research suggests that $\mathrm{SDB}$, a continuum that ranges from snoring to obstructive sleep apnea, may influence systemic processes including inflammation and insulin resistance $[61,63,65]$, appetite $[66,67]$ and sleep processes $[64,68]$ often with reciprocal and bi-directional effects $[62,66,65]$. Many of these processes have not been adequately explored in older adults. Future studies are needed to disentangle the contributions of factors like snoring, obesity, and inflammation; all of which appear to contribute to the development of chronic disease. 
The results of this study are consistent with other research showing that snoring is associated with various cardio-metabolic disorders including insulin resistance, hypertension, metabolic syndrome, and type-2 diabetes [26, 69-73]. The underlying mechanisms are also not well understood but growing evidence suggests that snoring may play a role in fragmenting sleep which is a modulator of metabolic homeostasis [74]. Other research shows a relationship between SDB, chronic low-grade inflammation, adipokine dysregulation, and the pathogenesis of metabolic diseases $[75,76]$. More research is needed to understand the relationship between SDB and metabolic dysregulation.

There are several limitations to our study. First, the design is cross-sectional so data on snoring and BMI were collected at the same time. As a consequence, there is no way to determine the temporality of the relationship between snoring and obesity. Secondly, sleep variables were self-reported and are subject to recall and information bias. An objective measure of disordered breathing might have reduced potential for misclassification [77]. It is possible that some of the association between snoring and obesity reflects undiagnosed sleep apnea, which has previously been associated with obesity [78]. Furthermore, although we adjusted for potential confounders, residual confounding remains a possibility, as in all observational studies [79]. Lastly, due to low cell counts we were unable to provide precise estimates of the effect size for some of the variables. Despite these limitations, the study also has strengths. They include recruitment of a community- based sample likely to be free of the referral biases that may occur from studies of clinic-based samples. The study was designed to minimize measurement error: data were collected using validated and standardized instruments, and questionnaires administered by welltrained staff following highly structured protocols.

\section{CONCLUSIONS}

The relationship of snoring and obesity has not been well explored. This study, in a 
sample of slum dwelling Indian women, found a significant relationship between snoring and obesity. In contrast to previous studies that found a consistent correlation between sleep duration and BMI, we found little association between the length of nighttime sleep and BMI except among those who reported snoring [60]. More research is needed to understand the underlying mechanisms connecting sleep-disordered breathing and BMI

\section{REFERENCES}

1. World Health Organization, Obesity and overweight. Found at http://www.who.int/newsroom/fact- sheets/detail/obesity-and-overweight Accessed on 06/24/18, 2017.

2. World Health Organization, WHO Global Database on Body Mass Index (BMI). Found at https://knoema.com/WHOGDOBMIMay/who-global-database-on-body-mass-indexbmi Accessed on July 2, 2018, 2018.

3. NCD Risk Factor Collaboration. Trends in adult body-mass index in 200 countries from 1975 to 2014: a pooled analysis of 1698 population-based measurement studies with $19 \cdot 2$ million participants. Lancet, 2016. 387: p. 1377-96.

4. Djalalinia S, Qorbani M, Peykari N, Kelishadi R. Health impacts of Obesity. Pak J Med Sci, 2015. 31(1): p. 239-42.

5. Ford ND, Patel SA, Narayan KM. Obesity in Low- and Middle-Income Countries: Burden, Drivers, and Emerging Challenges. Annu Rev Public Health, 2017. 38: p. 145164.

6. Yadav K, Krishnan A. Changing patterns of diet, physical activity and obesity among urban, rural and slum populations in north India. Obes Rev, 2008. 9(5): p. 400-8.

7. Gouda J, Prusty RK. Overweight and obesity among women by economic stratum in urban India. J Health Popul Nutr, 2014. 32(1): p. 79-88.

8. Behl S, Misra A. Management of obesity in adult Asian Indians. Indian Heart J, 2017. 69(4): p. 539- 544.

9. Hruby A, Hu FB. The Epidemiology of Obesity: A Big Picture. Pharmacoeconomics, 2015. 33(7): p. 673-89.

10. Chaput JP, Sjödin AM, Astrup A, Després JP, Bouchard C, Tremblay A. Risk factors for adult overweight and obesity: the importance of looking beyond the 'big two'. Obes Facts, 2010. 3(5): p. 320-7. 
11. Miller MA, Kruisbrink M, Wallace J, Ji C, Cappuccio FP. Sleep duration and incidence of obesity in infants, children, and adolescents: a systematic review and meta-analysis of prospective studies. Sleep, 2018. 41(4).

12. Jike M, Itani O, Watanabe N, Buysse DJ, Kaneita Y. Long sleep duration and health outcomes: A systematic review, meta-analysis and meta-regression. Sleep Med Rev, 2018. 39: p. 25-36.

13. Robertson AJ, Johnson P, Sullivan CE, Hennessy A. Neck circumference, BMI and weight gain in women who snore in pregnancy. Pregnancy Hypertension: An International Journal of Women's Cardiovascular Health, 2015. 5(1): p. 6,7.

14. Svensson M, Lindberg E, Naessen T, Janson C. Risk factors associated with snoring in women with special emphasis on body mass index: a population-based study. Chest, 2006. 129(4): p. 933-41.

15. Xiao Q, Gu F, Caporaso N, Matthews CE. Relationship between sleep characteristics and measures of body size and composition in a nationally-representative sample. $B M C$ Obes, 2016. 3: p. 48.

16. Knuiman M, James A, Divitini M, Bartholomew H. Longitudinal study of risk factors for habitual snoring in a general adult population: the Busselton Health Study. Chest, 2006. 130(6): p. 1779-83.

17. Zancanella E, Haddad FM, Oliveira LA, Nakasato A, Duarte BB, Soares CF, Cahali MB, Eckeli A, Caramelli B, Drager LF, Ramos BD, Nóbrega M, Fagondes SC, Andrada NC; Associação Brasileira de Otorrinolaringologia e Cirurgia Cérvico-Facial; Academia Brasileira de Neurologia; Sociedade Brasileira de Cardiologia; Sociedade Brasileira de Pediatria; Sociedade Brasileira de Pneumologia e Tisiologia. Obstructive sleep apnea and primary snoring: treatment. Braz J Otorhinolaryngol, 2014. 80(1 Suppl 1): p. S17-28.

18. Sogebi OA, Oyewole EA, Olusoga-Peters OO. Sleep disordered breathing (SDB) experiences associated with snoring in adult Nigerians. Afr Health Sci, 2011. 11(3): p. 309-14.

19. Wells J, The Metabolic Ghetto: An Evolutionary Perspective on Nutrition, Power Relations and Chronic Disease (p. 375). 2016, Cambridge, UK: Cambridge University Press.

20. Marchesini G, Pontiroli A, Salvioli G, Novi RF, Vitacolonna E, Taboga C, Ciccarone AM, Grossi E; QUOVADIS Study Group. Snoring, hypertension and Type 2 diabetes in obesity. Protection by physical activity. J Endocrinol Invest, 2004. 27(2): p. 150-7. 
21. Oates CS. Psychological and Metabolic Correlates of Obesity in African-Americans and Caucasians. Found at: https://apps.dtic.mil/dtic/tr/fulltext/u2/1014221.pdf Accessed on January 3, 2018, 2006.

22. O'Brien LM, Mervis CB, Holbrook CR, Bruner JL, Klaus CJ, Rutherford J, Raffield TJ, Gozal D. Neurobehavioral implications of habitual snoring in children. Pediatrics, 2004. 114(1): p. 44-9.

23. Beccuti G, Pannain S. Sleep and obesity. Curr Opin Clin Nutr Metab Care, 2011. 14(4): p. $402-12$.

24. Lugaresi E, Cirignotta F, Coccagna G, Piana C. Some epidemiological data on snoring and cardiocirculatory disturbances. Sleep, 1980. 3(3-4): p. 221-4.

25. Cho N, Joo S, Kim J, Abbott RD, Kim J, Kimm K, Shin C. Relation of habitual snoring with components of metabolic syndrome in Korean adults. Diabetes Res Clin Pract, 2006. 71(3): p. 256- 63.

26. Troxel WM, Buysse DJ, Matthews KA, Kip KE, Strollo PJ, Hall M, Drumheller O, Reis SE. Sleep symptoms predict the development of the metabolic syndrome. Sleep, 2010. 33(12): p. 1633-40.

27. Al-Delaimy WK, Manson JE, Willett WC, Stampfer MJ, Hu FB. Snoring as a risk factor for type II diabetes mellitus: a prospective study. Am J Epidemiol, 2002. 155(5): p. 38793.

28. Joo S, Lee S, Choi HA, Kim J, Kim E, Kimm K, Kim J, Shin C. Habitual snoring is associated with elevated hemoglobin A1c levels in non-obese middle-aged adults. J Sleep Res, 2006. 15(4): p. 437- 44.

29. Pradeepa R, Anjana RM, Joshi SR, Bhansali A, Deepa M, Joshi PP, et al. Prevalence of generalized

\& abdominal obesity in urban \& rural India--the ICMR-INDIAB Study (Phase-I) [ICMRNDIAB- 3]. Indian J Med Res, 2015. 142(2): p. 139-50.

30. Zhang X, Giovannucci EL, Wu K, Gao X, Hu F, Ogino S, Schernhammer ES, Fuchs CS, Redline S, Willett WC, Ma J. Associations of self-reported sleep duration and snoring with colorectal cancer risk in men and women. . Sleep, 2013. 36(5): p. 681-688.

31. Song Q, L X, Hu W, Zhou W, Liu A, Wang X, Wu S. Long Sleep Duration Is an Independent Risk Factor for Incident Atrial Fibrillation in a Chinese Population: A Prospective Cohort Study. Scientific Reports, 2017. 7(3679).

32. Endeshaw Y, Rice TB, Schwartz AV, Stone KL, Manini TM, Satterfield S, Cummings S, Harris T, Pahor M, ABC Health Study. Snoring, daytime sleepiness, and incident cardiovascular disease in the health, aging, and body composition study. Sleep, 2013. 36(11): p. 1737-45. 
33. Karnataka Slum Development Board, Slum-Mysore. https://www.karnataka.gov.in/ksdb/Pages/Slum-Statistics.aspx Accessed on July 27, 2018, 2016.

34. Shivakumar SP, Hanjagi, AD. Shodhganga. Appendix 1: Monitoring slums in Mysore City using spatial information technologies. Found at: http://shodhganga.inflibnet.ac.in/handle/10603/71790 Accessed on April 13, 2017, 2005.

35. Census 2011, Mysore City Census 2011 data. Found at: http://www.census2011.co.in/census/city/452-mysore.html Accessed on April 13, $2017,2015$.

36. Centre for Good Governance. Mysore: Strengthening NRCs for Supporting States and Cities in developing pro-poor urban policies and programme implementation. 2011, found at: http://mhupa- ray.gov.in/wp-content/uploads/2012/08/mysore-workshopreport.pdf Accessed on April 16, 2017.

37. Nair M, Ali MK, Ajay VS, Shivashankar R, Mohan V, Pradeepa R, Deepa M, Khan HM, Kadir MM, Fatmi ZA, Reddy KS, Tandon N, Narayan KM, Prabhakaran D. CARRS Surveillance study: design and methods to assess burdens from multiple perspectives. BMC Public Health, 2012. 12: p. 701.

38. National Heart Lung Blood Institute (NHLBI), Sleep Heart Health Study (SHHS). Found at: https://biolincc.nhlbi.nih.gov/studies/shhs/Accessed on May 20, 2017

39. Nikus K, Birnbaum Y, Eskola M, Sclarovsky S, Zhong-Qun Z, Pahlm O. Updated electrocardiographic classification of acute coronary syndromes. Curr Cardiol Rev, 2014. 10(3): p. 229-36.

40. Jih J, Mukherjea A, Vittinghoff E, Nguyen TT, Tsoh JY, Fukuoka Y, Bender MS, Tseng $\mathrm{W}$, Kanaya AM. Using appropriate body mass index cut points for overweight and obesity among Asian Americans. Prev Med, 2014. 65: p. 1-6.

41. Khoo SM, Tan WC, Ng TP, Ho CH. Risk factors associated with habitual snoring and sleep- disordered breathing in a multi-ethnic Asian population: a populationbased study. Respir Med, 2004. 98(6): p. 557-66.

42. Jetté M, Sidney K, Blümchen G. Metabolic equivalents (METS) in exercise testing, exercise prescription, and evaluation of functional capacity. Clin Cardiol, 1990. 13(8): p. 555-65.

43. World Health Organization, Global Physical Activity Questionnaire (GPAQ) Analysis Guide. Found at: http://www.who.int/ncds/surveillance/steps/resources/GPAQ_Analysis_Guide.pdf Accessed on July 2, 2018. 
44. Liberopoulos EN, Florentin M, Kei A, Mountzouri E, Agouridis A, Elisaf MS. Comparison of hemoglobin A1c and fasting glucose criteria to diagnose diabetes among people with metabolic syndrome and fasting glucose above $100 \mathrm{mg} / \mathrm{dL}(5.5 \mathrm{mmol} / \mathrm{L}) . J$ Clin Hypertens (Greenwich), 2010. 12(7): p. 543-8.

45. American College of Cardiology, New ACC/AHA High Blood Pressure Guidelines Lower Definition of Hypertension. Found at: http://www.acc.org/latest-incardiology/articles/2017/11/08/11/47/mon-5pm-bp-guideline-aha-2017 Accessed on July 2, 2018.

46. Stone NJ, Robinson JG, Lichtenstein AH, Bairey Merz CN, Blum CB, Eckel RH, Goldberg AC, Gordon D, Levy D, Lloyd-Jones DM, McBride P, Schwartz JS, Shero ST, Smith SC Jr, Watson K, Wilson PW; American College of Cardiology/American Heart Association Task Force on Practice Guidelines. ACC/AHA guideline on the treatment of blood cholesterol to reduce atherosclerotic cardiovascular risk in adults: a report of the American College of Cardiology/American Heart Association Task Force on Practice Guidelines. J Am Coll Cardiol, 2014. 63(25 Pt B): p. 2889-934.

47. Sniderman AD, Tsimikas S, Fazio S. The severe hypercholesterolemia phenotype: clinical diagnosis, management, and emerging therapies. J Am Coll Cardiol, 2014. 63(19): p. 1935-47.

48. National Heart Lung Blood Institute (NHLBI), Sleep Heart Health Study (SHHS). Found at: https://biolincc.nhlbi.nih.gov/static/studies/shhs/SHHS_1_Forms/SHHS_1_Sleep_Habits_Ques tionn aire_-_MN.pdf Accessed on July 2, 2018.

49. Haaramo P, Rahkonen O, Hublin C, Laatikainen T, Lahelma E, Lallukka T. Insomnia symptoms and subsequent cardiovascular medication: a register-linked follow-up study among middle-aged employees. J Sleep Res, 2014. 23(3): p. 281-9.

50. Johns MW. The Epworth Sleepiness Scale. Found at: http://epworthsleepinessscale.com/about-the- ess/ Accessed on July 2, 2018, 2018.

51. The Merck Manuals, Epworth Sleepiness Scale (ESS) Found at: https://www.merckmanuals.com/medical-calculators/EpworthSleepScale.htm. Accessed on July 8, 2018.

52. Montgomery DC, Peck EA, Vining GG. Introduction to Linear Regression Analysis 3rd Edition. 2001, Wiley-Interscience, New York, NY

53. X-Rates, Currency Calculator. Found at https://www.Xrates.com/calculator/?from $=\mathrm{USD} \&$ to $=\mathrm{INR} \&$ amount $=1$ Accessed on July 9, 2018. 
54. Schmidt-Nowara WW, Coultas DB, Wiggins C, Skipper BE, Samet JM. Snoring in a Hispanic- American population. Risk factors and association with hypertension and other morbidity. Arch Intern Med, 1990. 150(3): p. 597-601.

55. Nagayoshi M, Yamagishi K, Tanigawa T, Sakurai S, Kitamura A, Kiyama M, Imano H, Ohira T, Sato S, Sankai T, Iso H; CIRCS Investigators. Risk factors for snoring among Japanese men and women: a community-based cross-sectional study. Sleep Breath, 2011. 15(1): p. 63-9.

56. Shukla AD, Jain S, Mishra R, Singh AK. Does 'weight reduction' help all adult snorers? Lung India, 2013. 30(1): p. 16-9.

57. Patil SP, Schneider H, Marx JJ, Gladmon E, Schwartz AR, Smith PL. Neuromechanical control of upper airway patency during sleep. J Appl Physiol (1985), 2007. 102(2): p. $547-56$.

58. Lin BM, Hu FB, Curhan GC. Association Between Benzodiazepine Receptor Agonists and Snoring Among Women in the Nurses' Health Study. JAMA Otolaryngol Head Neck Surg, 2017. 143(2): p. 162-167.

59. Lauderdale DS, Knutson KL, Rathouz PJ, Yan LL, Hulley SB, Liu K. Cross-sectional and longitudinal associations between objectively measured sleep duration and body mass index: the CARDIA Sleep Study. Am J Epidemiol, 2009. 170(7): p. 805-13.

60. Taheri S. The link between short sleep duration and obesity: we should recommend more sleep to prevent obesity. Arch Dis Child, 2006. 9(11): p. 881-884.

61. Bhattacharjee R, Hakim F, Gozal D. Sleep, sleep-disordered breathing and lipid homeostasis: translational evidence from murine models and children. Clin Lipidol, 2012. 7(2): p. 203-214.

62. Gozal D, Kheirandish-Gozal L. Childhood obesity and sleep: relatives, partners, or both?-a critical perspective on the evidence. Ann N Y Acad Sci, 2012. 1264: p. 135-41.

63. Kim J, Hakim F, Kheirandish-Gozal L, Gozal D. Inflammatory pathways in children with insufficient or disordered sleep. Respir Physiol Neurobiol, 2011. 178(3): p. 465-74.

64. Spruyt K, Gozal D. The underlying interactome of childhood obesity: the potential role of sleep. Child Obes, 2012. 8(1): p. 38-42.

65. Arens R, Muzumdar H. Childhood obesity and obstructive sleep apnea syndrome. J Appl Physiol (1985), 2010. 108(2): p. 436-44. 
66. Spruyt K, Sans Capdevila O, Serpero LD, Kheirandish-Gozal L, Gozal D. Dietary and physical activity patterns in children with obstructive sleep apnea. J Pediatr, 2010. 156(5): p. 724-30, 730 e1- 730 e3.

67. Tauman R, Serpero LD, Capdevila OS, O'Brien LM, Goldbart AD, Kheirandish-Gozal L, Gozal D. Adipokines in children with sleep disordered breathing. Sleep, 2007. 30(4): p. 443-9.

68. Bhattacharyya N. Sleep and health implications of snoring: A populational analysis. Laryngoscope, 2015. 125(10): p. 2413-6.

69. Shin C, Kim J, Kim J, Lee S, Shim J, In K, Kang K, Yoo S, Cho N, Kimm K, Joo S. Association of habitual snoring with glucose and insulin metabolism in nonobese Korean adult men. Am J Respir Crit Care Med, 2005. 171(3): p. 287-91.

70. Thomas GN, Jiang CQ, Lao XQ, McGhee SM, Zhang WS, Schooling CM, Adab P, Lam $\mathrm{TH}$, Cheng KK. Snoring and vascular risk factors and disease in a low-risk Chinese population: the Guangzhou Biobank Cohort Study. Sleep, 2006. 29(7): p. 896-900.

71. Elmasry A, Janson C, Lindberg E, Gislason T, Tageldin MA, Boman G. The role of habitual snoring and obesity in the development of diabetes: a 10-year follow-up study in a male population. J Intern Med, 2000. 248(1): p. 13-20.

72. Al-Delaimy WK, M.J., Willett WC, Stampfer MJ, Hu FB. Snoring as a Risk Factor for Type II Diabetes Mellitus: A Prospective Study. Am J Epidemiol, 2002. 155(5): p. 387-393.

73. Hu FB, Willett WC, Colditz GA, Ascherio A, Speizer FE, Rosner B, Hennekens CH, Stampfer MJ. Prospective study of snoring and risk of hypertension in women. Am J Epidemiol, 1999. 150(8): p. 806-16.

74. Koren D, Dumin M, Gozal D. Role of sleep quality in the metabolic syndrome. Diabetes Metab Syndr Obes, 2016. 9: p. 281-310.

75. Leinum CJ, Dopp JM, Morgan BJ. Sleep-disordered breathing and obesity: pathophysiology, complications, and treatment. Nutr Clin Pract, 2009. 24(6): p. 675-87.

76. Sun L, Pan A, Yu Z, Li H, Shi A, Yu D, Zhang G, Zong G, Liu Y, Lin X. Snoring, inflammatory markers, adipokines and metabolic syndrome in apparently healthy Chinese. PLoS One, 2011. 6(11): p. e27515.

77. Norman MB, Pithers SM, Teng AY, Waters KA, Sullivan CE. Validation of the Sonomat Against PSG and Quantitative Measurement of Partial Upper Airway Obstruction in Children With Sleep- Disordered Breathing. Sleep, 2017. 40(3). 
78. Jehan S, Zizi F, Pandi-Perumal SR, Wall S, Auguste E, Myers AK, Jean-Louis G, McFarlane SI. Obstructive Sleep Apnea and Obesity: Implications for Public Health. Sleep Med Disord, 2017. 1(4).

79. Psaty BM, Koepsell TD, Lin D, Weiss NS, Siscovick DS, Rosendaal FR, Pahor M, Furberg CD. Assessment and control for confounding by indication in observational studies. J Am Geriatr Soc, 1999. 47(6): p. 749-54. 


\section{TABLES AND FIGURES}

Table 1. Description of study sample of slum dwelling women in Mysore, India $(\mathrm{N}=607)$

\begin{tabular}{|c|c|c|}
\hline & $\mathbf{N}$ & $\%$ \\
\hline \multicolumn{3}{|l|}{ Age (in years) } \\
\hline Mean (SD) & 50.035 & $(7.318)$ \\
\hline Median (Q1, Q3) & 50 & $(44,55)$ \\
\hline \multicolumn{3}{|l|}{ Education } \\
\hline No schooling & 381 & 62.8 \\
\hline Primary school & 61 & 10.0 \\
\hline High school & 117 & 19.3 \\
\hline Secondary and above & 48 & 7.9 \\
\hline \multicolumn{3}{|l|}{ Religion } \\
\hline Hindu & 510 & 84.2 \\
\hline Muslim & 76 & 12.5 \\
\hline Christian & 20 & 3.3 \\
\hline \multicolumn{3}{|l|}{ Caste } \\
\hline $\mathrm{SC} / \mathrm{ST}$ & 286 & 47.1 \\
\hline Other backward caste & 217 & 35.7 \\
\hline General caste & 104 & 17.1 \\
\hline \multicolumn{3}{|l|}{ Marital Status } \\
\hline Single & 7 & 1.2 \\
\hline Married & 312 & 51.4 \\
\hline Other & 288 & 47.4 \\
\hline \multicolumn{3}{|l|}{ Work Status } \\
\hline Employed & 373 & 61.4 \\
\hline Housewife & 234 & 38.6 \\
\hline \multicolumn{3}{|c|}{ Monthly Household Income (INR) } \\
\hline$<3000$ & 129 & 21.3 \\
\hline $3000-10,000$ & 321 & 53.0 \\
\hline$>10,000$ & 156 & 25.7 \\
\hline BMI & & \\
\hline
\end{tabular}




\begin{tabular}{lcc}
\hline Underweight/normal & 270 & 45.8 \\
Overweight & 91 & 15.4 \\
Obese I & 171 & 29.0 \\
Obese II & 57 & 9.7 \\
Snoring & & \\
Non-snorer & 374 & 63.9 \\
Moderate snorer & 40 & 6.8 \\
Habitual snorer & 171 & 29.2 \\
\hline
\end{tabular}

SD: standard deviation; Q1: first quartile; Q3: third quartile; SC/ST: scheduled caste/scheduled tribe; INR: Indian Rupees; BMI: body mass index; $\mathrm{kg} / \mathrm{m}^{2}$ : kilogram per meter squared Education: Defined as: No Schooling, Primary School (1-7 years), High School (8-12 years), and Secondary School or above $(12+$ years $)$

Marital Status: "Other" includes separated, divorced, and widow/widower.

BMI: Underweight: < $18.5 \mathrm{~kg} / \mathrm{m}^{2}$; Normal weight: $18.5-22.9 \mathrm{~kg} / \mathrm{m}^{2}$; Overweight: $23-24.9 \mathrm{~kg} / \mathrm{m}^{2}$; Obese I: $25-29.9 \mathrm{~kg} / \mathrm{m}^{2}$; Obese II: $\geq 30 \mathrm{~kg} / \mathrm{m}^{2}$

Snoring: "Non-snorer" defined as a never snored or a former snorer (used to snore, but no longer snores). "Moderate snorer" defined as a current snorer who snores 1-2 nights per week. "Habitual snorer" defined as a current snorer who snores 3-7 nights per week. 
Table 2. Factors associated with body mass index among slum dwelling women in Mysore, India (N=607)

\begin{tabular}{|c|c|c|c|c|c|c|c|c|c|}
\hline & \multicolumn{8}{|c|}{ BMI } & \multirow{3}{*}{ P-value } \\
\hline & \multicolumn{2}{|c|}{$\begin{array}{c}\text { Underwt/normal } \\
\mathrm{N}=270\end{array}$} & \multicolumn{2}{|c|}{$\begin{array}{c}\text { Overweight } \\
\text { N=91 }\end{array}$} & \multicolumn{2}{|c|}{$\begin{array}{c}\text { Obese I } \\
\mathrm{N}=171\end{array}$} & \multicolumn{2}{|c|}{$\begin{array}{c}\text { Obese II } \\
\mathbf{N}=57\end{array}$} & \\
\hline & $\mathbf{n}$ & $\%$ & $\mathbf{n}$ & $\%$ & $\mathbf{n}$ & $\%$ & $\mathbf{n}$ & $\%$ & \\
\hline \multicolumn{10}{|l|}{ DEMOGRAPHICS } \\
\hline \multicolumn{10}{|l|}{ Age (in years) } \\
\hline Mean (SD) & 50.79 & $(7.492)$ & 49.21 & $(7.536)$ & 49.12 & $(6.900)$ & 49.25 & $(6.862)$ & 0.065 \\
\hline Median (Q1, Q3) & 50 & $(45,58)$ & 48 & $(42,55)$ & 48 & $(43,55)$ & 49 & $(43,55)$ & - \\
\hline \multicolumn{10}{|l|}{ Education } \\
\hline No schooling & 196 & 72.6 & 53 & 58.2 & 100 & 58.5 & 24 & 42.1 & $<0.001$ \\
\hline Primary school & 24 & 8.9 & 11 & 12.1 & 13 & 7.6 & 9 & 15.8 & \\
\hline High school & 39 & 14.4 & 19 & 20.9 & 37 & 21.6 & 17 & 29.8 & \\
\hline Secondary \& above & 11 & 4.1 & 8 & 8.8 & 21 & 12.3 & 7 & 12.3 & \\
\hline \multicolumn{10}{|l|}{ Religion } \\
\hline Hindu & 235 & 87.4 & 74 & 81.3 & 146 & 85.4 & 42 & 73.7 & 0.115 \\
\hline Muslim & 26 & 9.7 & 15 & 16.5 & 19 & 11.1 & 14 & 24.6 & \\
\hline Christian & 8 & 3.0 & 2 & 2.2 & 6 & 3.5 & 1 & 1.8 & \\
\hline \multicolumn{10}{|l|}{ Caste } \\
\hline $\mathrm{SC} / \mathrm{ST}$ & 138 & 51.1 & 40 & 44.0 & 77 & 45.0 & 24 & 42.1 & 0.689 \\
\hline OBC & 87 & 32.2 & 37 & 40.7 & 62 & 36.3 & 23 & 40.4 & \\
\hline
\end{tabular}




\begin{tabular}{|c|c|c|c|c|c|c|c|c|c|}
\hline General caste & 45 & 16.7 & 14 & 15.4 & 32 & 18.7 & 10 & 17.5 & \\
\hline \multicolumn{10}{|l|}{ Marital Status } \\
\hline Single & 4 & 1.5 & 1 & 1.1 & 2 & 1.2 & - & - & 0.167 \\
\hline Married & 126 & 46.7 & 46 & 50.5 & 103 & 60.2 & 27 & 47.4 & \\
\hline Other & 140 & 51.9 & 44 & 48.4 & 66 & 38.6 & 30 & 52.6 & \\
\hline \multicolumn{10}{|l|}{ Work Status } \\
\hline Employed & 165 & 61.1 & 60 & 65.9 & 109 & 63.7 & 30 & 52.6 & 0.389 \\
\hline Housewife & 105 & 38.9 & 31 & 34.1 & 62 & 36.3 & 27 & 47.4 & \\
\hline \multicolumn{10}{|c|}{ Monthly Household } \\
\hline \multicolumn{10}{|l|}{ Income (INR) } \\
\hline$<3000$ & 67 & 24.9 & 17 & 18.7 & 30 & 17.5 & 12 & 21.1 & 0.437 \\
\hline $3000-10,000$ & 136 & 50.6 & 47 & 51.6 & 93 & 54.4 & 34 & 59.6 & \\
\hline$>10,000$ & 66 & 24.5 & 27 & 29.7 & 48 & 28.1 & 11 & 19.3 & \\
\hline \multicolumn{10}{|c|}{ HEALTH BEHAVIORS } \\
\hline \multicolumn{10}{|c|}{ Smokeless Tobacco use } \\
\hline Never user & 217 & 80.4 & 81 & 89.0 & 160 & 93.6 & 48 & 84.2 & 0.001 \\
\hline Former user & 8 & 3.0 & 2 & 2.2 & 2 & 1.2 & 5 & 8.8 & \\
\hline Current user & 45 & 16.7 & 8 & 8.8 & 9 & 5.3 & 4 & 7.0 & \\
\hline
\end{tabular}




\begin{tabular}{|c|c|c|c|c|c|c|c|c|c|}
\hline \multicolumn{10}{|l|}{ Alcohol use } \\
\hline Never used & 228 & 84.4 & 85 & 93.4 & 158 & 92.4 & 51 & 89.5 & 0.054 \\
\hline Former user & 8 & 3.0 & 3 & 3.3 & 4 & 2.3 & 2 & 3.5 & \\
\hline Current user & 34 & 12.6 & 3 & 3.3 & 9 & 5.3 & 4 & 7.0 & \\
\hline \multicolumn{10}{|l|}{ Caffeine consumption } \\
\hline Never & 17 & 6.3 & 3 & 3.3 & 12 & 7.0 & 4 & 7.0 & 0.837 \\
\hline Yes, but not daily & 6 & 2.2 & 2 & 2.2 & 6 & 3.5 & 1 & 1.8 & \\
\hline Yes, daily & 247 & 91.5 & 86 & 94.5 & 153 & 89.5 & 52 & 91.2 & \\
\hline \multicolumn{10}{|l|}{$\begin{array}{l}\text { Level of physical } \\
\text { activity }\end{array}$} \\
\hline Inactive/low & 29 & 10.7 & 7 & 7.7 & 20 & 11.7 & 7 & 12.3 & 0.914 \\
\hline Active & 113 & 41.9 & 40 & 44.0 & 74 & 43.3 & 27 & 47.4 & \\
\hline Highly active & 128 & 47.4 & 44 & 48.4 & 77 & 45.0 & 23 & 40.4 & \\
\hline \multicolumn{10}{|c|}{ CURRENT HEALTH STATUS } \\
\hline Diabetes & 64 & 23.7 & 23 & 25.3 & 63 & 36.8 & 36 & 63.2 & $<0.001$ \\
\hline Hypertension & 219 & 81.1 & 86 & 94.5 & 164 & 95.9 & 55 & 96.5 & $<0.001$ \\
\hline Hypercholesterolemi & & & & & & & & & \\
\hline
\end{tabular}




\begin{tabular}{|c|c|c|c|c|c|c|c|c|c|}
\hline (HCL) & 16 & 5.9 & 8 & 8.8 & 14 & 58.2 & 2 & 3.5 & 0.495 \\
\hline \multicolumn{10}{|l|}{ Anxiety/depression } \\
\hline None & 46 & 17.0 & 20 & 22.0 & 41 & 24.0 & 10 & 17.5 & 0.507 \\
\hline Moderate & 202 & 74.8 & 67 & 73.6 & 121 & 70.8 & 43 & 75.4 & \\
\hline Extreme & 22 & 8.1 & 4 & 4.4 & 9 & 5.3 & 4 & 7.0 & \\
\hline \multicolumn{10}{|l|}{ SLEEP FACTORS } \\
\hline \multirow{2}{*}{\multicolumn{10}{|c|}{$\begin{array}{l}\text { Duration of Sleep } \\
\text { (hrs/night) }\end{array}$}} \\
\hline & & & & & & & & & \\
\hline Weighted Average (SD) & 7.220 & $(1.443)$ & 7.183 & $(1.450)$ & 7.018 & $(1.485)$ & 7.211 & $(1.295)$ & 0.531 \\
\hline Median (Q1, Q3) & 7.143 & $(6,8)$ & 7.000 & $(6,8)$ & 7.000 & $(6,8)$ & 7.286 & $(6,8)$ & - \\
\hline \multicolumn{10}{|l|}{$\begin{array}{l}\text { Napping (times/usual } \\
\text { week) }\end{array}$} \\
\hline Mean (SD) & 0.715 & (1.283) & 0.637 & $(0.837)$ & 0.643 & $(0.858)$ & 0.825 & $(0.869)$ & 0.664 \\
\hline Median (Q1, Q3) & 0 & $(0,1)$ & 0 & $(0,1)$ & 0 & $(0,1)$ & 1 & $(0,1)$ & - \\
\hline \multicolumn{10}{|l|}{ Daytime Sleepiness } \\
\hline Normal sleepiness & 257 & 95.2 & 82 & 90.1 & 156 & 91.2 & 47 & 82.5 & 0.054 \\
\hline Average sleepiness & 7 & 2.6 & 7 & 7.7 & 10 & 5.8 & 5 & 8.8 & \\
\hline Abnormal sleepiness & 6 & 2.2 & 2 & 2.2 & 5 & 2.9 & 5 & 8.8 & \\
\hline
\end{tabular}




\begin{tabular}{|c|c|c|c|c|c|c|c|c|c|}
\hline \multicolumn{10}{|l|}{ Snoring } \\
\hline Non-snorer & 199 & 75.7 & 59 & 67.0 & 96 & 58.2 & 13 & 25.0 & $<0.001$ \\
\hline Moderate snorer & 12 & 4.6 & 7 & 8.0 & 13 & 7.9 & 7 & 13.5 & \\
\hline Habitual snorer & 52 & 19.8 & 22 & 25.0 & 56 & 33.9 & 32 & 61.5 & \\
\hline \multicolumn{10}{|c|}{$\begin{array}{l}\text { How often do you stop breathing } \\
\text { while sleeping }\end{array}$} \\
\hline Never & 242 & 91.3 & 79 & 89.8 & 152 & 90.5 & 50 & 89.3 & 0.728 \\
\hline Rarely & 9 & 3.4 & 2 & 2.3 & 5 & 3.0 & 2 & 3.6 & \\
\hline Sometimes & 8 & 3.0 & 6 & 6.8 & 7 & 4.2 & 3 & 5.4 & \\
\hline Frequently & 5 & 1.9 & - & - & 4 & 2.4 & 1 & 1.8 & \\
\hline $\begin{array}{l}\text { Always or almost } \\
\text { always }\end{array}$ & 1 & 0.4 & 1 & 1.1 & - & - & - & - & \\
\hline \multicolumn{10}{|l|}{ Insomnia } \\
\hline No & 118 & 43.7 & 43 & 47.3 & 85 & 49.7 & 35 & 61.4 & 0.530 \\
\hline Rarely & 25 & 9.3 & 9 & 9.9 & 13 & 7.6 & 4 & 7.0 & \\
\hline Occasionally & 49 & 18.1 & 14 & 15.4 & 23 & 13.5 & 5 & 8.8 & \\
\hline Frequently & 78 & 28.9 & 25 & 27.5 & 50 & 29.2 & 13 & 22.8 & \\
\hline $\begin{array}{l}\text { Ever use of sleep } \\
\text { medication }\end{array}$ & 10 & 3.7 & 4 & 4.4 & 8 & 4.7 & 4 & 7.0 & 0.765 \\
\hline
\end{tabular}


$\mathrm{SD}=$ standard deviation; $\mathrm{Q} 1=$ first quartile; $\mathrm{Q} 3=$ third quartile; $\mathrm{SC} / \mathrm{ST}=$ scheduled caste/scheduled tribe; $\mathrm{BMI}=$ body mass index;

$\mathrm{kg} / \mathrm{m}^{2}=$ kilogram per meter squared; Underwt= underweight; $\mathrm{eAG}=$ estimated average glucose $; \mathrm{mg} / \mathrm{dL}=$ milligram per deciliter; $\mathrm{BP}=$ blood pressure; INR= Indian Rupees; HCL= hypercholesterolemia; ESS= Epworth Sleep Scale

Snoring: "Non-snorer" defined as a never snored or a former snorer (used to snore, but no longer snores). "Moderate snorer" defined as a current snorer who snores 1-2 nights per week. "Habitual snorer" defined as a current snorer who snores 3-7 nights per week.

Education: No Schooling, Primary School (1-7 years), High School (8-12 years), and Secondary School or above (12+ years).

Marital Status: "Other" includes separated, divorced, and widow/widower. Caffeine Consumption: Defined as consumption of coffee or tea.

Level of Physical Activity: "Inactive/low" defined as <600 met-min. "Active" defined as 600-1200 met-min. "Highly active" defined as $>1200$ met-min.

BMI: Underweight $<18.5 \mathrm{~kg} / \mathrm{m}^{2}$; Normal weight $18.5-22.9 \mathrm{~kg} / \mathrm{m}^{2}$; Overweight= 23-24.9 kg/m ${ }^{2}$; Obese I= 25-29.9 kg/m $\mathrm{m}^{2}$; Obese II $\geq 30 \mathrm{~kg} / \mathrm{m}^{2}$.

Diabetes: Defined as eAG $>125 \mathrm{mg} / \mathrm{dL}$ or use of medication for diabetes.

Hypertension: Defined as systolic $\mathrm{BP} \geq 130 \mathrm{mmHg}$, diastolic $\mathrm{BP} \geq 80 \mathrm{mmHg}$, or use of medication for elevated blood pressure.

HCL: Defined as LDL-C $\geq 190 \mathrm{mg} / \mathrm{dL}$ or use of cholesterol lowering medication. Anxiety/Depression: Self-reported history of anxiety and/or depression.

Napping: Defined as napping for at least 5 minutes.

Daytime Sleepiness: "Normal sleepiness" defined as $0 \leq$ ESS $\leq 6$. "Average sleepiness" defined as $7 \leq$ ESS $\leq 8$. "Abnormal sleepiness" defined as $9 \leq \mathrm{ESS} \leq 24$.

How often do you stop breathing while sleeping: "Rarely" defined as $<1$ night per week. "Sometimes" defined as 1-2 nights per week. "Frequently" defined as 3-5 nights per week. "Always or almost always" defined as 6-7 nights per week.

Insomnia: "No" defined as <2 nights per month. "Rarely" defined as 2-4 nights per month. "Occasionally" defined as 5-15 nights per 
month. "Frequently" defined as 16-30 nights per month. If a subject had more than one of the five symptoms of insomnia, insomnia was categorized based on the most frequent symptom. 
Table 3. Factors associated with snoring among slum dwelling women in Mysore, India (N=607)

\begin{tabular}{|c|c|c|c|c|c|c|c|}
\hline & \multicolumn{6}{|c|}{ Snoring } & \multirow{3}{*}{ P-value } \\
\hline & \multicolumn{2}{|c|}{$\begin{array}{c}\text { Non-snorer } \\
\mathbf{N}=374\end{array}$} & \multicolumn{2}{|c|}{$\begin{array}{l}\text { Moderate snorer } \\
\qquad \mathrm{N}=\mathbf{4 0}\end{array}$} & \multicolumn{2}{|c|}{$\begin{array}{l}\text { Habitual snorer } \\
\qquad \mathbf{N}=\mathbf{1 7 1}\end{array}$} & \\
\hline & $\mathbf{n}$ & $\%$ & $\mathbf{n}$ & $\%$ & $\mathbf{n}$ & $\%$ & \\
\hline \multicolumn{8}{|l|}{ DEMOGRAPHICS } \\
\hline \multicolumn{8}{|l|}{ Age (in years) } \\
\hline Mean (SD) & 49.18 & $(7.23)$ & 49.37 & $(7.37)$ & 51.77 & $(7.23)$ & 0.001 \\
\hline Median (Q1, Q3) & 48 & $(43,55)$ & 50 & $(42,54.5)$ & 52 & $(45,58)$ & - \\
\hline \multicolumn{8}{|l|}{ Education } \\
\hline No schooling & 243 & 65.0 & 19 & 47.5 & 103 & 60.2 & 0.330 \\
\hline Primary school & 37 & 9.9 & 4 & 10.0 & 19 & 11.1 & \\
\hline High school & 65 & 17.4 & 12 & 30.0 & 37 & 21.6 & \\
\hline Secondary and above & 29 & 7.8 & 5 & 12.5 & 12 & 7.0 & \\
\hline \multicolumn{8}{|l|}{ Religion } \\
\hline Hindu & 316 & 84.7 & 30 & 75.0 & 142 & 83.0 & 0.590 \\
\hline Muslim & 46 & 12.3 & 8 & 20.0 & 22 & 12.9 & \\
\hline Christian & 11 & 2.9 & 2 & 5.0 & 7 & 4.1 & \\
\hline \multicolumn{8}{|l|}{ Caste } \\
\hline $\mathrm{SC} / \mathrm{ST}$ & 172 & 46.0 & 21 & 52.5 & 80 & 46.8 & 0.618 \\
\hline
\end{tabular}




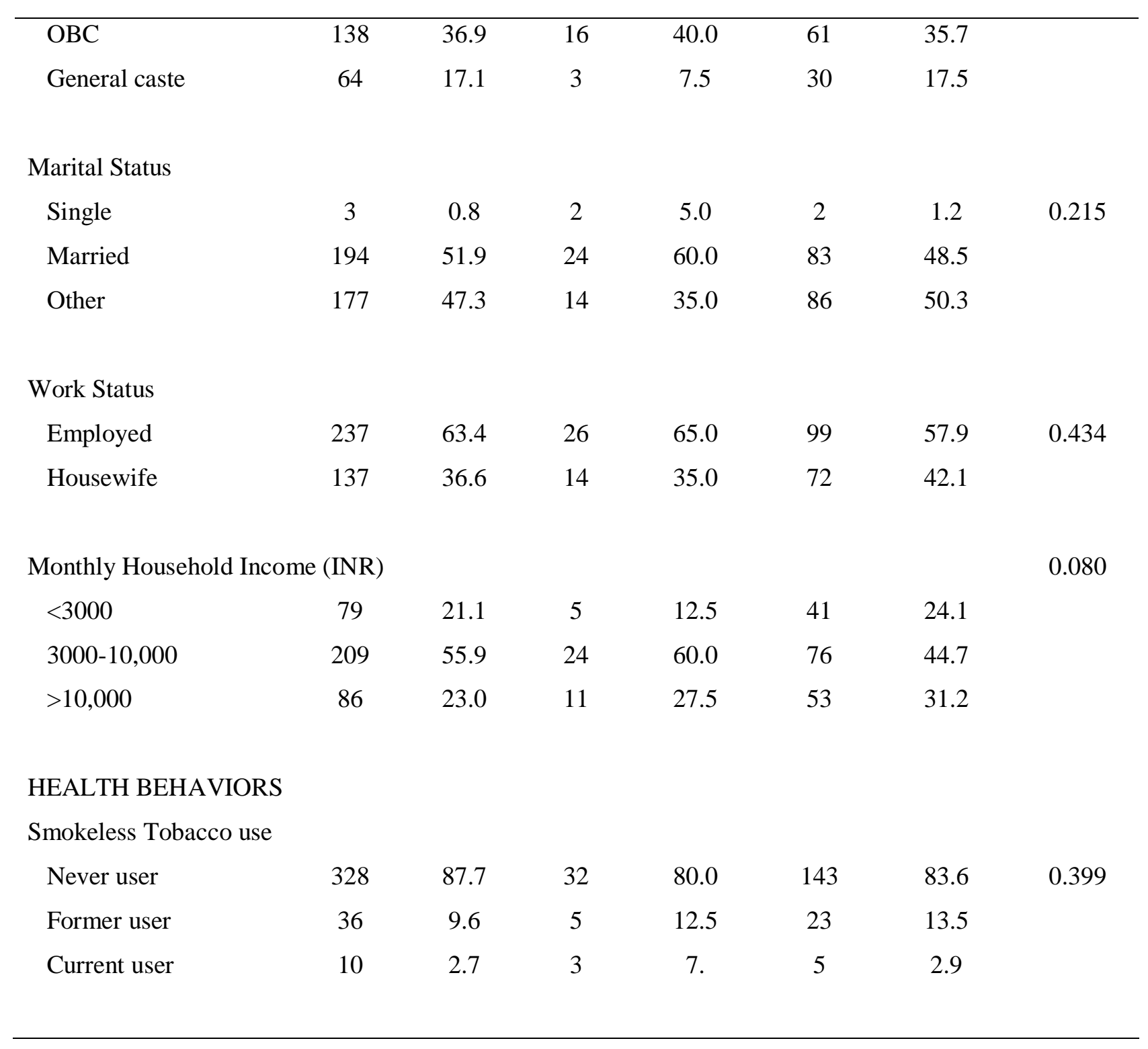




\begin{tabular}{|c|c|c|c|c|c|c|c|}
\hline \multicolumn{8}{|l|}{ Alcohol use } \\
\hline Never used & 334 & 89.3 & 37 & 92.5 & 145 & 84.8 & 0.239 \\
\hline Former user & 9 & 2.4 & 2 & 5.0 & 6 & 3.5 & \\
\hline Current user & 31 & 8.3 & 1 & 2.5 & 20 & 11.7 & \\
\hline \multicolumn{8}{|c|}{ Caffeine consumption } \\
\hline Never & 18 & 4.8 & 4 & 10.0 & 13 & 7.6 & 0.127 \\
\hline Yes, but not daily & 6 & 1.6 & 3 & 7.5 & 5 & 2.9 & \\
\hline Yes, daily & 350 & 93.6 & 33 & 82.5 & 153 & 89.5 & \\
\hline \multicolumn{8}{|c|}{ Level of physical activity } \\
\hline Inactive/low & 39 & 10.4 & 4 & 10.0 & 18 & 10.5 & 0.999 \\
\hline Active & 164 & 43.9 & 18 & 45.0 & 73 & 42.7 & \\
\hline Highly active & 171 & 45.7 & 18 & 45.0 & 80 & 46.8 & \\
\hline \multicolumn{8}{|c|}{ CURRENT HEALTH STATUS } \\
\hline \multicolumn{8}{|l|}{$\operatorname{BMI}\left(\mathrm{kg} / \mathrm{m}^{2}\right)$} \\
\hline Mean (SD) & 22.478 & (4.77) & 24.687 & $(5.26)$ & 26.007 & (5.06) & $<0.001$ \\
\hline Median (Q1, Q3) & 22 & $(19,25)$ & 25 & $(21.5,27)$ & 26 & $(22,29)$ & - \\
\hline \multicolumn{8}{|l|}{ BMI } \\
\hline Underwt/normal & 119 & 54.2 & 12 & 30.8 & 52 & 32.1 & $<0.001$ \\
\hline Overweight & 59 & 16.1 & 7 & 17.9 & 22 & 13.6 & \\
\hline
\end{tabular}




\begin{tabular}{|c|c|c|c|c|c|c|c|}
\hline Obese I & 96 & 26.2 & 13 & 33.3 & 56 & 34.6 & \\
\hline Obese II & 13 & 3.5 & 7 & 17.9 & 32 & 19.8 & \\
\hline Diabetes & 96 & 25.7 & 10 & 25.0 & 77 & 45.0 & $<0.001$ \\
\hline Hypertension & 319 & 85.3 & 36 & 90.0 & 166 & 97.1 & $<0.001$ \\
\hline HCL & 26 & 7.0 & 3 & 7.5 & 12 & 7.0 & 0.992 \\
\hline \multicolumn{8}{|l|}{ Anxiety/depression } \\
\hline None & 82 & 21.9 & 6 & 15.0 & 27 & 15.8 & 0.053 \\
\hline Moderate & 264 & 70.6 & 29 & 72.5 & 138 & 80.7 & \\
\hline Extreme & 28 & 7.5 & 5 & 12.5 & 6 & 3.5 & \\
\hline \multicolumn{8}{|l|}{ SLEEP FACTORS } \\
\hline \multicolumn{8}{|l|}{ Duration of Sleep } \\
\hline $\begin{array}{l}\text { (hours/night), } \\
\text { Weighted Average }\end{array}$ & 7.180 & $(1.49)$ & 6.911 & (1.12) & 7.284 & $(1.35)$ & 0.319 \\
\hline Median (Q1, Q3) & 7.143 & $(6,8)$ & 7 & $(6,8)$ & 7.714 & $(6.64,8)$ & - \\
\hline $\begin{array}{l}\text { Napping (times/us } \\
\text { week) }\end{array}$ & & & & & & & \\
\hline
\end{tabular}




\begin{tabular}{|c|c|c|c|c|c|c|c|}
\hline Mean (SD) & 0.62 & $(1.15)$ & 0.75 & $(0.89)$ & 0.83 & $(0.91)$ & 0.091 \\
\hline Median (Q1, Q3) & 0 & $(0,1)$ & 0.50 & $(0,1)$ & 1 & $(0,1)$ & - \\
\hline \multicolumn{8}{|l|}{ Daytime Sleepiness } \\
\hline Normal sleepiness & 359 & 96.0 & 34 & 85.0 & 146 & 85.4 & $<0.001$ \\
\hline Average sleepiness & 9 & 2.4 & 4 & 10.0 & 15 & 8.8 & \\
\hline Abnormal sleepiness & 6 & 1.6 & 2 & 5.0 & 10 & 5.8 & \\
\hline \multicolumn{8}{|c|}{$\begin{array}{l}\text { How often do you stop breathing } \\
\text { while sleeping }\end{array}$} \\
\hline Never & 337 & 91.6 & 34 & 85.0 & 151 & 90.4 & 0.470 \\
\hline Rarely & 10 & 2.7 & 1 & 2.5 & 6 & 3.6 & \\
\hline Sometimes & 15 & 4.1 & 4 & 10.0 & 5 & 3.0 & \\
\hline Frequently & 4 & 1.1 & 1 & 2.5 & 5 & 3.0 & \\
\hline $\begin{array}{l}\text { Always or almost } \\
\text { always }\end{array}$ & 2 & 0.5 & - & - & - & - & \\
\hline \multicolumn{8}{|l|}{ Insomnia } \\
\hline No & 179 & 47.9 & 18 & 45.0 & 83 & 48.5 & 0.477 \\
\hline Rarely & 27 & 7.2 & 4 & 10.0 & 20 & 11.7 & \\
\hline Occasionally & 62 & 16.6 & 9 & 22.5 & 22 & 12.9 & \\
\hline Frequently & 106 & 28.3 & 9 & 22.5 & 46 & 26.9 & \\
\hline
\end{tabular}




\begin{tabular}{llllllll}
\hline $\begin{array}{l}\text { Ever use of sleep } \\
\text { medication }\end{array}$ & 15 & 4.0 & 3 & 7.5 & 8 & 4.7 & 0.587 \\
\hline
\end{tabular}

$\mathrm{SD}=$ standard deviation; $\mathrm{Q} 1=$ first quartile; $\mathrm{Q} 3=$ third quartile; $\mathrm{SC} / \mathrm{ST}=$ scheduled caste/scheduled tribe; $\mathrm{BMI}=$ body mass index; $\mathrm{kg} / \mathrm{m}^{2}=$ kilogram per meter squared; Underwt= underweight; $\mathrm{eAG}=$ estimated average glucose; $\mathrm{mg} / \mathrm{dL}=$ milligram per deciliter; $\mathrm{BP}=$ blood pressure; INR= Indian Rupees; $\mathrm{HCL}=$ hypercholesterolemia; $\mathrm{ESS}=$ Epworth Sleep Scale Snoring: "Non-snorer" defined as a never snored or a former snorer (used to snore, but no longer snores). "Moderate snorer" defined as a current snorer who snores 1-2 nights per week. "Habitual snorer" defined as a current snorer who snores 3-7 nights per week.

Education: No Schooling, Primary School (1-7 years), High School (8-12 years), and Secondary School or above (12+ years).

Marital Status: "Other" includes separated, divorced, and widow/widower.

Caffeine Consumption: Defined as consumption of coffee or tea.

Level of Physical Activity: "Inactive/low" defined as <600 met-min. "Active" defined as 600-1200 met-min. "Highly active" defined as $>1200$ met-min.

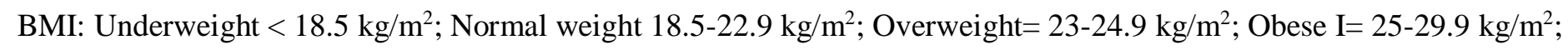
Obese II $\geq 30 \mathrm{~kg} / \mathrm{m}^{2}$.

Diabetes: Defined as eAG $>125 \mathrm{mg} / \mathrm{dL}$ or use of medication for diabetes.

Hypertension: Defined as systolic $\mathrm{BP} \geq 130 \mathrm{mmHg}$, diastolic $\mathrm{BP} \geq 80 \mathrm{mmHg}$, or use of medication for elevated blood pressure.

HCL: Defined as LDL-C $\geq 190 \mathrm{mg} / \mathrm{dL}$ or use of cholesterol lowering medication.

Anxiety/Depression: Self-reported history of anxiety and/or depression.

Napping: Defined as napping for at least 5 minutes.

Daytime Sleepiness: "Normal sleepiness" defined as $0 \leq \mathrm{ESS} \leq 6$. "Average sleepiness" defined as $7 \leq \mathrm{ESS} \leq 8$. "Abnormal 
sleepiness" defined as $9 \leq \mathrm{ESS} \leq 24$.

How often do you stop breathing while sleeping: "Rarely" defined as $<1$ night per week. "Sometimes" defined as 1-2 nights per week. "Frequently" defined as 3-5 nights per week. "Always or almost always" defined as 6-7 nights per week. Insomnia: "No" defined as $<2$ nights per month. "Rarely" defined as 2-4 nights per month. "Occasionally" defined as 5-15 nights per month. "Frequently" defined as 16-30 nights per month. If a subject had more than one of the five symptoms of insomnia, insomnia was categorized based on the most frequent symptom. 
Table 4. Odds of being overweight versus underweight/normal weight among slum dwelling women in Mysore, India ( $\mathrm{N}=607)$.

\begin{tabular}{|c|c|c|c|c|c|c|}
\hline & \multicolumn{3}{|c|}{ Unadjusted } & \multicolumn{3}{|c|}{ Adjusted } \\
\hline & OR & $(95 \% \mathrm{CI})$ & $\mathbf{P}$ & AOR & $(95 \%$ CI $)$ & P-value \\
\hline Age (in years) & 0.971 & $(0.939-1.003)$ & 0.078 & 0.950 & $(0.917-0.985)$ & 0.006 \\
\hline Diabetes & 1.089 & $(0.628-1.886)$ & 0.762 & 0.962 & $(0.529-1.750)$ & 0.900 \\
\hline Hypertension & 4.005 & $(1.546-10.375)$ & 0.004 & 4.841 & $(1.822-12.865)$ & 0.002 \\
\hline \multicolumn{7}{|l|}{ Snoring } \\
\hline Non-snorer & Ref. & --- & --- & Ref. & --- & --- \\
\hline Moderate snorer & 1.968 & $(0.741-5.223)$ & 0.174 & 2.057 & $(0.751-5.634)$ & 0.160 \\
\hline Habitual snorer & 1.427 & $(0.801-2.541)$ & 0.227 & 1.429 & $(0.787-2.597)$ & 0.241 \\
\hline
\end{tabular}

$\mathrm{OR}=$ odds ratio $\mathrm{AOR}=$ adjusted odds ratio $\mathrm{CI}=$ confidence interval $\mathrm{BMI}=$ body mass index; $\mathrm{kg} / \mathrm{m}^{2}=\mathrm{kilogram}$ per meter squared; $\mathrm{eAG}=$ estimated average glucose; $\mathrm{mg} / \mathrm{dL}=$ milligram per deciliter; $\mathrm{BP}=$ blood pressure

BMI: Underweight $<18.5 \mathrm{~kg} / \mathrm{m}^{2}$; Normal weight $18.5-22.9 \mathrm{~kg} / \mathrm{m}^{2}$; Overweight= 23-24.9 kg/m $\mathrm{m}^{2}$; Obese I= 25-29.9 kg/m²;

Obese II $\geq 30 \mathrm{~kg} / \mathrm{m}^{2}$.

Diabetes: Defined as eAG $>125 \mathrm{mg} / \mathrm{dL}$ or use of medication for diabetes. Hypertension: Defined as systolic BP $\geq 130$ $\mathrm{mmHg}$, diastolic $\mathrm{BP} \geq 80 \mathrm{mmHg}$, or use of medication for elevated blood pressure. 
Snoring: "Non-snorer" defined as a never snored or a former snorer (used to snore, but no longer snores). "Moderate snorer" defined as a current snorer who snores 1-2 nights per week. "Habitual snorer" defined as a current snorer who snores 3-7 nights per week 
Table 5. Odds of being obese I versus underweight/normal weight among slum dwelling women in Mysore, India $(\mathrm{N}=607)$.

\begin{tabular}{|c|c|c|c|c|c|c|}
\hline & \multicolumn{3}{|c|}{ Unadjusted } & \multicolumn{3}{|c|}{ Adjusted } \\
\hline & OR & $(95 \% \mathrm{CI})$ & P-value & AOR & $(95 \% \mathrm{CI})$ & P-value \\
\hline Age (in years) & 0.969 & $(0.943-0.995)$ & 0.020 & 0.941 & $(0.913-0.970)$ & $<0.001$ \\
\hline Diabetes & 1.878 & $(1.235-2.854)$ & 0.003 & 1.828 & $(1.156-2.891)$ & 0.010 \\
\hline Hypertension & 5.456 & $(2.414-12.332)$ & $<0.001$ & 5.624 & $(2.419-13.075)$ & $<0.001$ \\
\hline \multicolumn{7}{|l|}{ Snoring } \\
\hline Non-snorer & Ref. & --- & --- & Ref. & --- & --- \\
\hline Moderate snorer & 2.246 & $(0.988-5.107)$ & 0.054 & 2.421 & $(1.014-5.781)$ & 0.046 \\
\hline Habitual snorer & 2.232 & $(1.425-3.498)$ & $<0.001$ & 2.106 & $(1.310-3.384)$ & 0.002 \\
\hline
\end{tabular}

$\mathrm{OR}=$ odds ratio; $\mathrm{AOR}=$ adjusted odds ratio; $\mathrm{CI}=$ confidence interval; $\mathrm{BMI}=$ body mass index; $\mathrm{kg} / \mathrm{m}^{2}=\mathrm{kilogram}$ per meter squared; $\mathrm{e} \mathrm{AG}=$ estimated average glucose; $\mathrm{mg} / \mathrm{dL}=$ milligram per deciliter; $\mathrm{BP}=$ blood pressure

BMI: Underweight $<18.5 \mathrm{~kg} / \mathrm{m}^{2}$; Normal weight $18.5-22.9 \mathrm{~kg} / \mathrm{m}^{2}$; Overweight=23-24.9 kg/m ${ }^{2}$; Obese I= 25-29.9 kg/m $\mathrm{m}^{2}$; Obese II $\geq 30 \mathrm{~kg} / \mathrm{m}^{2}$.

Diabetes: Defined as eAG $>125 \mathrm{mg} / \mathrm{dL}$ or use of medication for diabetes.

Hypertension: Defined as systolic $\mathrm{BP} \geq 130 \mathrm{mmHg}$, diastolic $\mathrm{BP} \geq 80 \mathrm{mmHg}$, or use of medication for elevated blood pressure.

Snoring: "Non-snorer" defined as a never snored or a former snorer (used to snore, but no longer snores). "Moderate snorer" defined as a current snorer who snores 1-2 nights per week. "Habitual snorer" defined as a current snorer who snores 3-7 nights per week. 
Table 6. Odds of being obese II versus underweight/normal weight among slum dwelling women in Mysore, India (N=607)

\begin{tabular}{|c|c|c|c|c|c|c|}
\hline & \multicolumn{3}{|c|}{ Unadjusted } & \multicolumn{3}{|c|}{ Adjusted } \\
\hline & OR & $(95 \%$ CI $)$ & P-value & AOR & $(95 \%$ CI $)$ & P-value \\
\hline Age (in years) & 0.971 & $(0.933-1.011)$ & 0.153 & 0.912 & $(0.869-0.958)$ & $<0.001$ \\
\hline Diabetes & 5.518 & $(3.007-10.124)$ & $<0.001$ & 5.762 & $(2.857-11.621)$ & $<0.001$ \\
\hline Hypertension & 6.404 & $(1.512-27.122)$ & 0.012 & 7.448 & $(0.935-59.340)$ & 0.058 \\
\hline \multicolumn{7}{|l|}{ Snoring } \\
\hline Non-snorer & Ref. & --- & --- & Ref. & --- & --- \\
\hline Moderate snorer & 8.929 & $(3.008-26.505)$ & $<0.001$ & 9.882 & (3.033-32.196) & $<0.001$ \\
\hline Habitual snorer & 9.420 & $(4.616-19.223)$ & $<0.001$ & 8.220 & (3.851-17.547) & $<0.001$ \\
\hline
\end{tabular}

$\mathrm{OR}=$ odds ratio; $\mathrm{AOR}=$ adjusted odds ratio $\mathrm{CI}=$ confidence interval; $\mathrm{BMI}=$ body mass index $; \mathrm{kg} / \mathrm{m}^{2}=$ kilogram per meter squared; $\mathrm{e} \mathrm{AG}=$ estimated average glucose; $\mathrm{mg} / \mathrm{dL}=$ milligram per deciliter; $\mathrm{BP}=$ blood pressure

BMI: Underweight $<18.5 \mathrm{~kg} / \mathrm{m}^{2}$; Normal weight $18.5-22.9 \mathrm{~kg} / \mathrm{m}^{2}$; Overweight= 23-24.9 kg/m $\mathrm{m}^{2}$; Obese I= 25-29.9 kg/m²; Obese II $\geq 30 \mathrm{~kg} / \mathrm{m}^{2}$.

Diabetes: Defined as eAG $>125 \mathrm{mg} / \mathrm{dL}$ or use of medication for diabetes.

Hypertension: Defined as systolic BP $\geq 130 \mathrm{mmHg}$, diastolic $\mathrm{BP} \geq 80 \mathrm{mmHg}$, or use of medication for elevated blood pressure.

Snoring: "Non-snorer" defined as a never snored or a former snorer (used to snore, but no longer snores). "Moderate snorer" defined as a current snorer= 


\section{CONCLUSIONS}

Mera Dil was a cross-sectional study collected and analyzed biological and behavioral data from 607 slum-dwelling women in Mysore, India. The aims of the study were to: 1) examine levels of CVD risk factor knowledge and exploring whether that knowledge was associated with the adoption and maintenance of behavior to reduce cardiovascular risk; 2) explore whether parity in early life was a risk factor for CHD among middle age women; and 3) assess whether there was a relationship between snoring and obesity in slum-dwelling women. The study was informed by Weinstein \& Sandman's Precaution Adoption Process Model (PAPM) that posits that adoption and maintenance of health behaviors is associated with a series of stages: (i) being unaware of an issue, (ii) having awareness of an issue but not being personally engaged by it, (iii) engaging in the issue and deciding what to do next, (iv) planning to act, but not yet acting; and (v) deciding not to act or taking-action, and (vi) maintaining the results of that action [1]. PAPM was operationalized using the Adoption of Risk Reducing Behaviors Instrument (ARRBI) adapted from a measure developed and validated by Weinstein et al (24).

The participants in this study were, on average, 50 years of age and a majority reported their religion as Hindu (84.2\%). Nearly two out of three women had no formal schooling (62.8\%) and most were employed (61.4\%). About half were married (51.4\%), belonged to a scheduled caste or tribe (47.1\%), and lived in a household with a monthly income of 300010,000 Indian rupees $(53 \%)(1 \mathrm{USD}=68.78 \mathrm{INR})[2]$. One in three participants were obese (38.7\%) and almost four in 10 reported snoring (36.0\%). The average BMI of the women in the study was $23.7 \mathrm{~kg} / \mathrm{m} 2$ (SD:5.15; median: 23.0; interquartile range: 7.0).

Manuscript 1 describes the level of cardiovascular risk factor knowledge among slumdwelling women in Mysore, India. In this study, we found that slum-dwelling women had low knowledge about modifiable CVD risk factors; a finding consistent with studies of other slum-

dwellers in other parts the world [3,4]. About half (47\%) of participants answered less that 50\% 
of questions correctly, and only a third had knowledge scores about 70\%, which we defined as 'good knowledge'. Only four of seven traditional CVD risk factors; physical activity, smoking, overweight, and high cholesterol were recognized by greater than half of participants. Consistent with studies in other disadvantaged populations, this we found that CVD risk factor knowledge was significantly associated with age, education, monthly household income, marital status [58]. In this study, the lowest knowledge levels were found among older single women with no education and monthly household incomes of less than 3000 INR (approximately \$42 USD) [9]. Furthermore, women with no schooling had more 'Don't know' responses as compared to women with secondary education or more. Interestingly, women in lower castes had more knowledge about CVD risk factors than those in general or higher castes. We hypothesize that this increased knowledge is due to greater healthcare access provided by the Government of India's National Urban Health Mission, which provides low- and no-cost medical treatment to the lowest income families in India's urban slums [10]

We had hypothesized that knowledge of CVD risk factors would be associated with the adoption and maintenance of 'heart healthy' behavior. The data supported this hypothesis that knowledge of CVD risk factors was significantly associated with reported change and maintenance of health behavior. While this finding is consistent with other studies reporting that adequate knowledge about health risk is an important prerequisite for making appropriate health decisions $[11,12]$, the present study design was inadequate for assessing whether knowledge alone was sufficient to facilitate change or maintenance of health behavior. A large body of theory suggests that health behaviors are complicated and multi-factorial, and behavior change is dependent on a large number of internal factors including attitudes, beliefs, motivation, selfefficacy, social norms, and sociocultural contexts $[7,13]$. There is a clear and significant association between low health knowledge, adverse health outcomes, and poor use of health-care services [14]. Studies also suggest that higher levels of health knowledge influences attitudes toward behavior change [15], improves self-regulation skills and abilities, and enhances social 
facilitation [16]. The finding that $60 \%$ of participants in this study reported they were not thinking about changing their heart health behavior and a majority $(55.2 \%)$ of women had poor knowledge about heart disease risk factors, points to a serious public health need for health information interventions in this population.

Manuscript 2 assessed whether the lifetime number of live births for a woman is associated with later-life risk for CHD. This study found a 6.4\% prevalence of CHD among slum-dwelling women in Mysore. Nulliparous women were at heightened risk for CHD compared to parous women with up to five live births. In the full model, after adjusting for demographic factors including age, education, marital status, occupation, and income; behavioral and health factors including tobacco use, hypertension, diabetes mellitus, CHD; a family history of hypertension, diabetes and CHD; and reproductive factors including menarche, abortions, infant deaths, menopause, the relationship between parity and CHD strengthened further. Current evidence suggests that multiparity is a risk factor for CHD outcomes [17], so we had hypothesized that parity would be associated with CHD in this population. The results of this study do not provide support for that conclusion. In our population, $99 \%$ of women who gave birth to a live infant reported breastfeeding. Based on recent studies [18-20] this may have been protective against $\mathrm{CHD}$, but we were unable to test this hypothesis because of the homogeneity in lactation practices in this population. Further studies are needed to evaluate whether additional pregnancy-related variables including breastfeeding mediate the relationship between parity and CVD.

Manuscript 3 determined whether snoring is associated with increased risk for obesity among women. As we had hypothesized, this study found that snoring was associated with obesity and cardio-metabolic disorders. In an adjusted model, snorers had more than double the odds of having obesity I and more than seven times the odds of having obesity II compared to people not reporting that they snored. Participants that reported moderate snoring, which was significantly associated with obesity I, were at seven times increased odds for having obesity II. 
These relationships remained significant after controlling for age, diabetes, hypertension, hypercholesterolemia, and daytime sleepiness. There was no difference in obesity status among participants reporting other sleep-related issues including short sleep duration, napping, daytime sleepiness, sleep apnea, insomnia, or use of sleep medication. Snoring was less common among normal/underweight women, compared to women who were overweight or obese. These findings are consistent with previous studies showing that self-reported snoring in women was strongly associated with age and BMI [21-23]. This study also identified a relationship between snoring and several cardio-metabolic disorders including hypertension and Diabetes Type 2. Moderate and habitual snoring were significantly associated with both current and previous diagnosis of hypertension and Diabetes Type $2(\mathrm{p}<0.001)$. More research is needed to understand the underlying mechanisms connecting sleep-disordered breathing and BMI.

\section{Limitations and Strengths of the Study}

There are several limitations to our study. First, this is a cross-sectional study. As a consequence, there is no way to determine the temporality of the described relationships. Additionally, variables were self-reported and are subject to recall and information bias. Furthermore, although we adjusted for potential confounders, residual confounding remains a possibility as with all observational studies. Lastly, due to low cell counts we were unable to provide precise estimates of the effect size for some of the variables. Despite these limitations, the study also has strengths. They include recruitment of a community-based sample likely to befree of the referral biases that usually are present in clinic-based samples. The study was also designed to minimize measurement error: data were collected using validated and standardized instruments, and the questionnaire was administered by well-trained staff following highly structured protocols. 


\section{Future Extensions of the Study}

To our knowledge, this is one of the first studies in India to explore the prevalence of CHD in slum-dwelling women in South India. The findings are limited by a cross-sectional design and a modest sample size. With multiple studies suggesting a higher prevalence of major CHD risk factors such as uncontrolled hypertension and tobacco use among slum dwellers, there is a compelling public health need to carry out larger population-based studies to further examine the prevalence of heart diseases and their risk factors in slum-dwelling populations. In addition, most of what we understand about heart disease comes from research among men. There is growing evidence of unique gender-specific risk factors for CVD among womenparticularly those related to pregnancy and childbirth. There is a need for instance, for further studies of the effect of breastfeeding and breastfeeding duration on CHD risk among women in middle life.

Additional research is also needed to explore the effects of pregnancy-related disorders including gestational diabetes, preeclampsia, preterm labor, and pregnancy loss on CHD risk in middle- aged women. The goal should be to uncover biological, medical, and social bases of these and other differences with the goal of tailoring prevention and treatment for CHD among women. 


\section{REFERENCES}

1. Weinstein ND and PM Sandman. A model of the precaution adoption process: evidence from home radon testing. Health Psychol, 1992. 11(3): p. 170-80.

2. X-Rates, Currency Calculator. Found at https://www.Xrates.com/calculator/?from=USD\&to=INR\&amount=1 Accessed on July 9, 2018, 2018.

3. Aminde LN, Takah N, Ngwasiri C, Noubiap JJ, Tindong M, Dzudie A, Veerman JL. Population awareness of cardiovascular disease and its risk factors in Buea, Cameroon. BMC Public Health, 2017. 17(1): p. 545.

4. Boateng D, Wekesah F, Browne JL, Agyemang C, Agyei-Baffour P, Aikins AD, Smit HA, Grobbee DE, Klipstein-Grobusch K. Knowledge and awareness of and perception towards cardiovascular disease risk in sub-Saharan Africa: A systematic review. PLoS One, 2017. 12(12): p. e0189264.

5. Wong BM, Garcia Y, Barr A, Glazier RH, Abramson BL. Cardiovascular risk factor awareness in a disadvantaged inner-city population--implications for preventive strategies. Can J Cardiol, 2008. 24(9): p. 677-82.

6. Tsuji M, Arima H, Ohkubo T, Nakamura K, Takezaki T, Sakata K, Okuda N, Nishi N, Kadota A, Okamura T, Ueshima H, Okayama A, Miura K. Socioeconomic Status and Knowledge of Cardiovascular Risk Factors: NIPPON DATA2010. J Epidemiol, 2018. 28 Suppl 3: p. S46-S52.

7. Davis SK, Winkleby MA, Farquhar JW. Increasing disparity in knowledge of cardiovascular disease risk factors and risk-reduction strategies by socioeconomic status: implications for policymakers. Am J Prev Med, 1995. 11(5): p. 318-23.

8. Potvin L, Richard L, Edwards AC. Knowledge of cardiovascular disease risk factors among the Canadian population: relationships with indicators of socioeconomic status. CMAJ, 2000. 162(9 Suppl): p. S5-11.

9. XE, XE Currency Converter: INR to USD. Found at: https://www.xe.com/currencyconverter/convert/?Amount=1\&From=INR\&To=USD Accessed on November 11, 2018, 2018.

10. Rao KD, Peters DH. Urban health in India: many challenges, few solutions. Lancet Glob Health, 2015. 3(12): p. e729-30.

11. Homko CJ, Santamore WP, Zamora L, Shirk G, Gaughan J, Cross R, Kashem A, Petersen S, Bove AA. Cardiovascular disease knowledge and risk perception among underserved individuals at increased risk of cardiovascular disease. J Cardiovasc Nurs. 2008. 23(4): p. 332-7.

12. Boo S, Oh H, Froelicher ES, Suh CH. Knowledge and perception of cardiovascular disease risk among patients with rheumatoid arthritis. PLoS One, 2017. 12(4): p. e0176291. 
13. Kwasnicka D, Dombrowski SU, White M, Sniehotta F. Theoretical explanations for maintenance of behaviour change: a systematic review of behaviour theories. Health Psychol Rev, 2016. 10(3): p. 277-96.

14. Berkman ND, Sheridan SL, Donahue KE, Halpern DJ, Crotty K. Low health literacy and health outcomes: an updated systematic review. Ann Intern Med, 2011. 155(2): p. 97- 107.

15. Fabrigar LR, Petty RE, Smith SM, Crites SL Jr. Understanding knowledge effects on attitude-behavior consistency: the role of relevance, complexity, and amount of knowledge. J Pers Soc Psychol, 2006. 90(4): p. 556-77.

16. Ryan P. Integrated Theory of Health Behavior Change: background and intervention development. Clin Nurse Spec, 2009. 23(3): p. 161-70; quiz 171-2.

17. Lv H, Wu H, Yin J, Qian J, Ge J. Parity and Cardiovascular Disease Mortality: a DoseResponse Meta-Analysis of Cohort Studies. Sci Rep, 2015. 5: p. 13411.

18. Peters SA, van der Schouw YT, Wood AM, Sweeting MJ, Moons KG, Weiderpass E, Arriola L, Benetou V, Boeing H, Bonnet F, Butt ST, Clavel-Chapelon F, Drake I, Gavrila D, Key TJ, Klinaki E, Krogh V, Kühn T, Lassale C, Masala G, Matullo G, Merritt M, Molina-Portillo E, Moreno-Iribas C, Nøst TH, Olsen A, Onland-Moret NC, Overvad K, Panico S, Redondo ML, Tjønneland A, Trichopoulou A, Tumino R, Turzanski-Fortner R, Tzoulaki I, Wennberg P, Winkvist A, Thompson SG, Di Angelantonio E, Riboli E, Wareham NJ, Danesh J, Butterworth AS. Parity, breastfeeding and risk of coronary heart disease: A pan-European case-cohort study. Eur J Prev Cardiol, 2016. 23(16): p. 17551765 .

19. Schwarz EB, Ray RM, Stuebe AM, Allison MA, Ness RB, Freiberg MS, Cauley JA. Duration of lactation and risk factors for maternal cardiovascular disease. Obstet Gynecol, 2009. 113(5): p. 974-82.

20. Rajaei S, Rigdon J, Crowe S, Tremmel J, Tsai S, Assimes TL. Breastfeeding Duration and the Risk of Coronary Artery Disease. J Womens Health (Larchmt), 2018.

21. Svensson M, Lindberg E, Naessen T, Janson C. Risk factors associated with snoring in women with special emphasis on body mass index: a population-based study. Chest, 2006. 129(4): p. 933-41.

22. Schmidt-Nowara WW, Coultas DB, Wiggins C, Skipper BE, Samet JM. Snoring in a Hispanic-American population. Risk factors and association with hypertension and other morbidity. Arch Intern Med, 1990. 150(3): p. 597-601.

23. Nagayoshi M, Yamagishi K, Tanigawa T, Sakurai S, Kitamura A, Kiyama M, Imano H, Ohira T, Sato S, Sankai T, Iso H; CIRCS Investigators. Risk factors for snoring among Japanese men and women: a community-based cross-sectional study. Sleep Breath, 2011. 15(1): p. 63-9. 
24. Weinstein, PK, Amirkhosravi A, Angelopoulos TJ, Bushy A, Covelli MM, Dennis KE. Reducing cardiovascular risk in women with lupus: perception of risk and predictors of risk-reducing behaviors. J Cardiovasc Nurs, 2014. 29(2): pi 130-9. 


\section{VITA}

\section{KARL FRANCIS \\ KRUPP}

1980

B.A.,

Communications

University of

Minnesota Duluth,

Minnesota

2008

M.S., Public Health in Developing Countries

London School of Hygiene and Tropical

Medicine London, United Kingdom

2013-Present

Doctoral Candidate

Florida International University, Stempel College of Public Health and Social Work, Department of Health Promotion and Disease Prevention Miami, Florida

2017-2018

Global Health Equity Scholar

Fogarty International Center/National Health Lung Blood Institute, National Institutes for Health

Principle Investigator, Coronary Heart Disease in Slum-Dwelling Women in Mysore, India. $2017-2018$

Funders: Fogarty International Center and the National Heart, Lung, and Blood Institute (NHLBI) as a predissertation Global Health Equity Scholar (GHES).

Project Director, Parental Acceptability of HPV vaccine of school going adolescent girls in Mysore, India, 2009 - 2011

Public Health Research Institute of India, Mysore, India

Project Director, Integrating Traditional Birth Attendants in Prevention of Mother to Child Transmission of HIV Programs in Mysore, India, $2007-2011$.

Public Health Research Institute of India, Mysore, India

Project Director, HPV Screening and Vaccine Readiness Program, 2007

- 2009

Public Health Research Institute of India, Mysore, India

Principle Investigator, Physicians' attitudes toward HPV vaccination and intention to recommend immunization in Mysore, India, 2007-2008

London School of Hygiene and Tropical Medicine 
Project Manager, The HSV-2 Study,

2005 - 2007

Prerana Women's Health Initiative, Mysore, India

PROFESSIONAL EXPERIENCE

2011- Present Grant Writer, Public Health Research Institute of India

2010 - 2011 Consultant Grant Writer, Global Campaign for

Microbicides

$2001-2010$ Wrote more than 30 successful grants totaling in excess of one million dollars with U.S. and international foundations, the State of California, City of San Francisco, National Institutes of Health, and pharmaceutical companies for Greenaction for Environmental Health and PHRII.

2005 - 2007 Developed and edited 10 bioethics training modules for the Indian Council of Medical Research funded by the NIH Fogarty International Center

2003 - 2005 Coordinated 20 nonprofit organizations as U.S. Medwaste Group Leader

for Healthcare Without Harm, a leading international organization

providing technical assistance on medical waste disposal to hospitals.

Summer Semester 2017: PHC 3101 Introduction to Public Health (3 credits); Instructor of Record Dr. Rashida Biggs, Clinical Assistant Professor, Department of Health Promotion and Disease Prevention

Summer Semester 2016: PHC 3101 Introduction to Public Health (3 credits); Instructor of Record Dr. Rashida Biggs, Clinical Assistant Professor, Department of Health Promotion and Disease Prevention

2018/19 Dissertation Year Fellowship, FIU University Graduate School

2017/18 Global Health Equity Scholars (GHES) Fellowship, Fogarty International Center and the National Heart, Lung, and Blood Institute (NHLBI). Project Title: Coronary Heart Disease in Slum-Dwelling Women in Mysore, India.

2013 Bronze Medal, Best Applied Research Presentation at the 20 ${ }^{\text {th }}$ Meeting of the International Society for Sexually Transmitted Diseases Research, 9-13 July 2013, Vienna, Austria, for oral presentation of "Acceptability of HPV Vaccination among Parents of Adolescent school going girls in Mysore, India".

2007 Travel Grant, Microbicides Conference, South Africa

\section{PUBLICATIONS IN PEER-REVIEW JOURNALS}

1. Nishimura H, Krupp K, Gowda S, Srinivas V, Arun A, Madhivanan P. Determinants of exclusive breastfeeding in rural South India. Int Breastfeed J. 2018 Aug 29;13:40.

2. Degarege A, Krupp K, Srinivas V, Ibrahimou B, Marlow LAV, Arun A, Madhivanan P. Determinants of attitudes and beliefs toward human papillomavirus infection, cervical cancer and human papillomavirus vaccine among parents of adolescent girls in Mysore, India. J Obstet Gynaecol Res. 2018 Nov;44(11):2091-2100. 
